\title{
The Economic Benefits of Portable Instrumentation on the Criminal Justice System: A Comprehensive Return-on-Investment Analysis
}

Korina Menking-Hoggatt

Follow this and additional works at: https://researchrepository.wvu.edu/etd

\section{Recommended Citation}

Menking-Hoggatt, Korina, "The Economic Benefits of Portable Instrumentation on the Criminal Justice System: A Comprehensive Return-on-Investment Analysis" (2017). Graduate Theses, Dissertations, and Problem Reports. 6217.

https://researchrepository.wvu.edu/etd/6217

This Thesis is protected by copyright and/or related rights. It has been brought to you by the The Research Repository @ WVU with permission from the rights-holder(s). You are free to use this Thesis in any way that is permitted by the copyright and related rights legislation that applies to your use. For other uses you must obtain permission from the rights-holder(s) directly, unless additional rights are indicated by a Creative Commons license in the record and/ or on the work itself. This Thesis has been accepted for inclusion in WVU Graduate Theses, Dissertations, and Problem Reports collection by an authorized administrator of The Research Repository @ WVU. For more information, please contact researchrepository@mail.wvu.edu. 


\title{
The Economic Benefits of Portable Instrumentation on the Criminal Justice System: A Comprehensive Return-on-Investment Analysis
}

\author{
Korina Menking-Hoggatt \\ Thesis submitted \\ to the Eberly College of Arts and Sciences \\ at West Virginia University \\ in partial fulfillment of the requirements for the degree of \\ Master of Science in \\ Forensic Science
}

\author{
Glen P. Jackson, Ph.D., Chair \\ Paul Speaker, Ph.D. \\ Casper Venter, M.S. \\ Department of Forensic and Investigative Science
}

Morgantown, West Virginia

2017

Keywords: seized drug, law enforcement, forensic, criminal justice, economics, cost Copyright 2017 Korina Menking-Hoggatt 


\section{Abstract \\ The Economic Benefits of Portable Instrumentation on the Criminal Justice System: A Comprehensive Return-on-Investment Analysis}

\section{Korina Menking-Hoggatt}

Prosecuting crime is an expensive endeavor. This thesis compiles data from a variety of sources to show that, in 2015, the average cost of prosecuting a seized-drug case in the United States was about $\$ 26,000$. Of that amount, crime laboratories only cost about $\$ 275$ per seized-drug case, or less than $\sim 1 \%$ of the total cost of prosecuting a drug case. We show that the criminal justice system could save millions of dollars per year by strategically investing in portable chemical instrumentation and conducting seized-drug confirmatory analyses at the scene of the crime, or at booking, instead of in the laboratory. Such investments would require that on-site analyses meet the same strict standards for drug identifications as conventional laboratory protocols and that drug identification reports be completed before booking.

By implementing confirmatory portable instrumentation to analyze seized-drug samples in the field, the initial cost of investment can be justified by the benefits and cost savings in the court system. For example, one major economic benefit of on-site testing is the reduction of pretrial costs—like jail time - for suspects awaiting trial. Our calculations show that marginal savings between $\$ 1.5 \mathrm{M}$ and $\$ 20 \mathrm{M}$ within the first year and between $\$ 8 \mathrm{M}$ and $\$ 90 \mathrm{M}$ by the fifth year of implementation are possible for each set of portable instruments purchased. The economic analysis includes expenses such as the capital equipment costs, supplies, service contracts, full-time equivalent employees and their benefits and travel. The estimated cost of deployment is $\sim \$ 327,000$ in the first year and an additional cost of $\sim \$ 214,000$ a year thereafter. On-site analyses are expected 
to save an average of 150 jail days per case, which, at an average cost of $\$ 129$ per day, would save approximately $\$ 10 \mathrm{~K}$ per case. In addition to the economic benefits, some additional benefits for pre-booking drug tests include reduced recidivism rates, better prosecutorial accuracy, increased public faith, and decreased compensation costs for the wrongly convicted. For all these reasons, portable instrumentation can greatly benefit the entire criminal justice system. 


\section{Acknowledgements}

I would like express my gratitude to my committee chair, Dr. Jackson, for his willingness to accept me as a graduate student in the Jackson research group. Without his confidence in my abilities, and his patient advice through my thesis, I would not have made it this far.

I would also like to thank my other committee members. Dr. Speaker was an invaluable source of knowledge on economic analysis, and his project FORESIGHT was a critical part of my thesis. Mr. Casper Venter was supportive and provided practical experience from his years as a forensic chemist, clandestine laboratory analyst, and lab manager. Without his insight, I would not have been able to make practical conclusions about application in the field.

Finally, I would like to thank my personal support group of friends and family for always believing in me. Their words of support and encouragement remained with me through every challenge I have faced.

No one truly accomplishes any great task alone. Thank you all. 


\section{Table of Contents}

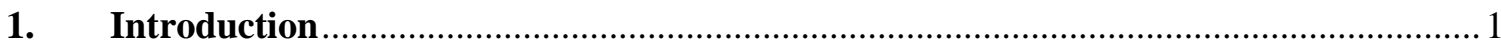

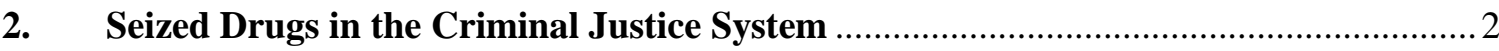

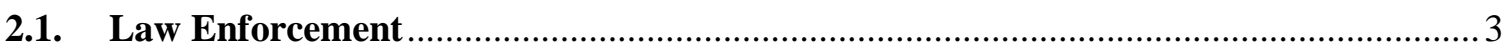

2.2. The Role of Crime Laboratories and On-Site Testing ................................................5

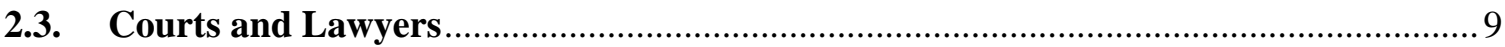

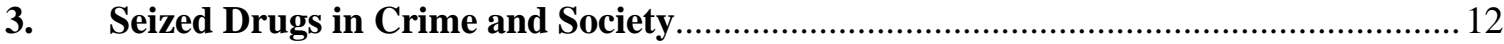

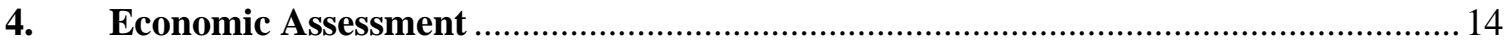

5. The Effect of Forensic Science on the Criminal Justice System ...................................16

5.1. Benefits of Portable Instrumentation to the Criminal Justice System ....................... 18

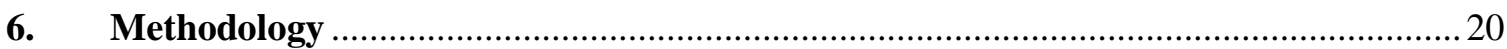

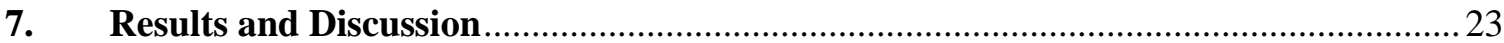

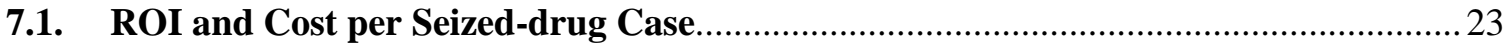

7.2. Startup Cost of Portable Instrumentation .................................................................. 32

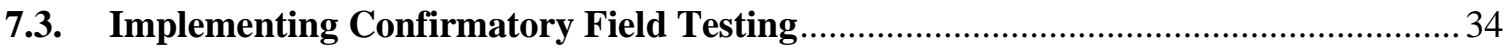

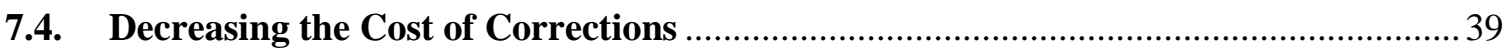

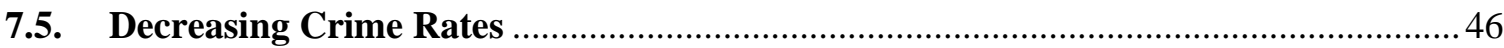

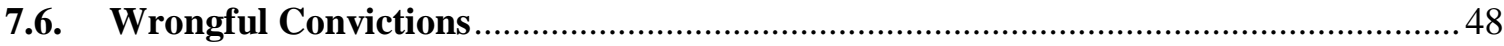

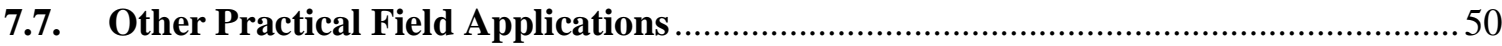

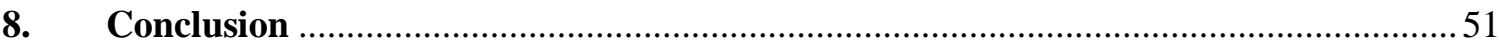

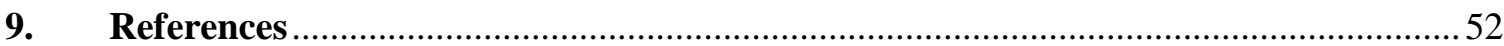

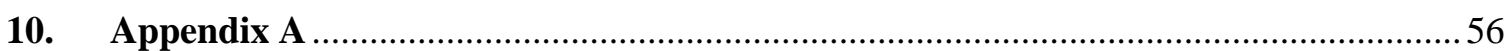




\section{List of Tables}

Table 1: page 6- Nationally Estimated Number of Requests for Services Received and Completed by Publicly Funded Forensic Crime Labs, by type of request, 2009

Table 2: page 6- Nationally Estimated Number of Requests for Services Backlogged in Publicly Funded Forensic Crime Labs, by type of request, Yearend 2008-09

Table 3: page 9- ASTM Categories for Analytical Techniques

Table 4: page 24- Cost of Crime by Offense

Table 5: page 38- Five-year Breakdown of On-site Seized-Drug Testing

\section{List of Figures}

Figure 1: page 2- The flow of seized-drug cases through the criminal justice system

Figure 2: page 19- Breakdown of the 2015 UCR seized-drug arrests by drug type

Figure 3: page 26- Heat map of the total cost per seized-drug case for each state

Figure 4: page 27- The total average cost per seized-drug case by state and with the area breakdown

Figure 5: page 28- The percentage of seized-drug cases versus the cost of a seized-drug case for that state

Figure 6: page 31- The number of seized-drug arrests versus the average total cost of a seized-drug case for that state

Figure 7: page 34- Price quote for a Torion-T9

Figure 8: page 42- Marginal cost savings in the first year of investing in portable instrumentation compared to the number of cases processed

Figure 9: page 43- Marginal cost savings in the third year of investing in portable instrumentation compared to the number of cases processed

Figure 10: page 43- Marginal cost savings in the fifth year of investing in portable instrumentation compared to the number of cases processed

Figure 11: page 44- Marginal cost savings in the first year of investing in portable instrumentation compared to the average daily cost of incarcerating a person pretrial

Figure 12: page 45- Marginal cost savings in the third year of investing in portable instrumentation compared to the average daily cost of incarcerating a person pretrial

Figure 13: page 45- Marginal cost savings in the fifth year of investing in portable instrumentation compared to the average daily cost of incarcerating a person pretrial 


\section{Introduction}

The first phase of this research project involved collecting a variety of publicly available data to calculate the state-level and national-level cost per seized-drug case. The second phase of this project involved a detailed analysis of the different ways that portable chemical instrumentation can benefit the criminal justice system. Seized-drug cases are processed by law enforcement officers, evidence handlers, forensic scientists, and the court system, and each sector requires significantly different resources in terms of cost, personnel and time. The ability to make an on-site identification of seized-drugs has the potential to save time and money in a variety of different ways, in addition to providing more accurate and efficient prosecution of criminals. The information provided in this thesis can assist stakeholders in their decision-making process when they are seeking ways to save money in the battle against drug crimes.

In a fair and functional democracy, the criminal justice system is protects a citizen's right to due process. In the United States (US), the first 10 amendments to the constitution provides such protections, and the $6^{\text {th }}$ amendment to the constitution specifically protects a citizen's right to a fair and speedy trial. ${ }^{1}$ For the criminal justice system to work effectively, many participants- law enforcement officers, forensic scientists, judges, lawyers, and corrections officers- must operate in synchrony in a very complex and costly system.

When a new policy or procedure is introduced to one part of the criminal justice system, the change often has some intended and unintended consequences on the other parts of the system. A procedure change in a crime laboratory can change the arrest protocol, evidence collection, and/or the presentation of a case to the judges and lawyers. This paper considers how the implementation of portable on-site testing of drugs is likely to impact different parts of the criminal 
justice system and provides reasons for how portable instrumentation can streamline the prosecution of drug crimes.

An important part of the transparency of publicly funded agencies is public access to how these agencies spend taxpayer's money. Transparency helps build trust with the public, justifies their expenses, and guides future decision-making policies. Although the collected data is made available to the public, the data is often fragmented and rarely assimilated into large or national databases. For this reason, a large part of this project involved compiling data from a variety of different jurisdictional websites to calculate both the current cost of prosecuting seized-drug cases and the return on investment (ROI) of portable instrumentation. The cost per seized-drug case and the ROI was broken down into law enforcement, the court system, and correction areas.

\section{Seized Drugs in the Criminal Justice System}

Each area of the criminal justice system has a different role in processing seized drugs. To understand how portable instrumentation can benefit the entire criminal justice system, we first need a strong understanding of the differences in the service objectives for each area of the criminal justice system. Figure 1 provides a flow chart of a seized-drug case through the criminal justice

$\begin{aligned} & \text { Reported or } \\ & \text { observed } \\ & \text { illegal activity } \\ & \text { referred, } \\ & \text { rejected, } \\ & \text { or } \\ & \text { dismissed }\end{aligned} \rightarrow$ Arrest
Figure 1: The flow of seized-drug cases through the criminal justice system and the possible
outcomes.


system. ${ }^{2}$ The next few sections provide background into the specific roles and objectives of the different branches of the criminal justice system in order to better understand the factors which that drive the decision-making in each branch.

\subsection{Law Enforcement}

A typical seized-drug case begins with a suspected illegal activity followed by an arrest and an initial investigation of a suspect or suspects by law enforcement officers. ${ }^{3}$ According to the Crime in the US 2015 report, the majority of the drug arrests are for possession, which are usually on the order of 1 gram or less. ${ }^{4}$ The arresting officer is then responsible for detaining the suspect and handling the evidence during the arrest, which includes any preliminary field testing that might be required in the officer's jurisdiction. The police officer will then submit the seized drug(s) to a forensic laboratory for confirmatory testing, and proceed with the arrest, booking, and the filing of charges against the defendant before the laboratory results are reported. If the laboratory results identify the seized drug as a legal substance, then the civil liberties of the individual have been infringed, and resources have been spent detaining an innocent person. One goal of confirmatory testing in the field is to help prevent such wrongful arrests. Other objectives are to enhance the speed and reliability of seized-drug prosecutions.

Jurisdictions vary greatly in the number of arrests for seized drugs. The variety in drug arrests is determined largely by how the laws are written in that state or jurisdiction. For example, in Harris County, Texas, possession of any controlled drug, like marijuana, is an automatic felony. ${ }^{5}$ A seized-drug arrest in these types of counties will lead to a case entering the court system and a combination of incarceration and a fine as punishment for the arrestee. On the other hand, in states where medicinal or recreational marijuana is legal, the number of seized-drug cases processed by the courts will be much smaller. In 2015 alone, almost 39\% of seized-drug arrests were for the 
possession of marijuana for personal use, which can vary in the amount criminalized depending on the state. ${ }^{6}$ Because legalization has only been in effect for few years in a small number of states, more data needs to be collected before direct correlation can be made between the changes in the drug laws and the effect on the criminal justice system. To track such relationships the US Sentencing Commission (USSC) monitors the sentencing of federal courts, and every year the USSC calculates the number of cases sentenced in federal court by the type of drug involved.

In 2012, Colorado was the first state to legalize marijuana. In the subsequent years, many states have followed suit by changing their marijuana laws to permit medical and/or recreational marijuana. Since 2012, the USSC has calculated a 50\% decrease the number of federal prison sentences related to marijuana -a decrease of almost 7,000 cases to 3,500 cases a year on the federal level. ${ }^{7}$ Given the cost of prosecuting drug crimes (see section 4), cases like this show that changes in state law has the greatest potential to influence the cost of the criminal justice system to taxpayers. By changing the laws, or the severity of the punishment associated with a seized-drug crime, the number of prosecutions and prison inmates can be significantly decreased, albeit with the effect of lessening the deterrents for drug use.

Another duty of law enforcement officers that depends on a jurisdiction's procedure for handling seized-drug cases is the performance of presumptive field tests on suspected seized drugs. Field tests determine whether or not a substance found at a scene, or on a suspect, is a controlled substance. When performed by a field officer, any seizure resulting in positive field test result is sent to the forensic drug laboratory to confirm the seized drug's identity. Confirmation using an analytical scheme is required because field color tests, by nature, have an unacceptable level of false positive rates. ${ }^{8}$ The number of seized drugs sent to crime laboratories can be minimized by allowing officers to screen suspected drugs before seizing and submitting them for analysis by a 
crime laboratory. When screening tests are negative, suspects can be immediately released without any further inconvenience.

A forensic handbook published by the Wisconsin Department of Justice for their police officers in 1973 contained the warning, "results of drug screening using the field testing kit must be viewed in their proper perspective", which acknowledges the limitations of color tests more than forty years ago. ${ }^{9}$ The science and challenges of using presumptive tests in the field will be discussed in greater detail in the next section. The main point is that presumptive tests are useful for decreasing the number of arrests and the number of items of evidence collected by officers in the field but, due to the nature of the tests, some legal substances can cause false positive color test results. False positives can be reduced with proper training and a scientific understanding of color test limitations, but to be admissible in court, a field color test must include a more comprehensive analytical scheme, such as described by the Scientific Working Group for the Analysis of Seized Drugs (SWGDRUG) and American Society of Testing and Materials (ASTM) standards. ${ }^{10}$

\subsection{The Role of Crime Laboratories and On-Site Testing}

In publicly funded crime laboratories, the second largest request is for the analysis of a controlled substance. For example, in 2009 seized-drug analyses was performed in more than $80 \%$ of publicly funded state crime laboratories and comprised 33\% of the samples submitted for forensic analysis (Table 1). Seized drugs also had the second highest backlog of samples at the end of 2009 at $12 \%$ of the total backlog in forensic laboratories (Table 2). The year 2009 was the last time a nationwide census of publicly funded crime laboratories was conducted. ${ }^{11}$ Crime laboratories are still unable to deal with the large volume of seized-drug samples being submitted, despite the scientific and technological advances in preparation and automation of drug identification. 


\begin{tabular}{|c|c|c|c|c|}
\hline \multirow[b]{3}{*}{ Type of request } & \multirow{2}{*}{\multicolumn{2}{|c|}{ Received }} & \multirow{2}{*}{\multicolumn{2}{|c|}{ Completed }} \\
\hline & & & & \\
\hline & Number & Percent & \begin{tabular}{|l|l} 
Number & \\
\end{tabular} & Percent \\
\hline All requests & $4,120,000$ & 100 & $3,905,000$ & 100 \\
\hline Forensic biology* & $1,389,000$ & 34 & $1,312,000$ & 34 \\
\hline Controlled substances & $1,356,000$ & 33 & $1,262,000$ & 32 \\
\hline Toxicology & 613,000 & 15 & 591,000 & 15 \\
\hline Latent prints & 271,000 & 7 & 275,000 & 7 \\
\hline Crime scene & 190,000 & 5 & 190,000 & 5 \\
\hline Firearms/toolmarks & 147,000 & 4 & 131,000 & 3 \\
\hline Trace evidence & 56,000 & 1 & 46,000 & 1 \\
\hline Digital evidence & 31,000 & 1 & 31,000 & 1 \\
\hline Questioned documents & 13,000 & -- & 12,000 & -- \\
\hline Impressions & 11,000 & -- & 10,000 & -- \\
\hline Other forensic requests & 42,000 & 1 & 42,000 & 1 \\
\hline \multicolumn{5}{|c|}{$\begin{array}{l}\text { Note: National estimates are based on imputations for labs that did } \\
\text { not report data on requests received and completed. See } \\
\text { Methodology for imputation procedures. Totals exclude requests } \\
\text { outsourced to other labs. }\end{array}$} \\
\hline
\end{tabular}

\begin{tabular}{|c|c|c|c|c|}
\hline \multirow{2}{*}{ Type of request } & \multicolumn{2}{|c|}{ Yearend 2008} & \multicolumn{2}{|c|}{ Yearend 2009} \\
\hline & Number & Percent & Number & Percen \\
\hline All requests & $1,184,500$ & 100 & $1,193,800$ & 10 \\
\hline Forensic biology* & 887,400 & 75 & 905,200 & 7 \\
\hline Controlled substances & 142,100 & 12 & 137,700 & 1 \\
\hline Latent prints & 53,100 & 4 & 49,500 & \\
\hline Firearms/toolmarks & 46,700 & 4 & 48,700 & - \\
\hline Toxicology & 30,400 & 3 & 28,600 & \\
\hline Trace evidence & 14,700 & 1 & 13,200 & \\
\hline Impressions & 5,500 & -- & 5,700 & -- \\
\hline Questioned documents & 2,100 & -- & 2,400 & -- \\
\hline Digital evidence & 1,300 & -- & 1,300 & -- \\
\hline Other forensic requests & 1,100 & -- & 1,500 & -- \\
\hline $\begin{array}{l}\text { Note: National estima } \\
\text { report backlog data. } \\
\text { procedures. Totals exc }\end{array}$ & $\begin{array}{l}\text { ased on } \\
\text { Methodo }\end{array}$ & utation & or labs that & $\begin{array}{l}\text { t did not } \\
\text { bs. }\end{array}$ \\
\hline
\end{tabular}

In 2012, the president of American Society of Crime Lab Directors (ASCLD), Jill Spriggs, spoke at a federal judiciary hearing about the backlog of seized drugs cases in crime laboratories. In the hearing, she suggested that the continuously rising increase in backlogged samples was due to the growing number of synthetic drugs submissions. The identification of new psychoactive substance (NPSs), or synthetic seized drugs, is more difficult and time consuming for a forensic chemist because chemical structures can vary greatly and may not have been observed or reported before. ${ }^{12}$ Her comment was addressing the point that crime laboratories are struggling to maintain their current analysis of routine seized drugs, so they cannot be expected to also process the rising number of more complicated and time consuming synthetic drugs. To meet the evolving needs of modern crime, forensic laboratories need to consider implementing new procedures and new technologies with the specific goal of reducing the number of seized-drug cases entering the system and the length of time required to reach case resolution.

Currently, portable instruments are only used when there is an urgent need for fast, accurate, and reliable analysis. Clandestine laboratories and suspected arson scenes benefit from 
portable instruments because the environment can be hazardous to first responders, and because they require the rapid analysis of the physical evidence to prevent the loss of evidence. ${ }^{13}$ Gas chromatography/ mass spectrometry (GC/MS) systems are well suited for explosives, arson and drug analyses, so in principle GC/MS instruments could be shared by other departments in a crime laboratory and increase the quality of casework for other types of forensic analysis.

A research group in Australia recently tested the ability of a modern portable GC/MS instrument to detect ignitable liquids (ILs) in the field. The instrument, a TRIDION-9 which incorporates a toroidal ion trap mass spectrometer, was able to detect 9 out of 11 ILs at concentrations as low as $0.1 \mu \mathrm{L}$, even when the ILs were in the presence of background materials that often give false positive readings. ${ }^{14}$ The current standard of IL analysis utilizes a bench top GC/MS, which also have limitations for determining the presence of IL under the same conditions presented by the research group. This study shows the competitiveness between portable instruments and traditional bench-top instruments.

Another study performed by the Las Vegas Metropolitan Police Department (LVMPD) showed the practicality of using portable Raman spectroscopy for field drug testing, specifically the ReporteR by SciAps, Inc. ${ }^{15}$ The LVMPD currently requires law enforcement officers to perform color tests on any seized drugs recovered from a suspect and submit the evidence to the crime laboratory with a field checklist of the results. ${ }^{16}$ The agency tested the field application of the ReporteR as a more accurate field test which might decrease the problem of misinterpreting the field color tests. The research concluded that the portable Raman instrument yielded quality results on par with the laboratory tests, even when the seized drug was analyzed in the original packaging. ${ }^{15}$ The LVMPD research concluded that the use of portable Raman spectroscopy would benefit their agency's field testing results by the use of more accurate portable instrumentation. 
Seized-drug analysts and scientific organizations have formed consensus agreement on the best analytical schemes to identify scheduled drugs. The approved recommendations were first promulgated by SWGDRUG in the early 2000s. ${ }^{17}$ The SWGDRUG recommendations were most approved as the standard for seized-drug analysis through ASTM E2329-14 in 2014. ${ }^{10}$ The same ASTM standard has recently been adopted as the first recommendation on the registry of approved standards for the National Institute of Science and Technology (NIST) Organization for Scientific Area Committees (OSAC) in July of 2016. ${ }^{18}$

During the maturation and use of these standards, the National Academy of Sciences report (NAS), and a more recent report released by the President's Council of Advisors on Science and Technology (PCAST), were both satisfied with the current techniques forensic laboratories are using to identify unknown substances. ${ }^{19,20}$ Even though SWGDRUG, ASTM, and NIST OSAC are not legally mandated standards, most accredited crime laboratories in the US voluntarily adopted these standards.

In a nutshell, the recommendations stipulate that more than one test must be performed and that at least one of the techniques must be highly discriminating, such as GC/MS, FTIR or Raman. The chosen analytical scheme is at the discretion of each forensic laboratory. The different types of drug identification techniques are grouped from category A techniques- such as Raman spectroscopy or mass spectrometry, which have the highest discriminating power- to category C techniques - such as color tests, which have the least discriminating power (Table 3). ${ }^{17}$

The types of field tests currently performed by field officers on suspected drugs are typically color tests, which are considered a category $\mathrm{C}$ technique with low discriminating power. According to previously mentioned standards, color tests are insufficient to identify seized drugs. Judges have recently used SWGDRUG and ASTM standards to reject the use of drug evidence 


\begin{tabular}{|c|c|c|}
\hline Category A & Category B & Category C \\
\hline $\begin{array}{c}\text { Infrared } \\
\text { Spectroscopy }\end{array}$ & $\begin{array}{c}\text { Capillary } \\
\text { Electrophoresis }\end{array}$ & Color Tests \\
\hline Mass Spectrometry & $\begin{array}{c}\text { Gas } \\
\text { Chromatography }\end{array}$ & $\begin{array}{l}\text { Fluorescence } \\
\text { Spectroscopy }\end{array}$ \\
\hline $\begin{array}{l}\text { Nuclear Magnetic } \\
\text { Resonance } \\
\text { Spectroscopy }\end{array}$ & $\begin{array}{l}\text { Ion Mobility } \\
\text { Spectrometry }\end{array}$ & Immunoassay \\
\hline $\begin{array}{c}\text { Raman } \\
\text { Spectroscopy }\end{array}$ & $\begin{array}{c}\text { Liquid } \\
\text { Chromatography }\end{array}$ & Melting Point \\
\hline $\begin{array}{c}\text { X-Ray } \\
\text { Diffractrometry }\end{array}$ & $\begin{array}{l}\text { Microcrystalline } \\
\text { Tests }\end{array}$ & $\begin{array}{c}\text { Ultraviolet } \\
\text { Spectroscopy }\end{array}$ \\
\hline & $\begin{array}{l}\text { Pharmaceutical } \\
\text { Identifiers }\end{array}$ & \\
\hline & $\begin{array}{c}\text { Thin Layer } \\
\text { Chromatography }\end{array}$ & \\
\hline & $\begin{array}{l}\text { Cannabis only: } \\
\text { Macro- and Micro- } \\
\text { scopic Examination }\end{array}$ & \\
\hline
\end{tabular}

that is based only on color test results. A judge presiding over the case of California vs Rios rejected the results of a seized drug identification by color test in court because a color test alone was not sufficient. ${ }^{21}$ Another judge upheld an appeal because the color test results did not meet the widely accepted minimum standards described by the SWGDRUG, ASTM, and NIST OSAC standards. ${ }^{22}$ Similarly, in December of 2015, an Orlando man was arrested when a field test result was interpreted as positive for methamphetamine by the arresting officer. ${ }^{23}$ The man was detained for six months until the confirmatory results by the crime laboratory identified the seized substance to be Krispy Kreme doughnut glaze. ${ }^{24}$

\subsection{Courts and Lawyers}

One of the court's main objectives is for the punitive sanction of the drug violation, including the jail time, fines, and fees imposed by the court system. ${ }^{3}$ The monetary reclamation steps are an important source of income for the courts; they help the courts stay solvent and keep 
the criminal justice system functioning. Incarceration is used as both a punishment for the convicted and crime deterrent for the population. ${ }^{25,26}$

Chronologically, lower level courts are the first to handle most seized-drug cases. Petty drug crimes, such as possession, are rarely heard above the lowest level courts and, in some states, the cases are sent directly to a drug court. ${ }^{25}$ Cases where more investigation and preparation are involved, will also first be heard by these lower level courts, then trial courts, and finally, if appeals are filed, appellate courts or supreme courts. The system is designed to serve as a deterrent, and ideally should prevent recidivism. However, due to large backlogs, which slow casework, the criminal justice system fails to prevent recidivism. The difficultly in balancing these needs is reflected in the variety of solutions that different jurisdictions have used and continue to develop.

To prevent crime laboratory backlogs and prosecute crimes more quickly, one county in Alabama in 2012 permitted field officers and technicians to use a portable Raman spectroscopy instrument to test seized drugs in the field. ${ }^{27}$ By processing the suspected seized drug more quickly, the courts were able to resolve cases more quickly and the collect fines and fees in a more timely manner. The money collected created more income for the criminal justice system and the technology essentially "paid for itself". ${ }^{27}$ Money was also saved by the entire criminal justice system because cases were not dismissed based on lack of confirmatory evidence. Another benefit was that compensation packages did not have to be paid to the wrongly convicted.

Until the confirmatory results are reported by the forensic laboratory, the only information about the suspected seized drug are the results of the positive field color test; and due to crime laboratory backlogs, months often pass before evidence is analyzed in the crime laboratory. ${ }^{8,27,28}$ Without understanding the scientific limitations of a color test, and the combination of pressure to resolve cases quickly within the criminal justice system, positive color test results are often over 
exaggerated and used as a bargaining tools in plea bargains. A lawyer may incorrectly use the positive test as the basis for prosecution or indictment, which can subsequently be overturned by confirmatory analysis at a later date, whereupon exoneration compensation is required. ${ }^{29}$ Some judges understand the limitations of color tests and have deemed color tests inadmissible as evidence in their courts. ${ }^{8,21}$

Even if an illegal substance is identified in a seized-drug case, a prosecuting attorney may discard the drug charge to go after a defendant for a more serious charge, such as murder or assault, or refer suspects to drug court to receive the addiction help they need. ${ }^{11}$ For example, states such as Texas and Arkansas have been recently seeking alternatives to incarceration for low-level, nonviolent drug offenses. ${ }^{30}$ The purpose of seeking alternatives to incarceration is to allow officers to focus their attention on prevention and protection; another effect is the possible cost-effectiveness of not incarcerating these type of offenders. If addicts are offered treatment, then there is a possibility they will not commit additional crimes. ${ }^{25}$ By addressing the addiction of offenders with multiple drug charges, then the system can help citizens improve their lives while decreasing the number of seized-drug crimes and ultimately reduce the burden on the criminal justice system.

The possible fines and jail time associated with seized-drug cases can vary greatly depending the laws and jurisdiction where the crime occurred and the schedule level of the identified seized drug. In West Virginia, the state code $\$ 60 \mathrm{~A}-4-401$ defines the sentencing guidelines for different scheduled drugs as follows: ${ }^{31}$

(i) A controlled substance classified in Schedule I or II, which is a narcotic drug, is guilty of a felony and, upon conviction, may be imprisoned in the state correctional facility for not less than one year nor more than fifteen years, or fined not more than twenty-five thousand dollars, or both;

(ii) Any other controlled substance classified in Schedule I, II or III is guilty of a felony and, upon conviction, may be imprisoned in the state correctional facility for not less than one year nor more than five years, or fined not more than fifteen thousand dollars, or both;

(iii) A substance classified in Schedule IV is guilty of a felony and, upon conviction, may be imprisoned in the state correctional facility for not less than 
one year nor more than three years, or fined not more than ten thousand dollars, or both;

(iv) A substance classified in Schedule V is guilty of a misdemeanor and, upon conviction, may be confined in jail for not less than six months nor more than one year, or fined not more than five thousand dollars, or both: Provided, That for offenses relating to any substance classified as Schedule V in article ten of this chapter, the penalties established in said article apply.

The penalty imposed by the court system can vary greatly, as seen by the example above. The end result of each seized-drug case is at the discretion of the court system; lawyers, judges, and juries. A quicker resolution can lead to multiple benefits, including; 1) the protection of a citizen's $6^{\text {th }}$ amendment right; 2 ) a convicted suspect being less likely to recidivate because they recognize the relationship between crime and punishment; and 3) innocent suspect not being held by the system any longer than necessary.

\section{Seized Drugs in Crime and Society}

Seized-drug cases are a major type of evidence submitted to crime laboratories because these cases are pervasive in both crime and society. The quantitative financial assessment of seized-drug cases in the criminal justice system is difficult for many reasons. ${ }^{29}$ Seized-drug cases on their own are often considered a victimless crime, which means that courts are not pressured by a victim or a victim's family to pursue such crimes in a timely manner. In addition, many drug crimes are not reported because the parties involved do not want to admit their participation in any illegal activity. What is more difficult to quantify is the role of seized drugs in other types of crimes. For example, if an assault takes place and the aggressor is in possession of a controlled substance, then the assault may take priority over the seized-drug case. ${ }^{32}$ Many burglaries are committed to support drug habits. ${ }^{33}$ Even though the FBI attempts to track arrest statistics, the main drawback to the data collected is the crime must be reported to law enforcement in order to 
be entered into the database. For all these reasons, drug crime is notoriously difficult to track, quantify, and monetize.

When a crime occurs, the suspect could be under the influence of drugs, which falls under forensic toxicology, but seized drugs might not be collected at the time of arrest, which means no seized-drug evidence will be included in the report of the crime. An example would be an addict who steals property or money to support his/her habit. ${ }^{33}$ Depending on the crime committed, the offense could be categorized on a spectrum from robbery, to assault with a deadly weapon, to homicide, depending on how the crime was committed. The cases considered in this study were only the cases categorized as a drug abuse violations by the Uniform Crime Report (UCR) because these arrests involved seized-drug evidence being submitted to a crime laboratory for further testing. 6

Recently, a growing problem for officers is handling seized drugs in the field, and the increasing risk of exposure to hazardous chemicals. Specifically, the synthetic opioid fentanyl and its analogues are commonly found as adulterant cutting agents in heroin seizures, and sometimes cocaine. Fentanyl itself is $50-100$ times more potent than morphine or heroin. ${ }^{34}$ Other synthetic analogues, such as carfentanyl, can be many thousands of time more potent than heroin. ${ }^{35}$ When used in prescription medications, fentanyl is administered on the nanogram scale, but accidental inhalation exposures can easily exceed the effective dose. The rapid onset of overdose symptoms is within 2-3 minutes, which also makes fentanyl extremely dangerous.

Due to the potency fentanyl analogs, the US has seen a large increase in the number of accidental overdose deaths. In the first half of 2016 , there was a $57 \%$ increase in overdose deaths. ${ }^{36}$ When the officers and technicians in the field handle an unknown substances, they put themselves at risk since such a small amount of fentanyl can kill a person. The threat of accidental inhalation 
or absorption is serious and must be considered when making any changes to current procedure. Due to fentanyl's hazardous nature, unknown substances suspected of containing fentanyl should be handled carefully in a controlled environment, and this increases the difficulty of performing field testing. A forensic scientist or crime scene technician are trained to handle hazardous substances and can assist in keeping everyone safe in the field.

\section{Economic Assessment}

Whereas for-profit businesses tend to follow a set of best business practices, publicallyfunded forensic services currently do not. A challenge of being a publically funded service is that the criminal justice system, like any government service, has very different objectives from those of for-profit businesses. The goal of publically-funded services is always to maximize output for a set budget. $^{37}$ Recent studies, such as one by the National Institute of Justice's project FORESIGHT, have collected self-reported financial information from accredited forensic laboratories around the world, but mostly in the US. FORESIGHT creates metrics by which individual laboratories can assess their performance. FORESIGHT allows a laboratory productivity and cost effectiveness to be compared to similar laboratories. The goal of the FORESIGHT project is to understand what works in forensic laboratory management by tracking specific metrics and to enable forensic laboratories in personal metric assessment when change is implemented. ${ }^{38}$

Despite the difficulties of comparing forensic laboratories to each other directly, there are

some similarities to the budgeting problems that hospital laboratory administrators face. ${ }^{39}$ By using the same techniques, and expanding the analysis to include the changes to other areas of the criminal justice system (such as law enforcement and the court system), the larger cost and time saving benefits can be revealed. One such technique is a financial ratio, which compares individual 
operations to a calculated economic standard and adjusts for size and operation differences between laboratories. ${ }^{39}$

A major objective of crime laboratories is to maximize the number of samples analyzed for their given budget, and the return on investment (ROI) metric can be useful for laboratory managers. Even more useful is the inverse of the ROI, which is the average cost per case. The ROI is a useful metric to evaluate productivity (equation 1). ${ }^{37}$ If laboratories track their ROI, the manager could improve their ROI ratios by considering strategies that may not immediately seem cost effective, but are beneficial in the long term. ${ }^{37}$

$$
\mathrm{ROI}=\frac{\mathrm{CASE}}{\mathrm{TOTEXP}}=\frac{\text { LaborProductivity } \times \text { LaborExpenseRatio }}{\text { AverageCompensation } \times \text { TestingIntensity }}
$$

Equation 1: The verbal representation of the ROI decomposition equation, based on the DuPont expansion. ${ }^{37}$

The DuPont expansion form of the ROI equation was chosen for this paper because of the ability to breakdown financial information into components such as efficiency and analytical process measures. ${ }^{37}$ In this research project, the testing intensity ratio in equation 1 is a fixed value based on FORESIGHT 2015 data of 6.36 tests per case. ${ }^{40}$ Based on the results of a reliable field testing scheme, a prosecutor could offer a plea bargain at the time of arraignment, and if accepted by the defendant, the case could be closed and sentencing can begin. As soon as one case is resolved, the prosecutor can begin the next case. The streamlining of case resolution will increase the labor productivity ratio and increase the overall ROI. Increasing the ROI due to improving labor productivity is a favorable investment.

When performing economic assessments of a scientific technique, the effectiveness can be thought of as a function of both the quality and time of analysis. ${ }^{41}$ The task of choosing which departments will receive additional funds for new instruments or methodologies can be difficult because financial accounting is a zero-sum game; increasing funds in one department reduces 
funds to other departments. However, if the cost to the crime laboratory has the potential to save money in other areas of the criminal justice system, then the ROI analysis needs to consider the broader financial impacts of the investment. This comprehensive cost benefit analysis is the primary goal of this thesis, and the results should be of interest to State Attorney Generals, because they are typically the individuals responsible for the budget of each state's criminal justice system.

\section{The Effect of Forensic Science on the Criminal Justice System}

Forensic service requests start when a law enforcement officer collects and sends evidence to a crime laboratory for analysis. Prosecutors must also decide if there is enough evidence to file charges, and whether laboratory results will be necessary to obtain a conviction. Forensic scientists are integral to the criminal justice system decision making process because the scientific results inform prosecutors about the severity of the charges. ${ }^{29}$ Other stakeholders in the system, such as police and lawyers, need the results of forensic analyses to support and guide an investigation or to begin building a case for trial. By including the results of seized-drug evidence in the case file earlier in an investigation — as would be achieved with portable instrumentation — plea bargaining or trial preparation could proceed more quickly. A study conducted on the role of forensic evidence in criminal justice case processing showed a strong correlation between evidence collection and subsequent increase in convictions, in some cases as high as a $23 \%$ increase in convictions. ${ }^{42}$ Such studies reinforce the importance of timely results for seized-drug analysis.

Forensic science has helped exonerate the innocent and convict the criminals, but the large backlogs in crime laboratories can be the cause long trial delays. Quick trial resolution is desirable for several reasons; 1 ) to protect the accused from unnecessary public scorn; 2) to reduce the cost of incarcerating suspects while they await trial; and 3) to limit the possibility of an impaired defense because too much time has passed since the commission of the crime. ${ }^{1}$ 
In 1999, a study examined the timeliness of criminal case processing in nine different states, from arrest to disposition. On average, only $52 \%$ of all the court cases were resolved within 180 days of the arrest and only $89 \%$ were resolved within a year. ${ }^{43}$ The same study found the majority of the cases handled were drug-related, and they were resolved by the individuals eventually signing a guilty plea. ${ }^{43}$ Unfortunately, in many states, if an individual signs a guilty plea, the evidence submitted to the forensic laboratory may never be processed because the case is considered resolved. ${ }^{44,16}$ Also, if a detained suspect is unable to post bail after being arrested, the individual will remain in jail until trial. Whether the accused is detained in jail, or out on bail, their life is being affected by the pending charges again them, and their $6^{\text {th }}$ amendment right could be challenged.

Incorrect or misleading interpretation of field color tests results is a problem. In 2014-2015, Harris County, Texas had 73 drug case exonerations. In Harris County any drug possession carries a felony charge, so individuals are strongly motivate to avoid felony charges. ${ }^{45}$ Therefore, suspects frequently signed plea bargains to lessen the charges against them. This situation caused problems when the evidence sent to the crime laboratory was finally tested and the evidence submitted was legal substances. The individuals who signed plea bargains were not actually in possession of a controlled substance.

As discussed in section 2.2, ASTM 2329-14 takes the position that no single technique is adequate to provide sufficient confidence for seized-drug identification, but that a combination of tests—-such as color tests and GC/MS analysis—is required to identify seized drugs. If an analytical scheme such as a color test and GC/MS was conducted in the field, and prior to the prosecutors offering plea bargains to the Harris County suspects, then a large portion of the wrongful convictions could have been avoided. With the high false positive rates of color field 
tests, some lawyers and judges agree that the results of these tests should be excluded from the charging process. ${ }^{8,22}$

\subsection{Benefits of Portable Instrumentation to the Criminal Justice System}

Current available studies indicate that various areas of the criminal justice system are inefficient in regards to use of time, resources, and funding, but are also ineffective in their achievement of the larger punitive and deterrence goals of the system. Confirmatory field testing using portable instrumentation can resolve many of these issues, particularly in relation to seized drugs cases. Faster results will decrease the amount of time people spend in jail pretrial. Faster results will also lead to swifter punishment, which has been shown to decrease the recidivism rates. Higher accuracy in the field means fewer false positives and fewer wrongful convictions. All of these reasons argue for the benefits of testing seized drugs in the field.

The Crime in the US report breaks down seized-drug arrests into two categories: possession or sales/manufacturing. ${ }^{6}$ Possession offenses are typically small amounts of drugs for personal use, sometimes referred to as "simple possession" and make up the majority of drug offenses at the arrest level. ${ }^{46}$ Possession charges have a higher rate of plea bargains at over $99 \%$ of arrests resulting in a plea, while sales and manufacturing cases typically go to trial. ${ }^{46}$ Of the 12,000 seizeddrug cases completed by the US Attorneys in the fiscal year 2015, only 120 of those cases were for drug possession, about $1 \% .{ }^{47}$ Yet, according to the UCR report, $83.8 \%$ of the arrests in 2015 were for possession charges (figure 2). ${ }^{6}$ The testing of these small amounts of seized drugs in the field can greatly improve the quality of a citizen's due process in the criminal justice system since a large number of the arrests are for possession and can be resolved in a matter of days rather than months by using field tests with greater accuracy and reliability. 


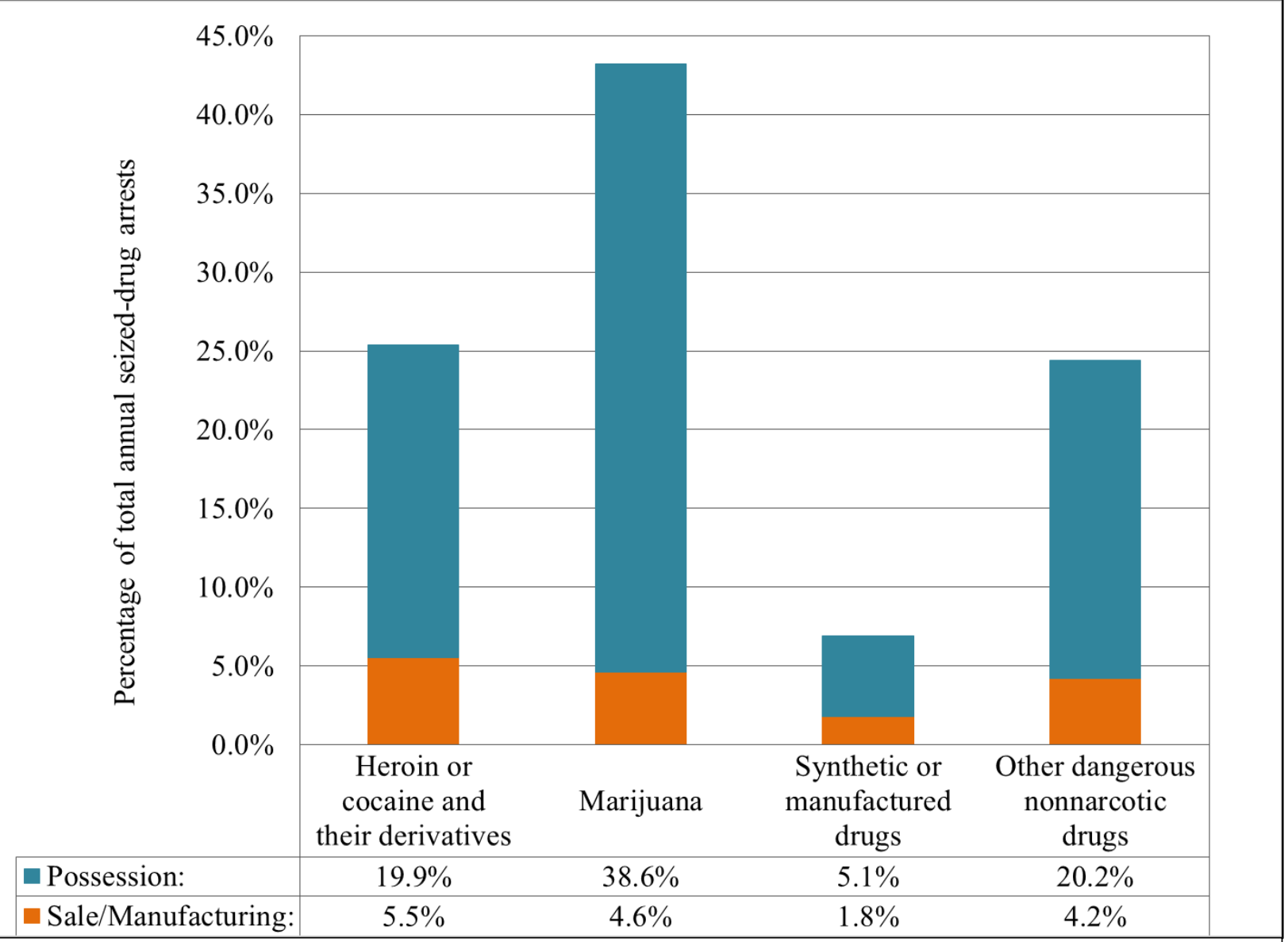

Figure 2: Breakdown of the 2015 UCR seized-drug arrests by drug type. ${ }^{6}$

Prosecuting a possession charge is also different from prosecuting a sale and manufacturing charge. The possession of an illegal substance is enough to charge a person with a crime. When prosecuting for sales and manufacturing, the law enforcement officers and lawyers must conduct thorough investigations to prove intent to distribute and/or manufacture the drugs, but with possession charges, a plea bargain can be coerced out of a pressured individual before thorough laboratory testing is conducted. For example, in 2015, 16,000 people were sentenced in Harris County Texas for possession of less than one gram of seized drugs. ${ }^{46}$ In some cases signing a plea bargain allowed the person to be released quickly due to time already served in jail. The lighter plea bargain is more enticing than being found guilty in trial and receiving a longer, more severe sentence. $^{46}$ 
An article discussing the danger of pursuing convictions based only on field color tests found that in the first seven months of 2014, 15 seized-drug samples sent to a Florida laboratory to be tested for methamphetamine were not illegal substances. When the department examined the arrest reports, they determined that $21 \%$ of the samples listed as methamphetamine by police officers was in fact not methamphetamine. Furthermore, of the $21 \%$ of samples that were not methamphetamine, half of the samples were contained legal substances. ${ }^{22}$ In cases like these, when confirmatory tests are run after the suspect has already signed a plea bargain and been convicted, clearing the wrongful conviction is difficult and incurs significant legal resources. ${ }^{5}$ Wrongful convictions can also unfairly damage the reputation and livelihood of citizens. ${ }^{26}$ For all these reasons, a confirmatory field method for seized drug identification could greatly benefit the criminal justice system.

\section{Methodology}

Websites of reputable US agencies provided all the data necessary to calculate the 2015 ROI and cost per seized-drug case, the most recent year for which data was available. These sources included the Federal Bureau of Investigation Uniform Crime Report (FBI-UCR), the Bureau of Labor Statistics (BLS), Project FORESIGHT, and multiple data collections performed by the US Census Bureau. A few of the databases provided a breakdown of the data into three different areas of interest: police protection, corrections, and judicial and legal services. From these online resources, the data was compiled into five categories to enable the ROI to be computed: 1) the total personnel expenditures for seized-drug cases (PEXP); 2) the number of full-time equivalent employees for seized-drug cases (FTE); 3) the number of seized-drug tests completed (TEST); 4) the number of seized-drug cases completed (CASE); and 5) the total expenditures spent on seized-drug cases (TOTEXP) (equation 2). ${ }^{37}$ 


$$
\frac{\text { CASE }}{\text { TOTEXP }}=\frac{\frac{\text { TEST }}{\text { FTE }} \times \frac{\text { PEXP }}{\text { TOTEXP }}}{\frac{\text { PEXP }}{\text { FTE }} \times \frac{\text { TEST }}{\text { CASE }}}
$$

Equation 2: Decomposition of the ROI economic metric. ${ }^{37}$

Four UCR reports are produced by the Federal Bureau of Investigation (FBI) each year, and they are made available to the public on the FBI-UCR website. ${ }^{6}$ The report used in this study was Crime in the US 2015. ${ }^{6}$ This report provided the annual total arrest numbers and a breakdown of arrests by offense type, such as murder or larceny, for a total of 26 different offense categories. In the same report, the seized-drug cases were categorized as "drug abuse violations", and these numbers provided the basis for calculating the percentage of seized drugs arrests at both the state and national level. The number of seized-drug arrests were also used as the number of cases processed (CASE in equation 2). One assumption in using the number of arrests as the of seizeddrug cases is that an arrest is the first step in a seized-drug case, and once an arrest is made, the suspect's right to due process and speedy trial has begun.

The US Census Bureau conducts nationwide surveys of state and local governments every four years. Once the US Census Bureau analyzes the data from their surveys, the summaries are published and specific measures of the raw, aggregated data are made available to the public. From the multiple databases available, two were used for the ROI calculation of each state. The US Census Bureau survey in 2012 provided the employment and payroll data for each state and area of the criminal justice system (PEXP and FTE in equation 2), and the survey of local and government finances in 2014 provided the total expenditures for each state and area of the criminal justice system (TOTEXP in equation 2). ${ }^{48,49}$ Additional BLS metrics were adjusted to calibrate the employment, payroll, and expenditures to the year 2015 . 
A few measures used to calculate the ROI and cost per seized-drug case were aggregated and could not be broken down specifically by state. The data from FORESIGHT provided the number of tests per seized-drug case (TEST in equation 2), in addition to the cost per seized-drug case for crime laboratories in $2015 .^{38}$ The BLS statistics provided the consumer price index (CPI) and the national employment, hours, and earnings growth. The CPI allows for an inflation adjustment to any monetary data. In this research, the inflation value was applied to the total expenditures for 2014 and the total personnel data from 2012. The inflation adjustment was calculated by dividing the CPI of the year the data was collected into the CPI for the year of interest and then multiplying that value by the available data measure (equation 3), or an increase of $1.03 \%$, for example. The latter number was used to adjust the number of employees for the job growth in the US and was found to be a decrease of $0.98 \% .{ }^{50}$ The job growth statistic was applied in the same way as the CPI, and these statistics were used to calibrate the online data to apply to the year 2015.

$$
\text { Adjusted Value }=\left(\frac{\text { Metric Value for Year of Interest }}{\text { Metric Value from the Data Collection Year }}\right) \times \text { Available Data Measure }
$$

Equation 3: Metric formula used to calibrate collected data to the year $2015 .{ }^{47}$

The final measures used to calculate the ROI and cost per seized-drug case can be found in Appendix A. 


\section{Results and Discussion}

\subsection{ROI and Cost per Seized-drug Case}

The results presented here are unique in that they account for all the arrests that enter each state's criminal justice system annually. By including both high- and low-cost cases in the average cost per seized case, both extremes of case costs are included. There are no studies describing the total cost of seized-drug cases to the criminal justice system, so to estimate the amount of resources (i.e. money and employees) devoted to seized-drug cases, online data was collected from the 2015 UCR report. ${ }^{6}$ Therefore, we first calculated the percentage of effort that the criminal justice system devotes to drug crime, then used that percentage of effort to calculate the percentage of cost devoted to drug crime.

The estimate of the percentage of seized-drug cases is achieved by dividing the total number of seized-drug arrests by the total number of arrests. We assume that equal resources are given to all types of casework, even though we know resources are not equally divided between all types of casework. For example, a study conducted in 2008 by McCollister et. al. showed the cost devoted to prosecuting a crime is dependent on the type of offense committed. The 2008 study estimated the actual tangible cost to the criminal justice system of a murder case was the highest, at almost $\$ 1.3$ million per case, whereas theft was the lowest, at about $\$ 3,500$ per case. Tangible costs do not include possible compensation to the victim(s) (table 4). The same study excluded the cost per seized-drug case for two main reasons: 1) the high frequency with which drugs are involved in other offenses, and 2) victim(s) of drug crime do not reliably report all drug crimes. ${ }^{32}$ When seized-drug crimes are involved in cases with a higher priority crime (such as drugs found on a murder suspect), the crime is not typically counted in the database as a drug crime. Therefore, 
each area; law enforcement, corrections, and the judicial and legal system (appendix A, table 4-9) using equation 2. The measures needed to calculate individual states and a national ROI were collected from the online databases and adjusted to the year 2015 using the appropriate metrics and equation 3. The details of which online sources provided the data to calculate the 2015 ROI and average cost per seized-drug case was outlined in section 6.1.

This project calculated the nationwide 2015 cost per seized-drug case to be about $\$ 26,000$ dollars, which is in reasonable agreement with the estimate of $\$ 38,000$, which derives from the inflation-adjusted estimate of $\$ 28,000$ in $2000 .{ }^{32}$ In contrast, the 2015 FORESIGHT reported the costs to the crime laboratories to be $\$ 276$ per case, or about $1 \%$ of the total, and ranged from $\$ 144$ $\$ 408$ per seized-drug case. ${ }^{40}$ The FORESIGHT project is the only available information of the cost of seized-drug cases for crime laboratories, so no comparison to other studies could be done. For ease of understanding, the average cost per seized-drug case will be referenced in the body and figures of this paper and the corresponding ROI metric is in appendix A.

The 2015 ROI and average cost per seized-drug case was also estimated for each state using the online data described in Section 6.1. Figure 3 is a heat map of the total cost per seizeddrug case for each state in the US and helps to visualize the differences in the cost by state on a nationwide scale. Stakeholders can first examine their state's average cost per seized-drug case compared to other states, and then determine which area is responsible for the majority of the processing seized-drug cases by referring to the area breakdown in figure 4 . The figures and scenarios presented in the next sections are to assist any stakeholders in understanding the areas outside the crime laboratory where time and money can be saved, or by streamlining the criminal justice process with portable instrumentation. 


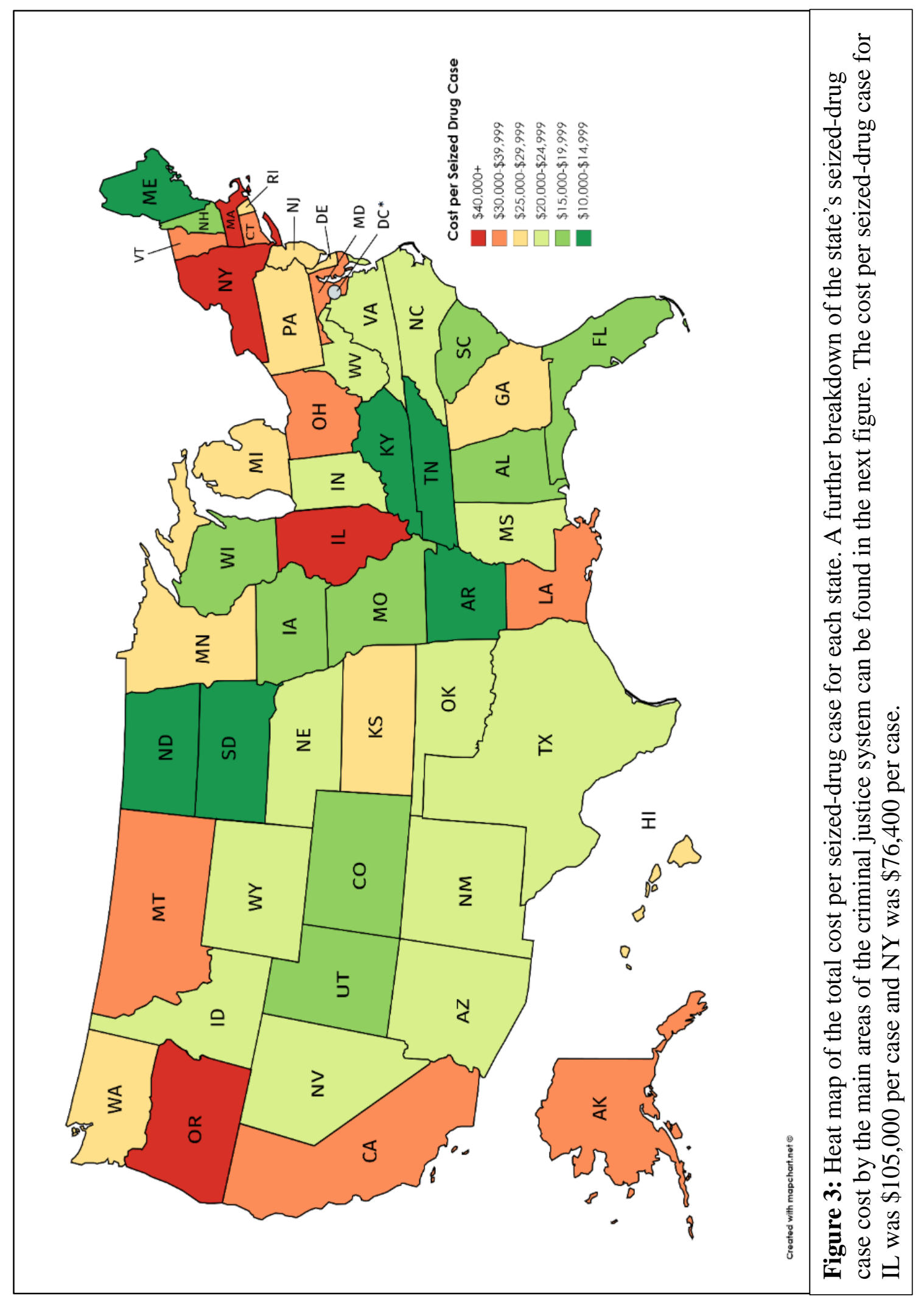




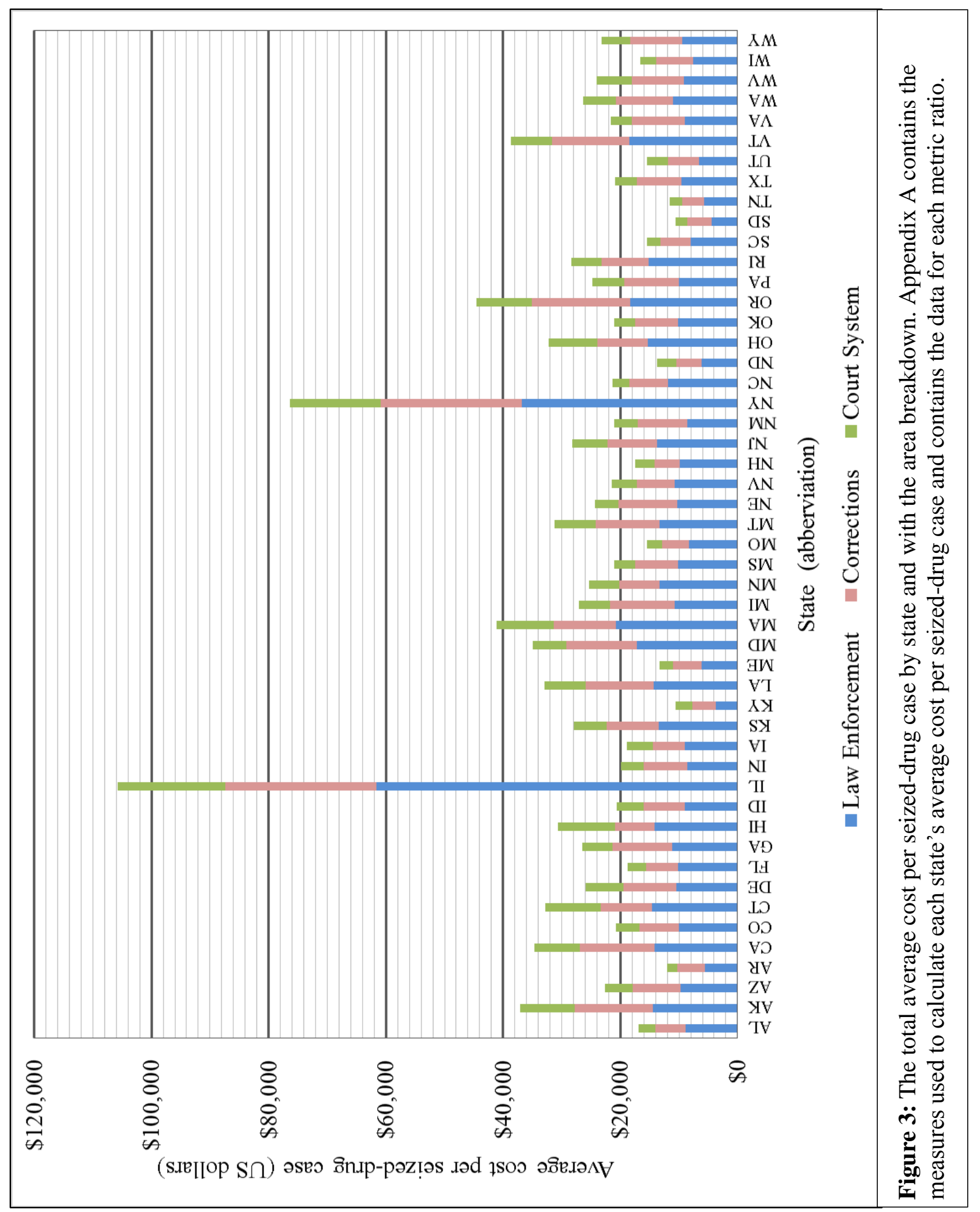


Section 2 addressed the variations between states depend on many factors, such as the population served, geographic location, jurisdiction, personnel, and differences in state law. Applying common-size business and economic measures, such as the ROI metric and the percentage of seized-drug arrests, allows stakeholders to compare the amount of funds they allocate despite the differences between states, and also allows the determination of the amount of resources being spent in their criminal justice system. ${ }^{51}$ Figure 5 shows a scatter plot of each state's percentage of seized-drug arrests versus the average cost per seized-drug case. The linear regression line shows no correlation $\left(\mathrm{R}^{2}=0.016\right)$ between a state's average total cost of prosecuting seized-drug cases and the percentage of cases in that state are seized-drug cases. The lack of

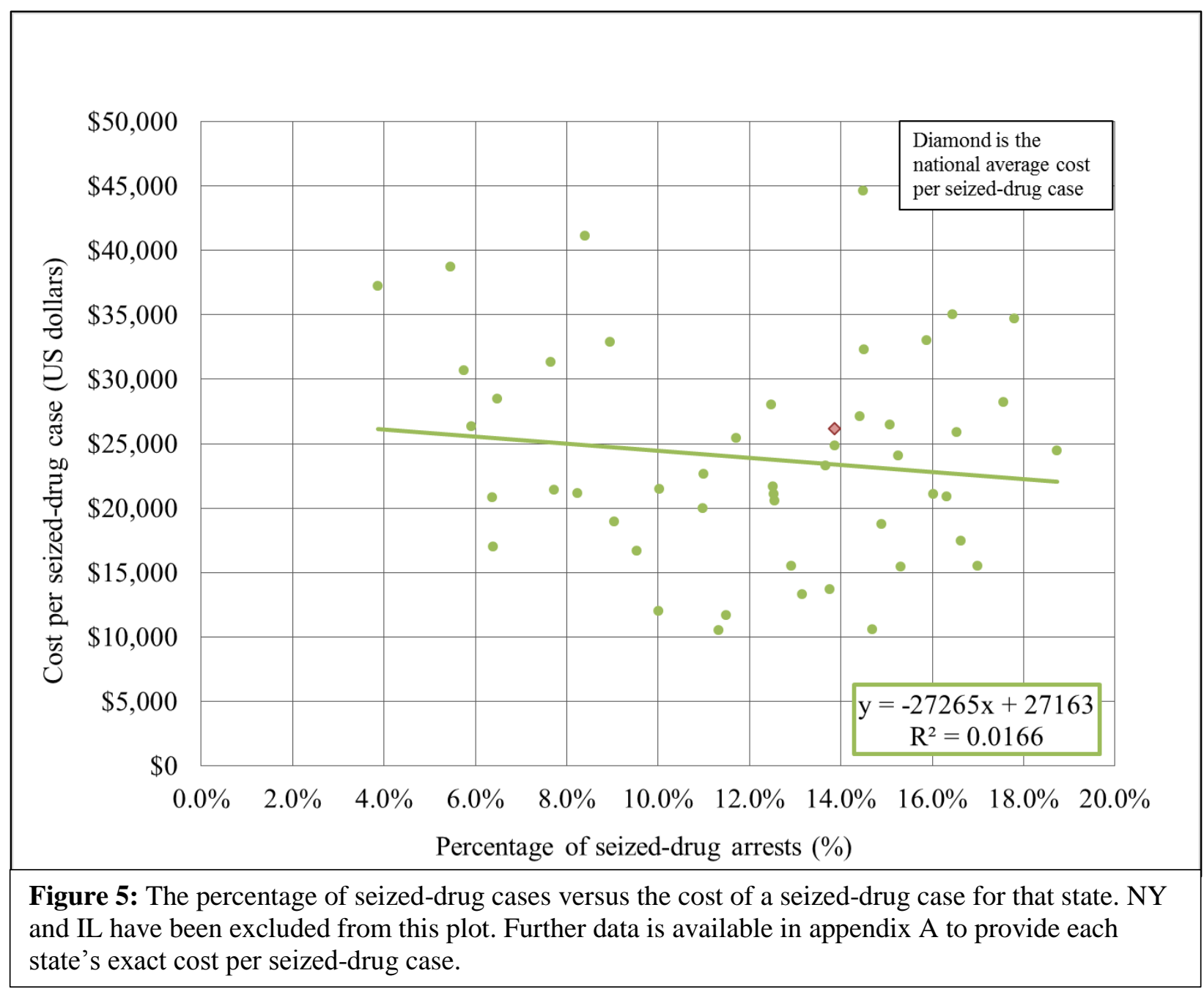


correlation means that the percentage of seized-drug cases and the average total cost of seizeddrug cases do not influence the ROI or average total cost per seized-drug case, so further analysis using the decomposition of the ROI can provide more information.

Using the DuPont expansion of the ROI economic metric (equations 1 and 2), we can compare the ratio measures in the ROI metric to the average cost per seized-drug case and determine which measure ratio (i.e. average compensation or labor productivity) is causing a change in the cost per seized-drug case. For example, Oregon has the highest cost per seized-drug case at $\$ 44,600$ and a percentage of seized-drug cases close to the national percentage at $14.5 \%$. The percentage of seized-drug cases was used to estimate the amount of resources devoted to processing seized-drug cases in each area, so a larger percentage means more resources devoted to seized-drug cases, but that does not always generate the highest average cost per seized-drug cases.

If we examine each ratio within the DuPont expansion ROI equation (equation 1), then we see that Oregon has higher average compensation and lower labor productivity than South Dakota, a state with a comparable percentage of seized-drug cases. The higher average compensation of about $\$ 64,400$ per FTE would be acceptable if labor productivity was higher, but it is not. South Dakota's percentage of seized-drug cases is $14.7 \%$, and the average compensation per FTE was almost $\$ 45,500$ annually per FTE. The combination of lower average compensation and higher labor productivity resulted in South Dakota having the lowest cost per seized-drug case at $\$ 10,500$ per seized-drug case. Higher average compensation and low labor productivity causes a decrease in the ROI and increases the cost per case, as seen by comparing Oregon and South Dakota.

Another example of applying the DuPont expansion shows for the states that had a lower percentage of seized-drug arrests does not always mean the average cost per seized-drug case will 
be lower. Alaska had the lowest percentage of seized-drug case at 3.9\%, but the state's average cost per seized-drug case was $\$ 37,200$ which is on the higher end of the average. Again, comparing the lowest cost per seized-drug case, Alaska and South Dakota had almost the same average compensation at about $\$ 45,000$ dollars per FTE, but South Dakota had a labor productivity that was over four times higher than Alaska's labor productivity. The higher labor productivity increased South Dakota's ROI and decreased their cost per seized-drug case. Due to the differences in the percentage of seized-drug cases and resource allocation, the benefits of portable instruments in the field will be different for each department, agency, or state.

When the average cost per seized-drug case is compared to the number of seized-drug arrests, the correlation is still absent $\left(\mathrm{R}^{2}=0.0025\right)$ in figure 6 . California has the highest annual number of seized-drug arrests, but the state does not have the highest average cost per seized-drug case. Even with a high average compensation of $\$ 87,800$ per FTE, the state's high labor productivity raises their ROI and decreases the average cost per seized-drug case. Texas has the second highest number of seized-drug arrests and the average cost per seized-drug case is almost $\$ 14,000$ lower than California. These examples show that a correlation between the number of seized-drug arrests and the average cost per seized-drug case cannot be made, and the importance of applying the DuPont expansion to understand what measures could be driving the higher costs.

The perspective of practitioners was beneficial in understanding the nature of the field work and dynamic needs of different states. A phone interview conducted with the Assistant Director of the Florida State Crime Laboratory was very enlightening and provided information not available in journals or articles. ${ }^{23}$ For example, Florida made national news when a positive presumptive field test for methamphetamine led to the arrest of a suspect, but confirmatory testing later identified the unknown substance as doughnut glaze. ${ }^{24}$ Since the incident, the Florida Assistant 


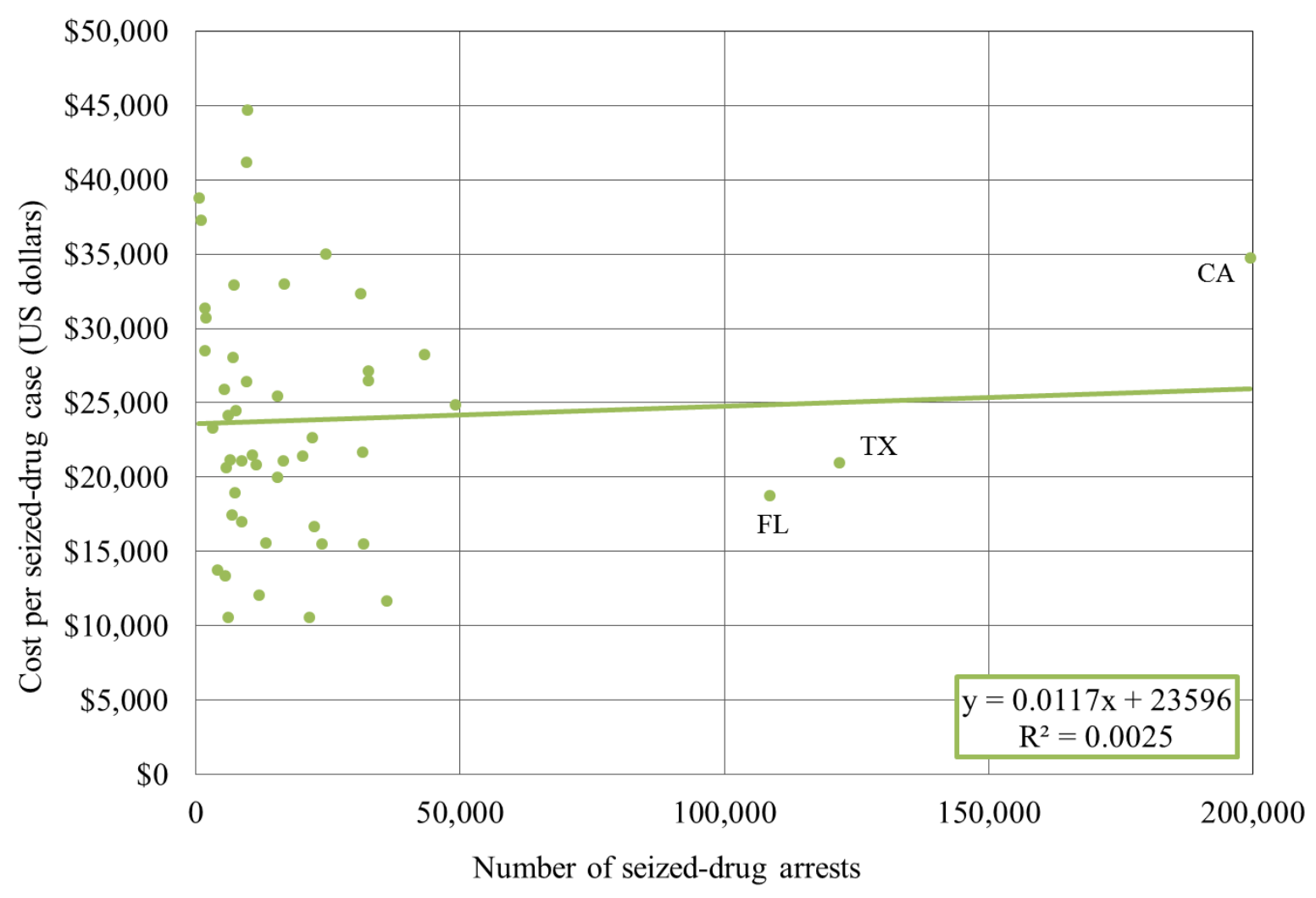

Figure 6: The number of seized-drug arrests versus the average total cost of a seized-drug case for that state. NY and IL have been excluded from this plot. Further data is available in appendix A to provide each state's exact cost per seized-drug case.

Director has noticed that drug unit spends more time on courtroom testimony and assigns this change to the increased scrutiny of defense lawyers when dealing with forensic testimony.

Historically, the Florida State Crime Laboratory has always been understaffed because the average compensation for the forensic analysts was the lowest in the state. However, a recent increase in state funding to support raising employee salaries has enable the State Crime Laboratory to become competitive with other laboratories in the state. Now, the State Crime Laboratory is able to retain employees and remain fully staffed, so the laboratory can deal with the incoming workload. ${ }^{23}$ When Attorney Generals contemplate additional investments in state 
funding, it is important to include these practical aspects with pure economic metrics. Some system or workflow may not offer direct financial benefits, but investments can have important long-term impact on the quality and timeliness of seized-drug casework.

\subsection{Startup Cost of Portable Instrumentation}

When considering an investment in upgrading or replacing new instrumentation, a stakeholder in the process will typically need to know the cost, time, and efficiency benefits of the new instrument; in addition to the initial investment, annual costs, additional training, and any other marginal costs of the new or upgraded instrument. The criminal justice system already employs forensic drug analysts who are familiar with the science and interpretation of seized-drug analyses, so existing analysts will only need minimal training to become familiar with using portable scientific instruments and analyzing seized-drug samples in the field. Crime laboratories will most likely be responsible for both the initial investment in the portable instrumentation and for providing the field analysts, which may not be a financially favorable investment to the crime laboratories. However, unlike previous studies, which tend to only consider the cost of casework to the crime laboratory, this analysis quantifies the costs to the crime laboratory relative to the entire criminal justice system. ${ }^{39}$ By expanding this study, the cost savings found in other areas justifies the initial investment in the crime laboratory instrumentation.

There are a variety of commercially-available portable GC/MS instruments. ${ }^{52}$ The initial investment cost of Perkin-Elmer TORION-T9 portable GC/MS instrument is about a $\$ 110,000$, which is similar to the average cost of a comparable bench-top GC/MS instruments currently used in crime laboratories. ${ }^{53} \mathrm{~A}$ validation process must be completed any time a new instrument is brought into the process, which takes an analyst away from casework. In theory, the validation time for a new portable instrument should be no more arduous than for bench-top instruments, 
since the objectives of validation will be the same (i.e. accuracy, precision, limit of detection, etc). Therefore, the validation time should be similar for either bench top or portable instruments, depending on any issues that may arise during the process. One caveat is that bench-top instruments are more likely to have auto-injectors, which can speed up method validation and improve the reproducibility of measurements. ${ }^{54}$ If an approximate validation period is two months, then the salary of the analyst performing the validation would be around $\$ 16,000$ (based on a total average FTE of $\$ 96,000$ per year), bringing the total initial investment to about $\$ 126,000 .^{38} \mathrm{~A}$ portable instrument will also have to be validated in the field environment which will some add travel time and expenses. During the validation process, a field scenario close to the crime laboratory could be chosen to reduce travel time.

Determining the annual cost of portable seized-drug analysis is more challenging. The total cost depends on factors such as travel time of the analyst and the number of samples processed on the instrument. A typical on-site scheme might warrant one calibration sample, two blanks, and an average of three different samples of the drug seizure, for a total of six test samples at each case, which agrees with the average number of tests per case from the 2015 FORESIGHT report. ${ }^{40}$

If the published specifications given for portable GC/MS instruments are accurate, then a typical portable GC/MS instrument should be able to process 150 tests per disposable helium carrier gas cartridge. ${ }^{55}$ The consumables included in the initial costs will run 1800 tests through the instrument, or 300 on-site analyses ( 6 on-site tests per case). For every 300 on-site tests, the laboratory will have to spend another $\$ 1,100$ in consumables to run another 1800 tests. ${ }^{53} \mathrm{An}$ abbreviated copy of a price quote for a Torion-T9 can be found in figure $7 .{ }^{53}$ The information for new instruments can be requested from any supplier by a laboratory interested in budgeting for a new purchase. Some of the consumables will be used during the validation process, so the first set 
of supplies will be less than 300 field processed cases and will vary depending on the parameters and outcome of the validation process. The quote shows that the approximate total 1 st year costs, including equipment, supplies, training and customer support, is approximately $\sim \$ 90 \mathrm{~K}$ for the instrument which will only be included in the first year cost and $\sim \$ 11 \mathrm{~K}$ in supplies which will need to be purchased yearly.

\begin{tabular}{|lrrrrr}
\hline & \multicolumn{2}{c}{ Torion T-9 Portable GC/MS System } & & \\
Part Number & Quantity & Description & Unit Price & Total \\
\hline NTSST090500 & 1 & Torion T-9 Portable GC/MS Instrument & $85,000.00$ & $85,000.00$ \\
\hline NTSSMIX0160 & 1 & CALION IS, Ampoule, Pkg. 1, SPS-3 IS & 155.00 & 155.00 \\
\hline NTSC19SN3B171 & 1 & SPME Syr. Blunt 19 Ga, DVB/PDMS Fiber, 3 & $1,250.00$ & $1,250.00$ \\
\hline NTSSCL60705 & 1 & Basic Needle Trap Kit, 110V, CLAIRION & $4,323.00$ & $4,323.00$ \\
\hline NTSST090506 & 1 & Torion T-9 Advance Starter Kit, 12Month & $7,300.00$ & $7,300.00$ \\
\hline NTSSMIX031019 & 1 & CALION PV Mix Std, Mininert, 19Ga, Pkg 3 & 500.00 & 500.00 \\
\hline NTSSG070037 & 1 & Helium Gas Cyl, HiPurity99.5\% 98mL Pkg12 & 569.00 & 569.00 \\
\hline NTSDNIST0004 & 1 & SOFTWARE NIST/EPA/NIH W AMDIS 2014 ED & $3,500.00$ & $3,500.00$ \\
\hline NTS02750005 & 1 & Rechargeable Battery, Lithium lon, T-9 & 625.00 & 625.00 \\
\hline N0239040 & 2 & Onsite Scientific Consulting Service GCM & $3,200.00$ & $6,400.00$ \\
\hline REGDELMBA & 1 & Regular Delivery & $2,294.46$ & $2,294.46$ \\
\hline SDS-NRMBA & 1 & Special Delivery services not required & & \\
\hline & & & & $111,916.46$ \\
& & & Sub Total & $10,306.70$ \\
& & Allowance & Total & $101,609.76$ \\
\hline
\end{tabular}

Figure 7: Example of a price quote for a Torion-T9 and the level of breakdown provided with a price quote. $^{49}$ 


\subsection{Implementing Confirmatory Field Testing}

There are several practical aspects to consider with on-site drug analyses. One issue is, who will conduct each analysis? The options vary from police officers to CSI technicians to trained drug analysts. To meet the stringent quality control requirements and scientific rigor necessary for admissibility in court, on-site drug analysis would be performed by seized-drug analysts. The seized-drug analysts could be based out of crime laboratories, or police departments, depending on the area the analyst was responsible for covering and/or the geography of a state. The latter would presumably facilitate communication first responders and the on-site drug analysts and enable faster response times.

The policies and procedures for field analysis will be determined by individual departments, depending on where forensic analysts are geographically located. In states with few crime laboratories and large geographic service areas, travel times for on-site drug analysis would be impractical. On the other hand, for states with large metropolises and multiple laboratories, onsite seized drug analysts would have less travel time between cases and could readily attend to several cases per day.

Another alternative to having analysts travel to crime scenes and arrest sites to perform onsite measurements is to conduct seized drug analyses in a room near the booking station. The chosen analytical schemes could use portable or conventional bench-top systems wherein confirmatory testing could be performed immediately upon booking suspects. Performing measurements at the scene of each crime has the benefit of providing the smallest potential for cross-contamination between cases. These are examples of additional pros and cons to consider when adopting protocols for casework. 
One anticipates that the workflow for on-site measurements requires a report to be generated by the field analyst, and the report will then be provided to the arresting officer to include the results of the seized-drug tests in the arrest report. If an on-site measurement result is positive for a controlled substance, the case would then be considered completed by the crime laboratory because the arrestee will be arraigned with confirmatory results of seized-drug possession, and the lawyers would begin the arbitration process immediately. The time between arraignment and a court date, would depend on the state and quality of seized drugs. We estimate that field testing could bring the average time to disposition to 30 days or less, especially given the recent success in Alabama. ${ }^{43}$

If the results of a pre-booking analysis was negative for controlled substances, then the suspect could be released immediately with no harmful ramifications. The ability to rapidly release innocent detainees would go a long way towards restoring faith in the criminal justice system, and it would enable punishments to be implemented more rapidly than could be measured.

Project FORESIGHT found the annual number of reports currently being generated by a forensic drug analyst to be around 480 reports a year. ${ }^{38}$ There are typically $\sim 260$ business days in a year, so the average productivity for a FTE is currently greater than 1.8 cases a day. In the laboratory, a FTE spends time processing cases and working on their instruments, also called analytical time. Laboratory managers and analysts also allot for non-analytical time, such as vacation, multiple sick/personal days, training requirements. Employees are permitted time away from the laboratory to testify in court, so their productivity on days when they perform analysis is significantly greater than the yearly average would suggest.

If an on-site seized drug analyst could average one to five cases per day in the field, the number of cases per analyst would range from 260-1300 cases a year. On a typical day, the field 
analyst might be able to process 3 on-site seized-drug cases a day, thus reaching 480 reports in 32 weeks, assuming five work days a week. The remaining 20 weeks of the full-time employee's year could be used for vacation days, down-time on the instrument, and court room testimony. These estimates are for analysts to spend $75 \%$ in analytical work and $25 \%$ in non-analytical work, for $61 \%$ of the year, for a total of $45 \%$ of their time on casework. This percentage is in-line with project FORESIGHT, which found the amount of work time that seized-drug analysts spend on casework is about $43 \% .^{38}$

When a laboratory is considering investment in a new instrument, often the investment is calculated over a multi-year period, such as a five-year plan. The instrument cost is and up-front cost in the first year, but continues to be used for several years thereafter. Once an instrument is purchased though, it begins to depreciate in value, so bi-yearly onsite technician visits and warranties are included in the projected investment costs. However, money spent on consumables, travel, and employees are the reoccurring costs and susceptible to inflation and cost-of-living raises. Table 5 gives an estimate of the five year breakdown of the cost from all the expenses necessary to maintain and staff on-site testing of seized drugs for typical work week; eight hours a day, five days a week, 39 weeks a year and assumes a $2 \%$ increase each year in consumables,

\begin{tabular}{|r|c|c|c|c|c|}
\hline Table 5: Five-year Breakdown of On-site Seized-Drug Testing \\
\hline & $\mathbf{1}$ year & $\mathbf{2}$ year & $\mathbf{3}$ year & $\mathbf{4}$ year & 5 year \\
\hline GC/MS & $\$ 90,794$ & $\mathrm{n} / \mathrm{a}$ & $\mathrm{n} / \mathrm{a}$ & $\mathrm{n} / \mathrm{a}$ & $\mathrm{n} / \mathrm{a}$ \\
\hline Raman & $\$ 27,500$ & $\mathrm{n} / \mathrm{a}$ & $\mathrm{n} / \mathrm{a}$ & $\mathrm{n} / \mathrm{a}$ & $\mathrm{n} / \mathrm{a}$ \\
\hline Color Tests & $\$ 2,900$ & $\$ 2,958$ & $\$ 3,017$ & $\$ 3,078$ & $\$ 3,139$ \\
\hline Supplies & $\$ 10,815$ & $\$ 16,400$ & $\$ 16,728$ & $\$ 17,063$ & $\$ 17,404$ \\
\hline 2 FTE & $\$ 192,000$ & $\$ 195,840$ & $\$ 199,757$ & $\$ 203,752$ & $\$ 207,827$ \\
\hline Vehicle & $\$ 2,664$ & $\$ 2,717$ & $\$ 2,772$ & $\$ 2,827$ & $\$ 2,884$ \\
\hline Travel & $\$ 663$ & $\$ 676$ & $\$ 690$ & $\$ 704$ & $\$ 718$ \\
\hline Ynnual Total & $\$ 327,336$ & $\$ 218,592$ & $\$ 222,963$ & $\$ 227,423$ & $\$ 231,971$ \\
\hline
\end{tabular}


inflation, and cost-of-living adjustments. The other 13 weeks are allotted for training, meetings, testifying, instrument maintenance, and vacation/sick days.

The implementation costs in Table 5 were derived from quotes for a portable GC-MS instrument and a portable Raman instrument. Actual costs would of course vary depending on the make and model of the selected instrumentation. For example, portable FTIR instruments would be approximately twice as expensive as portable Raman instruments, but would exceed ASTM requirements for the analytical scheme. ${ }^{10}$

The selected instruments and kits were: 1) TORION T-9 by Perkin Elmer; ${ }^{53}$ 2) a TruNarc Raman spectrometer by Bruker; ${ }^{56}$ 3) 10 kits of NIK® Master-Pak ${ }^{\mathrm{TM}}$ of color tests (total of 1300 color tests a year) by Safariland Group. ${ }^{57}$ The instruments and color expenses include the cost of training employees on the instruments, a five year warranty on the TruNarc, and two on-site technician visits a year for the TORION T-9. Each estimate takes into account the salary of two FTEs at the same average pay rate as mentioned in section 7.2. Estimates also include the cost of consumables each year for 1500 tests. This estimate assumes an average of 6 tests per seized-drug case $^{40}$ and an average of one case per day for 260 days each year. The cost of travel was assumed to be a 10-mile radius around the crime laboratory every work day in an agency issued midsized sedan. The costs of vehicles and mileage rates were obtained from the US General Services Administration (GSA) for $2015 .{ }^{58}$ The estimates made here will also be used in the next section to determine the savings.

Table 5 shows that the 1-year, 3-year and 5-year costs of implementing on-site seized drug analyses is expected to be $\sim \$ 330 \mathrm{~K}, \sim \$ 770 \mathrm{~K}$ and $\sim \$ 1.2$ million, respectively. Taken on their own, these can seem too expensive to justify. However, the financial analysis in the Section 7.3.2 shows that the cost of performing drug analyses is on the order of $1 \%$ of the cost of prosecuting a drug 
crime. In this context, it is reasonable to see how an added expense to the crime laboratory system could be beneficial to the criminal justice system if the savings to the courts and the police outweigh the cost to the crime laboratory. The savings to the crime laboratory would be relatively modest, since the number of casework samples entering the crime lab system would only decrease by $260-1300$ cases per year. At an average cost of $\$ 275$ per case, the cost benefit to the crime laboratory is only on the order of $\sim \$ 70 \mathrm{~K}-\$ 340 \mathrm{~K}$ per year, which is not likely to break even. However, the following analysis estimates the potential cost savings to other areas of the criminal justice system, and these savings are substantially larger than the cost of implementation to the crime laboratory system.

\subsection{Decreasing the Cost of Corrections}

To comply with citizens' constitutional right to a speedy trial, the American Bar Association (ABA) sets guidelines for the disposition time of cases. The ABA recommends that 90\% of cases be resolved within 120 days, $98 \%$ in 180 days, and $100 \%$ be resolved within 365 days. However, a study in 1999 conducted by Ostrom and Hanson showed that the disposition time in nine randomly-sampled court systems across the US are closer to only $52 \%$ resolved in 180 days and $89 \%$ resolved in 365 days. No estimate was provided for the percentage of cases resolved in a 120 days. ${ }^{43}$ Therefore, according the Ostrom and Hanson study, approximately half of cases are resolved at 180 days, so 180 days serves as a good approximation for the average time to disposition for seized-drug cases.

While cases are unresolved, suspects are either held in jail awaiting trial after arraignment, or they are allowed to await trial outside of jail if they post bail or are released on personal recognizance. ${ }^{3}$ According to Ostrom and Hanson, approximately 50\% of suspects awaiting trial are held in jail, which means that the weighted average number of days in jail is around 90 days 
per case. ${ }^{43}$ If confirmatory tests could be performed at the time of arrest using portable instrumentation, then case resolution would occur as soon as the court date was set or a plea bargain was reached, thus saving significant incarceration costs. The question is, how much does pretrial incarceration cost the system, and how much could be saved by resolving cases more quickly?

The Vera Institute of Justice (VIJ) annually tracks the incarceration rates across the US. They also asses the cost of the correction systems, but do not provide a breakdown of the offense type for inmates currently in jail awaiting pretrial. A study conducted by VIJ in 2014 analyzed the average daily cost per inmate for 35 different jail systems across the US. ${ }^{59}$ After adjusting for inflation from 2014 to 2015, the average daily cost per inmate of the 35 jail systems surveyed was $\sim 130$ per day per inmate. The lowest average cost per day was $\$ 48$ (Cherokee County, Georgia) while the highest was $\$ 575$ (New York City, New York).

Applying the total cost over 5 years from table 5 and the average daily cost of incarcerating an inmate previously listed, along with the two extremes of the highest and lowest average daily incarceration costs per inmate, then the estimated marginal savings of portable instrumentation was determined. Studies have shown that $99 \%$ of seized-drug cases result in a plea bargain and the other $1 \%$ proceed to trial. ${ }^{46}$ However, Ostrom and Hanson's data implies that many suspects wait a long time before they plea, presumably due to the wait for suspected seized-drug analysis reports to be filed by the crime laboratory. Project FORESIGHT data shows that only 5\% of drug samples remain untested after 30 days, ${ }^{38}$ which indicates that there must be other factors in the criminal justice system that account for the additional $~ 150$ days seen between arrests and resolution of cases. A possible explanation for the discrepancy in time between the 30 days taken to analyze a drug sample and the 180 days taken to resolve an average case is that the police department might not send the evidence out for analysis until the charges are officially brought against the suspect. 
There may also be other aspects of the investigation that need to be completed after the lab results are returned.

To calculate the reduction in incarceration costs, we considered only those cases that result in plea bargains because the cost and time of a trial is the same whether or not portable instrumentation is used. Approximately 50\% of current seized-drug cases are completed within the 180 days of arrest, and approximately $50 \%$ of those waiting for case resolution are held in jail pretrial. ${ }^{43}$ A conservative estimate for the benefit of on-site testing is that portable instruments could enable case resolution in 30 days ( 2 days for arraignment and 28 days for the court date), which is a saving of 150 days per case. Given that the average cost of a day in jail is $\$ 129$, one can therefore expect to save approximately $\$ 19,500$ each time a suspect has a reduced jail time, which is approximately $50 \%$ of those awaiting trial. The average weighted savings are therefore closer to $\$ 10,000$ per case.

Figure 8-10 show the expected marginal savings (difference between the implementation costs and the expected savings) to the pretrial population held awaiting a court date for different jurisdictions under different scenarios. For example, Figure 8 shows the 1-year marginal savings for jurisdictions with the cheapest, mean, and most expensive jail costs, over a variety of number of cases handled per year with portable equipment. Figures 9 and 10 show the same saving over 3 and 5 years, respectively. 


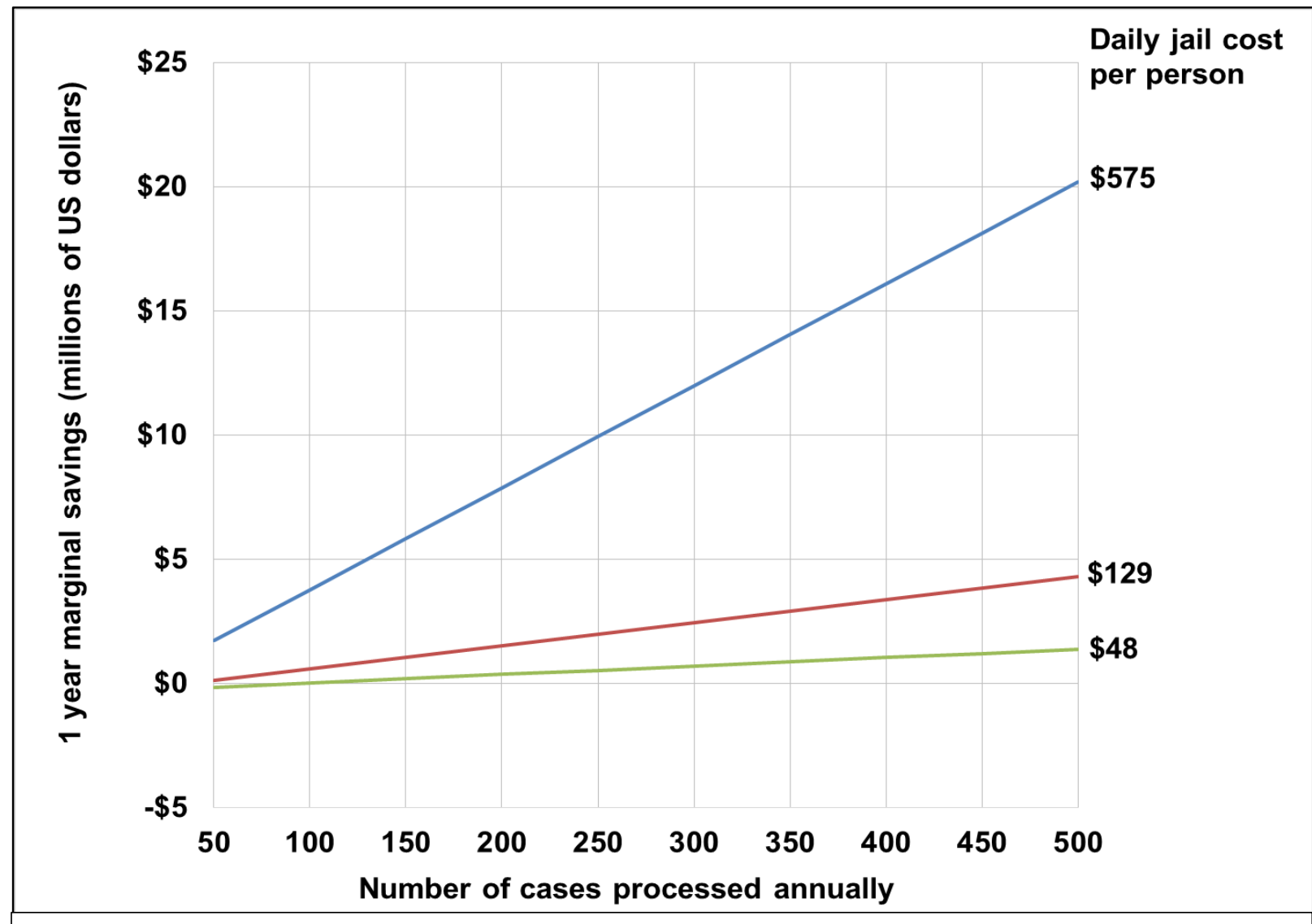

Figure 8: Estimate marginal cost savings in the first year of investing in portable instrumentation compared to the number of cases processed annually using portable instrumentation. Three different average daily costs per inmate are plotted. 


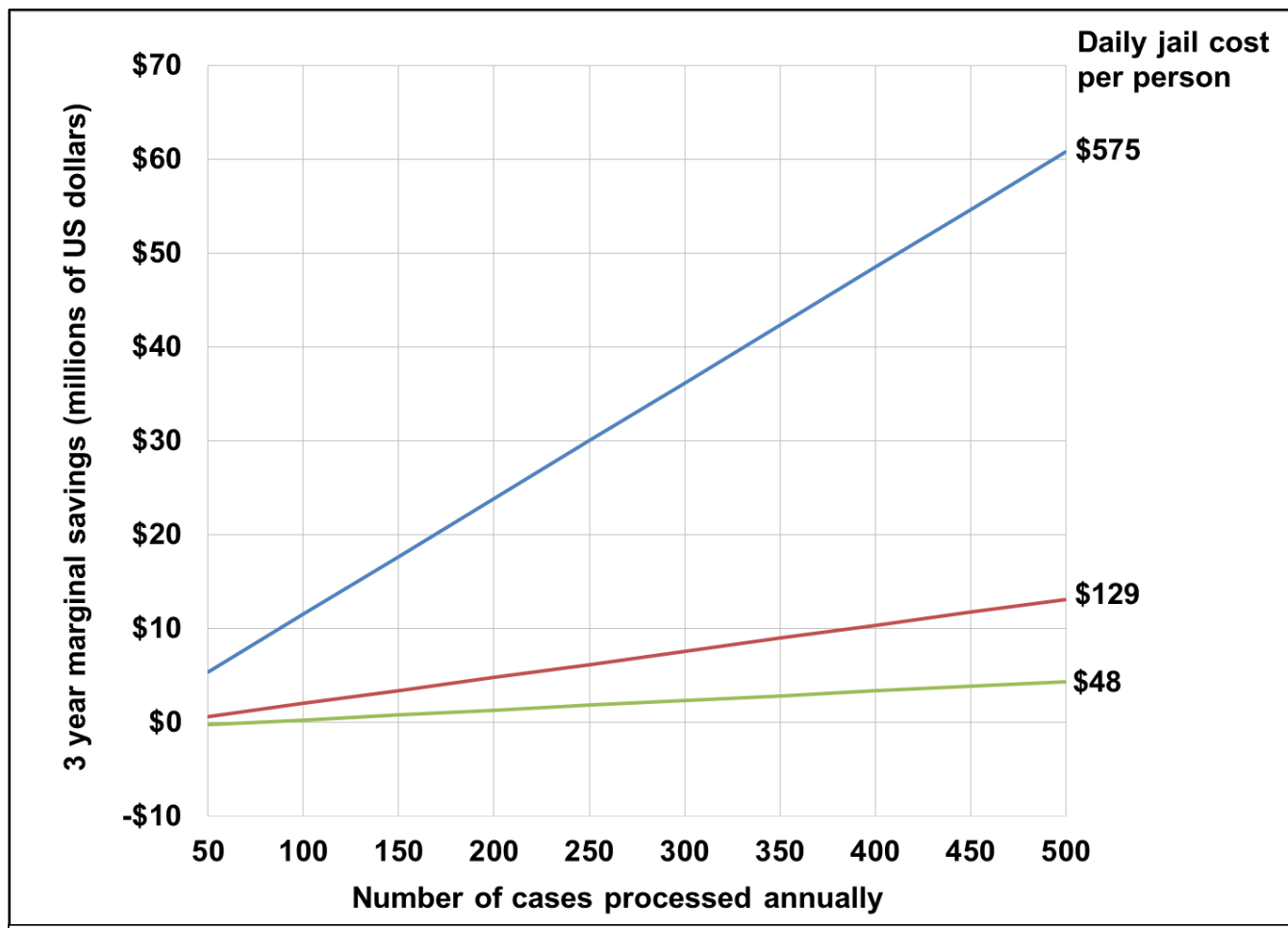

Figure 9: Estimate marginal cost savings in the third year of investing in portable instrumentation compared to the number of cases processed annually using portable instrumentation. Three different average daily costs per inmate are plotted.

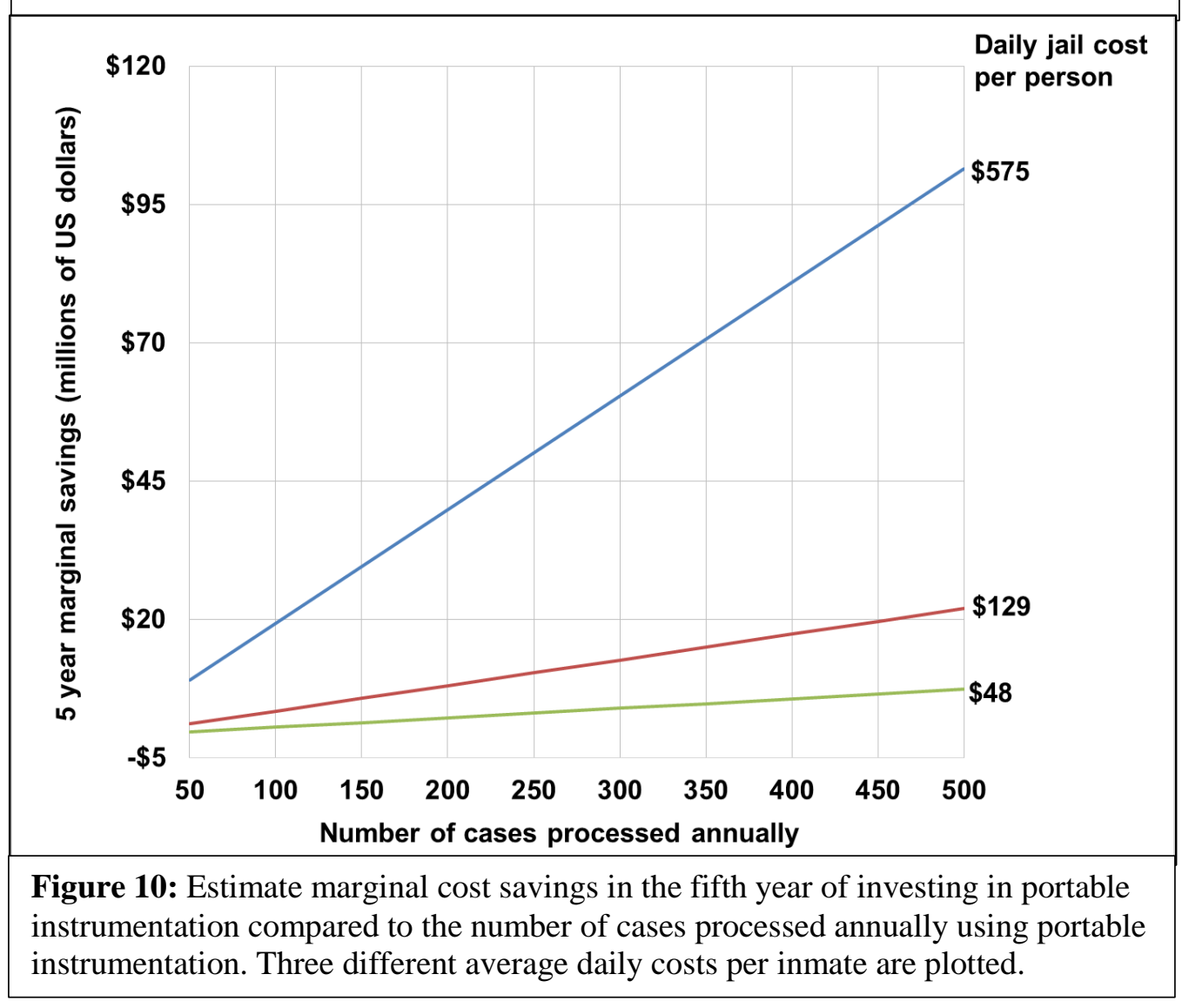


Another way to approach the cost savings of portable instrumentation is to vary the average daily cost of incarcerating an inmate and use the number of cases processed with portable instrumentation to determine the effects on the estimated cost savings (i.e. Figures 11-13). If only the pretrial population for seized-drug is considered in the calculation; 100 seized-drug cases are processed in the first year, and the average daily incarceration costs are $\$ 150$ per inmate per day, then an estimated $\$ 1.92$ million in marginal savings can be expected in correction costs alone. Even at the lowest daily incarceration cost per inmate of $\sim \$ 50$ per day, the estimated cost savings will be seen within the first year. The use of portable instrumentation to shorten the time a suspect is held pretrial quickly returns with cost savings.

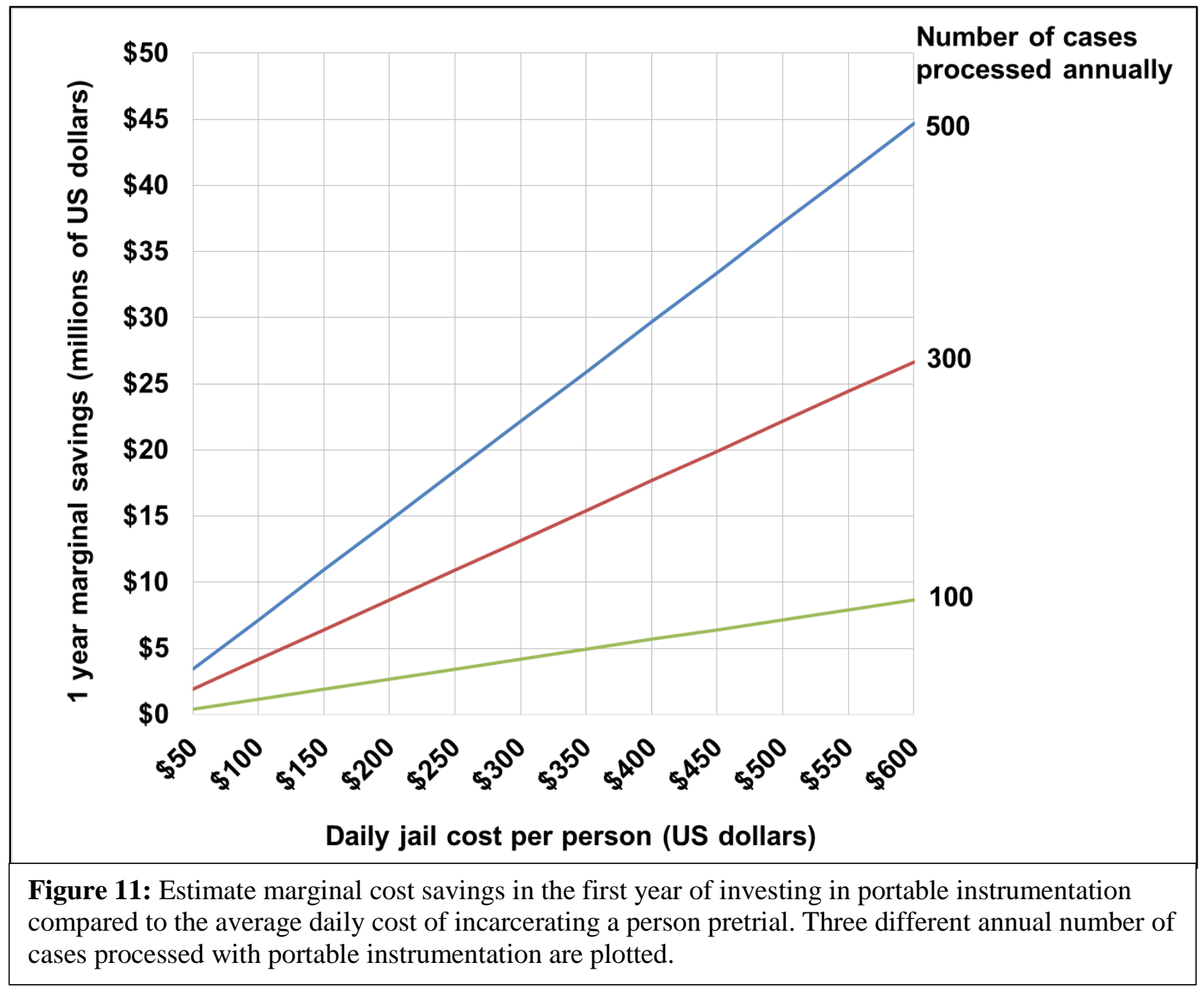




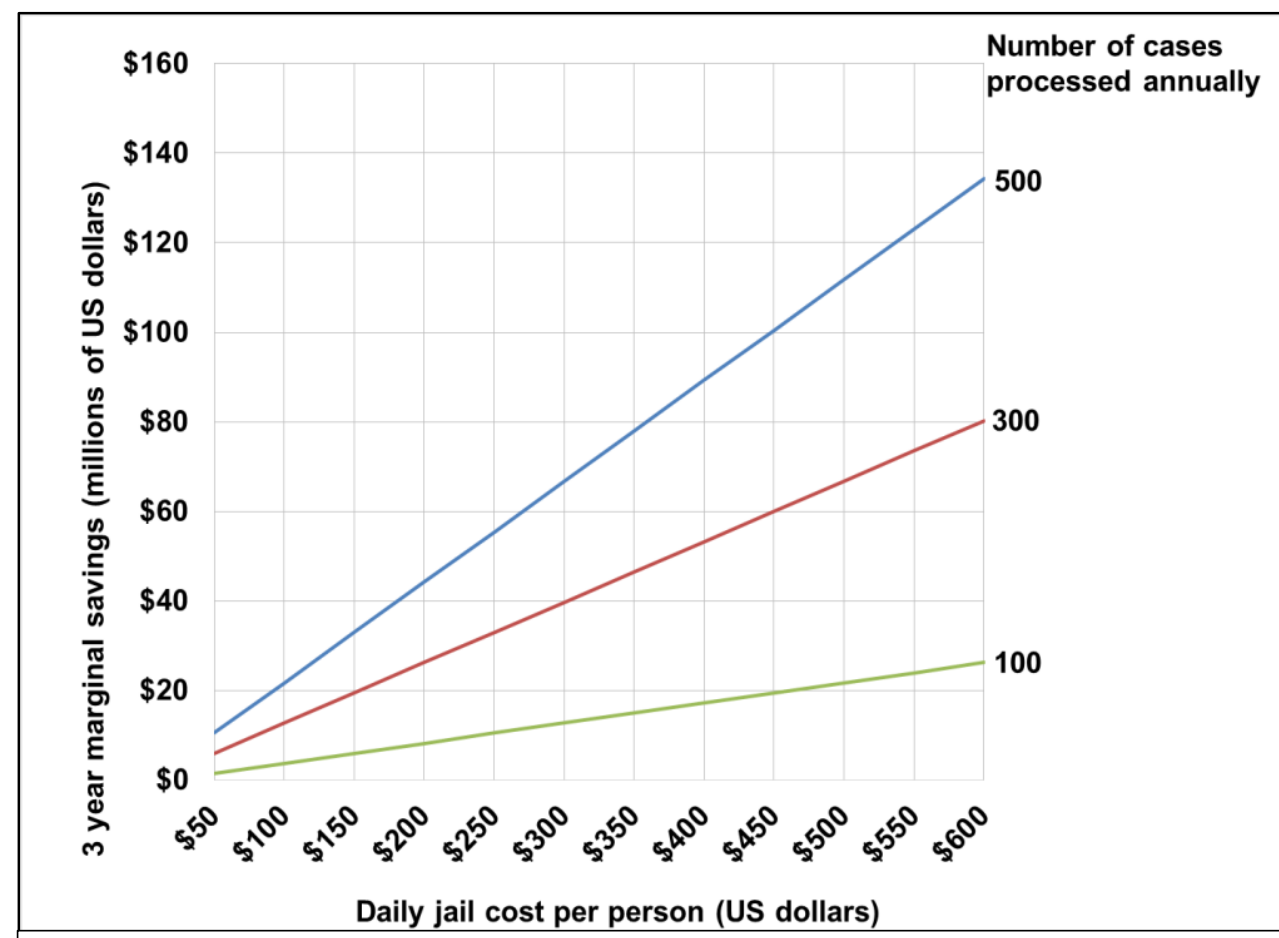

Figure 12: Estimate marginal cost savings in the third year of investing in portable instrumentation compared to the average daily cost of incarcerating a person pretrial. Three different annual number of cases processed with portable instrumentation are plotted.

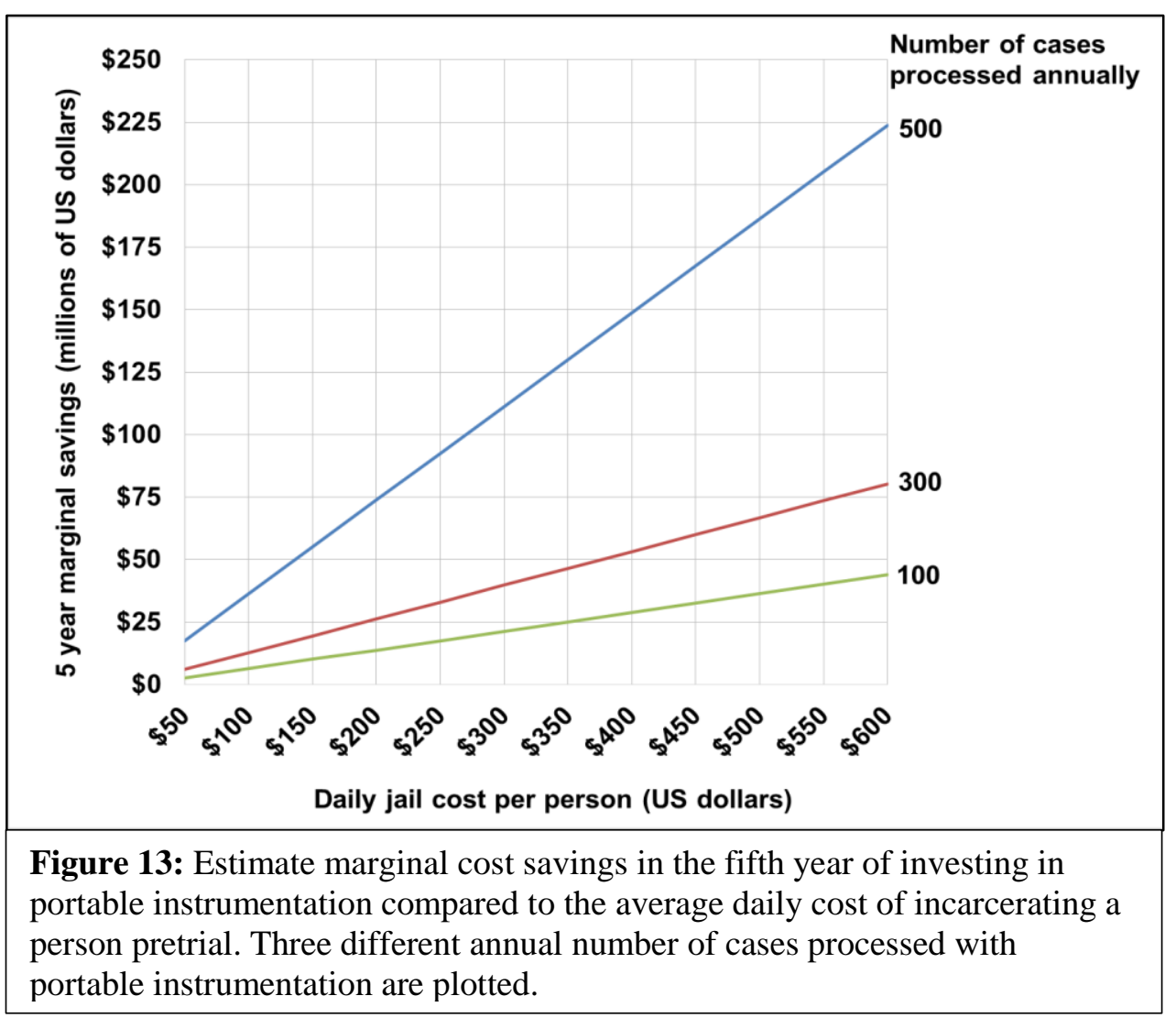


Portable instruments will enable seized drugs to be identified in the field with a sufficient degree of confidence by meeting the SWGDRUG, ASTM, or OSAC recommended criteria for drug identification. With the confirmatory method scheme, the identity of a seized-drug will be known in the field, and a suspect will either be immediately arrested or released. Portable instruments, with higher certainty and specificity, will reduce the problem of false positives and prevent innocent people from being sent to jail while waiting for their seized-drug evidence to be tested, then the state will not have to pay the incarceration costs or reparations to the wrongfully convicted. Any jurisdiction or state that has a high number of individuals being held awaiting a court date for seized-drug cases can benefit from using portable instruments to decrease the time awaiting trail and the cost of housing an inmate.

\subsection{Decreasing Crime Rates}

The right to a speedy trial is beneficial to both the accused and the criminal justice system. The Sixth Amendment protects fundamental values of the accused, such as due process, selfincrimination, and so forth. ${ }^{43}$ A consequence of the $6^{\text {th }}$ amendment is that it also pushes the courts to process cases in a timely fashion. The timely processing of cases assists the courts in dealing with incoming cases, but the opposite point of view argues that fast case processing decreases the quality of litigation. ${ }^{43}$ The benefit of portable instrumentation is the ability to provide quality results in a timely fashion, and therefore keep cases moving through the criminal justice system.

Since at least as long ago as the philosopher Cesare Beccaria in 1764, many criminologists have believed that swift punishment is an important part of crime deterrence. ${ }^{26}$ Deterrence theory is comprised of three main components; severity, certainty, and celerity, or the speed of punishment. Severity of punishment for a seized-drug crime is determined by the laws in place and the courts issuing the sentence. Portable instruments can provide both the certainty and the 
celerity of punishment. In Alabama, the backlog in the seized-drug unit was 18 months, so dismissing charges was often a solution to alleviate the burden on the states' criminal justice system. ${ }^{27}$ Arrested individuals chose pretrial incarceration in hopes of their case being dismissed, but in the instance of an individual being released due to their case being dismissed, no justice is served and the purpose of the criminal justice system fails.

In line with the deterrence theory, recent studies have shown the release of low- and moderate-risk suspects in a speedy fashion (within 24 hours of arrest) correlates to reduced recidivism rates, or the chances of the same person committing a crime later. One study estimated the chance of a defendant being arrested during the pretrial phase was $40 \%$ more likely if they were held 2-3 days after arrest and 51\% more likely to recidivate within the first two years after completion of their case ${ }^{60} \mathrm{~A}$ different study estimated the defendants were $74 \%$ more likely to be arrested during the pretrial phase if the defendant was held longer than three days before release. ${ }^{61}$ A confirmatory field test of the seized drug would provide drug identification with fast and accurate reporting of the results, so resolution can be reached at the time of the defendant's arraignment for maximum effect of the punishment. Innocent people on the other hand would be released more quickly and trust in the criminal justice system would be maintained. Guilty defendants would be prosecuted more quickly and therefore less likely to recidivate because the punishment was administered close to the commission of the crime.

A theory explaining the correlation between extended time in pretrial incarceration and the increase in the chance a defendant will recidivate was summarized by one study as the concept of destabilization. ${ }^{60}$ The main premise behind this theory is the longer a person remains in pretrial detention, the more unstable becomes their place in the community. A felony defendant can be held pretrial for 60 days in Louisiana to allow for the district attorney to accept the charges against 
the defendant. ${ }^{46}$ During that 60 days, a person can sit in jail for charges that may not be filed. While they are being detained, the life they have is severely impacted; job status, housing arrangements, familial relationships, and other responsibilities will suffer. When this situation occurs, the criminal justice system is failing to meet the right to a speedy trial and the taxpayer's money is wasted.

A goal of the criminal justice system is to deter crime, but the recent studies show the system in its current capacity does not achieve that goal. Recidivism of the same criminals increases the amount of work on all areas of the entire criminal justice system and reiterates the lack of the system to deter crime in the first place. If the use of portable instrumentation for seized drugs could lower the rates of recidivism in a community, then crime rates due to the same people recommitting crimes would being to drop. The lower crime rates would lead to lower costs to the taxpayer and an improved trust in the criminal justice system.

\subsection{Wrongful Convictions}

Another way to decrease expenditures and gain public trust is to decrease the number of wrongful convictions. There are only 18 states that do not compensate the wrongly convicted; Alaska, Arizona, Arkansas, Delaware, Georgia, Idaho, Indiana, Kansas, Kentucky, Nevada, New Mexico, North Dakota, Oregon, Pennsylvania, Rhode Island, South Carolina, South Dakota, and Wyoming. ${ }^{62}$ The remaining states and the federal government do offer compensation to the wrongfully convicted, and spend millions of dollars every year on compensating the wrongfully convicted. States typically do not report reparation costs, so it is not possible to accurately assess the potential savings of avoiding wrongful convictions. However, an additional benefit of on-site seized-drug testing is the ability to obtain the correct answers more quickly, and therefore avoid wrongful accusations and convictions. By enabling a more accurate prosecution rate, portable 
instrumentation has the potential to increase public confidence in the prosecutorial system; more important, citizens are more likely to be granted their constitutional rights with the efficiency of portable instruments.

The media focuses on exoneration of people wrongfully convicted of violent crimes, and the typical settlement for wrongful convictions for seized drugs is not available. An example of how costly wrongful convictions can be is in the state of Illinois, particularly the city of Chicago, and has made national news due to the high number and cost of wrongful convictions. The exoneration of 85 wrongfully convicted individuals between 1989 and 2010 cost the taxpayers $\$ 214$ million in damages and a total of 926 years of unlawful incarceration. ${ }^{63}$ Even at the lowest incarceration cost of $\$ 48$ per day, $\$ 16$ million dollars was spent only on incarcerating the wrongfully convicted, for a total cost of $\$ 230$ million. Of course, seized-drug offenders are rarely sentenced to life in prison, but examples of cost-benefit ratios for seized-drug cases have been identified.

In Harris County, Texas, there were 42 exonerations in 2015 for seized drugs that were later tested in the crime laboratory and identified as legal substances. ${ }^{5}$ Texas is also a state that offers compensation to the wrongfully convicted, but the compensation rate is unknown. To provide a scenario, if each person was given $\$ 50,000$ for their time spent in jail, the cost that Harris County would be responsible for a total of at least $\$ 2.1$ million in unnecessary costs. If each person was held for 90 days in jail, then even at the lowest daily jail cost per person, an additional $\$ 182,000$ was spent in unnecessary jail costs, raising the total amount spent to almost $\$ 2.3$ million. The wrongful convictions in Harris County stemmed from the faulty use of field color tests, so Harris County, Texas could greatly benefit from more accurate field testing. 


\subsection{Other Practical Field Applications}

The practicality of sending an analyst to every arrest site may not be possible, so every jurisdiction must consider their individual objectives and goals to determine if portable instrumentation will benefit their region. Portable instrumentation analytical schemes can provide accurate and reliable results with the addition of rapid analysis which can be performed without the typical laboratory setup. The setups can be unconventional and in any location that requires both rapid and confirmatory analysis. An area in a booking station, or point of entry into the US, can contain all the portable instruments necessary to perform rapid and confirmatory analysis of seized drugs. A suspect would be detained shortly pending the confirmatory results, and once the results are obtained, either released if a negative result or arrested and processed if a positive result. All these steps could be performed by portable instrumentation and within a reasonable detainment time, therefore protecting a US citizen or foreign national's rights.

On-site analysis using portable instrumentation can also be beneficial because a trained forensic analyst will be present in the field to assist with evidence collection and streamlining the chain of custody. A forensic analyst is taught to analyze and preserve evidence for any type of analysis. When on the scene, the forensic analyst can aid in the collection of other types of evidence, and the officer can focus on investigating the crime scene and handling the suspect(s) and victim(s). Once confirmatory analysis of the seized drug is performed in the field, the evidence can go directly into evidence storage because no further testing is required. Any other collected evidence can be transported to the proper department by the forensic analyst when they return to the crime laboratory. By reducing the amount of people handling evidence, a clear chain of custody can be established and maintained throughout the process. 


\section{Conclusion}

The research showed the majority of the portable instrumentation's economic benefits decrease unnecessary expenditures in the correction system, and possible further benefits through increasing both the certainty and speed of punishment. The direct cost savings to a state's correction system can be estimated multiplying the number of people being held awaiting pretrial for seized drugs by the cost of incarcerating an individual in jail per day, and the number of cases processed with portable instrumentation. The certainty and speed of punishment enabled by portable instrumentation can indirectly lead to decreased recidivism rates and reduce compensation of the wrongfully convicted. Any jurisdiction which has a high recidivism rate and/or wrongful conviction rate can benefit from the swift and certain results that a portable instrument will provide, in addition to the benefit of cost savings to the correction system.

When stakeholders are deciding which procedure or instrument to choose for a specific department or agency, the importance of understanding the effect on the larger criminal justice system is essential. If a state has an unmanageable seized-drug case backlog, portable instrumentation would decrease the number of samples submitted to the laboratory and expedite the criminal justice system process in the form of confirmatory results available in time for the arraignment of the defendant. The economic measures and visual representation in this study of portable instrumentation's effect on the cost per seized-drug case provided in Section 7.3 can be used by any area to address their specific needs. Understanding the amount being spent on the different elements, or ratios, of the ROI metric and which areas are responsible for the majority of the cost. The economic analysis in this study showed the savings for states with very high daily incarceration costs could return marginal savings as high as $\$ 100$ million dollars by the fifth year

of investment, which is a return of more than $8,000 \%$. Stakeholders can improve the strength of 
their decision for investing in new technology, making the best use of the taxpayer's money by simply reviewing each area's ROI metric prior and post investment in the new technology and procedures.

\section{References}

1. Frase, R. S., The Speedy Trial Act of 1974. Univ. Law Chicago Rev. 1976, 43, 667-723.

2. Criminal Justice System Flowchart. Bureau of Justice Statistics: 2017.

3. Waldron, R. J.; Quarles, C. L.; McElreath, D. H.; Waldron, M. E.; Milstein, D., The Criminal Justice System: An Introduction. 5th ed.; K\&M Publisher, Inc.: Tulsa, Oklahoma, 2009.

4. Crime in the US; 2016.

5. National Registry of Exonerations; University of Michigan Law School: 2017.

6.2015 Crime in the United States; 2016.

7. Number of Cases by Drug Type Over Time. US Sentencing Commision: 2016.

8. Harris, A., A Test of a Different Color: The Limited Value of Presumptive Field Drug Tests and Why That Value Demands Their Exclusion from Trial. SW. Law Rev. 2010, 40, 531-550.

9. Warren, R. W., Criminal Investigation and Physical Evidence Handbook 2nd ed.; Wisconsin Department of Justice, 1973.

10.Standard Practice for Identification of Seized Drugs. In E2329-14, ASTM International: 2014.

11.Durose, M. R.; Walsh, K. A.; Burch, A. M. Census of Publicly Funded Forensic Crime Laboratories, 2009.; Bureau of Justice Statistics: 2012.

12.Hearing on Improving Forensic Science in the Criminal Justice System. In Committee on the Judiciary United States Senate, 2nd ed.; 2012.

13.Eckenrode, B. A., Environmental and Forensic Applications of Field-Portable GC-MS: An Overview. J. Am. Soc. Mass. Spectrom. 2001, 12, 683-693.

14.Visotin, A.; Lennard, C., Preliminary Evaluation of a Next-Generation Portable Gas Chromatograph Mass Spectrometer (GC-MS) for the On-Site Analysis of Ignitable Liquid Residues. Aust. J. For. Sci. 2015, 48, 203-221. 
15.Fedchak, S. Presumptive Field Testing Using Portable Raman Spectroscopy: Research and Development on Instrumental Analysis for Forensic Science; Las Vegas Metropolitan Police Department: 2014.

16.Controlled Substances Section. https://www.lvmpd.com/en-us/Pages/ForensicLaboratoryControlledSubstances.aspx (accessed 23 February 2017).

17.Scientific Working Group for the Analysis of Seized Drugs Recommendation; United States Department of Justice Drug Enforcement Administration: 2011.

18.OSAC registry. Organization of Scientific Area Committees: 2017.

19.Strengthening Forensic Science in the United States: A Path Forward; The National Academies: 2009.

20.Forensic Science in Criminal Courts: Ensuring Scientific Validity of Feature-Comparison Methods; President's Council of Advisors on Science and Technology: 2016.

21.California vs Rios. In C. J. Plourd, 2016.

22.Gabrielson, R.; Sanders, T., How a \$2 Roadside Drug Test Sends Innocent People to Jail. The New York Times Magazine 2016.

23.Interview with Florida Forensic Assistant Director. Menking-Hoggatt, K., Ed. 2017.

24.Minshew, C., Arrest Report/ Lab Results: Orlando Officer Mistoke Doughnut Glaze for Meth. In Orlando Sentinel, 2016.

25.Hepburn, J. R. H., A. N., The Effect of the Threat of Legal Sanction on Program Retention and Completion: Is That Why They Stay in Drug Court? Crime \& Delinquency 2007, 53 (2), 255-280.

26.Dilulio, J. J., Deterrence Theory. 2010.

27.ThermoScientific Thermo Scientific TruNarc Enables Faster Case Adjudication and Improves Efficiency of Prosecution; Jacksonville State University: 2013.

28.West Virginia State Crime Lab: Drug Section. Menking-Hoggatt, K., Ed. 2017.

29.Strom, K. J.; Hickman, M. J.; Smiley-McDonald, H. M.; Ropero-Miller, J. D.; Stout, P. M., Crime Laboratory Personnel as Criminal Justice Decision Makers: A Study of Controlled Substance Case Processing in Ten Jurisdictions. For. Sci. Policy Manage. 2011, 2, 57-69.

30.Smart on Crime: Reforming the Criminal Justice System; Department of Justice: 2013.

31.West Virginia State Code §60A-4-401. Legislature, Ed. 2016. 
32.McCollister, K. E.; French, M. T.; Fang, H., The Cost of Crime to Society: New CrimeSpecific Estimates for Policy and Program Evaluation. Drug Alcohol Depend. 2010, 108, 98 109.

33.Felson, R. B.; Staff, J., Committing Economic Crime for Drug Money. Crime \& Delinquency 2015, 63 (4), 375-390.

34.Kuhlman, J. J.; McCaulley, R.; Valouch, T. J.; Behonick, G. S., Fentanyl Use, Misuse, and Abuse: A Summary of 23 Postmortem Cases. J. Anal. Toxicol. 2003, 27, 499-504.

35.Casale, Return of the Death Dragon. For. Chem. 2017.

36.Wakeman, S., Fentanyl: The Dangers of this Potent "Man-Made" Opioid. Havard Health Publ. 2016.

37.Speaker, P., The Decomposition of Return on Investment for Forensic Laboratories. For. Sci. Policy Manage. 2009, 1, 96-102.

38.Project FORESIGHT Annual Report, 2013-2014; West Virginia University: 2016.

39.Speaker, P., Financial Management of Forensic Science Laboratories: Lessons from Project FORESIGHT 2011-2012. For. Sci. Policy Manage. 2015, 6, 7-29.

40.Project FORESIGHT Annual Report, 2014-2015; West Virginia University: 2017.

41.Kobus, H.; Houck, M.; Speaker, P.; Riley, R.; Witt, T., Managing Performance in the Forensic Sciences: Expectations in Light of Limited Budgets. For. Sci. Policy Manage. 2010, 2, $36-43$.

42.Peterson, J. L.; Crim, D.; Hickman, M. J.; Strom, K. J.; Johnson, D. J., Effect of Forensic Evidence on Criminal Justice Case Processing. J. For. Sci. 2013, 58, S78-S90.

43.Ostrom, B. J.; Hanson, R. A. Efficiency, Timeliness, Quality: A New Perspective from Nine State Criminal Trial Courts; National Center for State Courts: 1999.

44.King, W.; Maguire, E., Assessing the Performance of Systems Designed to Process Criminal Forensic Evidence. For. Sci. Policy Manage. 2009, 1, 159-170.

45.Balko, R., Faulty Drug Field Tests Bring False Confessions, Bad Convictions. The Washington Post Febuary 11, 2016.

46.Borden, T. Every 25 seconds: The Human Toll of Criminalizing Drug Use in the United States; American Civil Liberties Union: 2016.

47.United States Attorneys' Annual Statistical Report; Department of Justice: 2015.

48.State and Local Government Finances. US Census Bureau: 2014.

49.Government Employment and Payroll. US Census Bureau: 2012. 
50.Databases, Tables, and Calculators. Bureau of Labor Statistics: 2017.

51.Speaker, P. J., Key Performance Indicators and Managerial Analysis for Forensic Laboratories. For. Sci. Policy Manage. 2009, 1, 32-44.

52.Snyder, D. T.; Pulliam, C. J.; Ouyang, Z.; Cooks, R. G., Miniature and Fieldable Mass Spectrometers: Recent Advances. Anal. Chem. 2016, 88 (1), 2-29.

53.PerkinElmer, Intrument Startup Quote. 2017.

54.Samms, W. C.; Mozayani, A., Considerations of Design and Implementaiton of a Paperless Forensic Laboratory. For. Sci. Policy Manage. 2012, 3, 12-19.

55.Product Note: Torion T-9 portable GC/MS. Perkin Elmer: 2015.

56.Thermo Scientific Portable Analytical Instrument Inc. Thermo Scientific: Tewksbury, MA, 2017.

57.NIK Master-Pak ${ }^{\mathrm{TM}}$. The SAFARILAND Group: 2016.

58.2015 GSA vehicle and mileage rates. US General Services Administration: 2015.

59.Henrichson, C.; Rinaldi, J.; Delaney, R. The Price of Jails: Measuring the Taxpayer Cost of Local Incarceration; 2015.

60.Lowenkamp, C. T.; VanNostrand, M.; Holisinger, A. The Hidden Costs of Pretrial Detention; Arnold Foundation: 2013.

61.Pretrial Justice: How Much Does It Cost?; 20170112-01; Pretrial Justice Institute: 2017.

62.Compensating the Wrongly Convicted; The Innocence Project: 2017.

63.Lydersen, K. Wrongful Conviction Costs Keep Climbing 2013. https://www.bettergov.org/news/wrongful-conviction-costs-keep-climbing (accessed 16 July 2017). 


\section{Appendix A}

The data contained in this appendix was collected and analyzed using the method detailed in section 6 . The columns with black font is a data point value collected from an online database and adjusted to the year 2015 using the appropriate years and their corresponding metrics. The columns with red font are calculated using the percentage of seized-drug arrests. The columns with blue font are the numbers used in the ROI equation (equation 2). The abbreviations are as follows; law enforcement (LE), corrections (CR), and court system (CJ). The states are always the first column on the chart, but the headings change depending on which part of the chart is shown. 
Table 1: Data for calculating the total ROI and cost per seized-drug case, Part 1 of 3

\begin{tabular}{|c|c|c|c|c|c|}
\hline State & \begin{tabular}{|c|} 
Number of Test \\
Performed \\
(FORESIGHT \\
mean 2014-2015) \\
\end{tabular} & \begin{tabular}{|c|} 
Seized Drug \\
Cases Processed
\end{tabular} & $\begin{array}{c}\text { Total Expenditures (LE, } \\
\text { including crime labs and } \\
\text { corrections) (whole US } \\
\text { dollars) }\end{array}$ & $\begin{array}{c}\text { Total Expenditures (CJ) } \\
\text { (whole US dollars) }\end{array}$ & $\begin{array}{c}\text { Total Expenditures (whole } \\
\text { US dollars) }\end{array}$ \\
\hline Alabama & 55,561 & 8,736 & $\$ 1,924,092,245$ & $\$ 401,734,907$ & $\$ 2,325,827,152$ \\
\hline Alaska & 6,354 & 999 & $\$ 720,522,377$ & $\$ 243,865,223$ & $\$ 964,387,600$ \\
\hline Arizona & 140,283 & 22,057 & $\$ 3,616,075,510$ & $\$ 926,954,177$ & $\$ 4,543,029,687$ \\
\hline Arkansas & 76,015 & 11,952 & $\$ 1,230,422,572$ & $\$ 211,063,382$ & $\$ 1,441,485,954$ \\
\hline California & $1,269,017$ & 199,531 & $\$ 30,332,232,533$ & $\$ 8,615,277,821$ & $\$ 38,947,510,354$ \\
\hline Colorado & 72,956 & 11,471 & $\$ 3,035,409,203$ & $\$ 719,571,483$ & $\$ 3,754,980,686$ \\
\hline Connecticut & 45,423 & 7,142 & $\$ 1,869,238,510$ & $\$ 758,714,300$ & $\$ 2,627,952,811$ \\
\hline Delaware & 34,051 & 5,354 & $\$ 635,041,572$ & $\$ 205,003,443$ & $\$ 840,045,014$ \\
\hline Florida & 691,039 & 108,654 & $\$ 11,413,275,597$ & $\$ 2,310,533,259$ & $\$ 13,723,808,856$ \\
\hline Georgia & 208,029 & 32,709 & $\$ 4,654,299,484$ & $\$ 1,096,414,906$ & $\$ 5,750,714,390$ \\
\hline Hawaii & 11,747 & 1,847 & $\$ 674,266,988$ & $\$ 312,361,879$ & $\$ 986,628,867$ \\
\hline Idaho & 36,424 & 5,727 & $\$ 737,142,890$ & $\$ 204,718,376$ & $\$ 941,861,266$ \\
\hline Illinois & 136,982 & 21,538 & $\$ 7,136,585,088$ & $\$ 1,499,788,697$ & $\$ 8,636,373,784$ \\
\hline Indiana & 98,008 & 15,410 & $\$ 2,256,052,227$ & $\$ 553,466,082$ & $\$ 2,809,518,309$ \\
\hline lowa & 46,434 & 7,301 & $\$ 1,178,174,732$ & $\$ 355,765,592$ & $\$ 1,533,940,324$ \\
\hline Kansas & 44,825 & 7,048 & $\$ 1,262,388,350$ & $\$ 321,383,292$ & $\$ 1,583,771,642$ \\
\hline Kentucky & 136,683 & 21,491 & $\$ 1,468,130,146$ & $\$ 540,268,388$ & $\$ 2,008,398,535$ \\
\hline Louisiana & 105,983 & 16,664 & $\$ 2,725,149,567$ & $\$ 742,475,556$ & $\$ 3,467,625,123$ \\
\hline Maine & 34,999 & 5,503 & $\$ 459,939,941$ & $\$ 98,565,682$ & $\$ 558,505,623$ \\
\hline Maryland & 156,119 & 24,547 & $\$ 4,374,405,020$ & $\$ 858,281,242$ & $\$ 5,232,686,262$ \\
\hline Massachusetts & 60,789 & 9,558 & $\$ 3,585,580,395$ & $\$ 1,103,381,419$ & $\$ 4,688,961,814$ \\
\hline Michigan & 207,775 & 32,669 & $\$ 4,961,962,291$ & $\$ 1,186,457,791$ & $\$ 6,148,420,082$ \\
\hline Minnesota & 98,497 & 15,487 & $\$ 2,677,634,040$ & $\$ 692,916,210$ & $\$ 3,370,550,250$ \\
\hline Mississippi & 55,599 & 8,742 & $\$ 1,218,652,227$ & $\$ 252,636,824$ & $\$ 1,471,289,051$ \\
\hline Missouri & 202,318 & 31,811 & $\$ 2,690,134,680$ & $\$ 530,627,484$ & $\$ 3,220,762,164$ \\
\hline Montana & 10,863 & 1,708 & $\$ 542,543,888$ & $\$ 158,612,067$ & $\$ 701,155,955$ \\
\hline Nebraska & 48,120 & 7,566 & $\$ 822,354,746$ & $\$ 166,298,803$ & $\$ 988,653,548$ \\
\hline Nevada & 68,306 & 10,740 & $\$ 1,841,133,728$ & $\$ 460,501,010$ & $\$ 2,301,634,737$ \\
\hline New Hampshire & 43,197 & 6,792 & $\$ 579,933,997$ & $\$ 135,031,086$ & $\$ 714,965,083$ \\
\hline New Jersey & 275,064 & 43,249 & $\$ 5,481,171,987$ & $\$ 1,487,402,889$ & $\$ 6,968,574,876$ \\
\hline New Mexico & 41,423 & 6,513 & $\$ 1,348,237,829$ & $\$ 326,010,846$ & $\$ 1,674,248,674$ \\
\hline New York & 373,586 & 58,740 & $\$ 15,689,747,522$ & $\$ 3,976,499,881$ & $\$ 19,666,247,403$ \\
\hline North Carolina & 128,466 & 20,199 & $\$ 4,865,635,846$ & $\$ 746,175,383$ & $\$ 5,611,811,228$ \\
\hline North Dakota & 26,012 & 4,090 & $\$ 313,835,565$ & $\$ 95,109,623$ & $\$ 408,945,188$ \\
\hline Ohio & 198,527 & 31,215 & $\$ 5,167,486,510$ & $\$ 1,786,208,475$ & $\$ 6,953,694,985$ \\
\hline Oklahoma & 104,781 & 16,475 & $\$ 1,796,849,632$ & $\$ 376,369,991$ & $\$ 2,173,219,622$ \\
\hline Oregon & 61,590 & 9,684 & $\$ 2,357,292,300$ & $\$ 629,286,845$ & $\$ 2,986,579,145$ \\
\hline Pennsylvania & 311,977 & 49,053 & $\$ 6,880,928,367$ & $\$ 1,918,890,528$ & $\$ 8,799,818,895$ \\
\hline Rhode Island & 10,659 & 1,676 & $\$ 601,999,993$ & $\$ 136,393,968$ & $\$ 738,393,961$ \\
\hline South Carolina & 152,061 & 23,909 & $\$ 1,862,815,942$ & $\$ 325,114,345$ & $\$ 2,187,930,287$ \\
\hline South Dakota & 38,860 & 6,110 & $\$ 356,777,932$ & $\$ 83,796,594$ & $\$ 440,574,526$ \\
\hline Tennessee & 230,181 & 36,192 & $\$ 2,991,358,802$ & $\begin{array}{l}693,087,452 \\
\end{array}$ & $\$ 3,684,446,253$ \\
\hline Texas & 773,847 & 121,674 & $\$ 12,845,706,898$ & $\$ 2,775,973,079$ & $\$ 15,621,679,976$ \\
\hline Utah & 84,219 & 13,242 & $\$ 1,223,173,006$ & $\$ 372,171,549$ & $\$ 1,595,344,555$ \\
\hline Vermont & 3,695 & 581 & $\$ 337,970,563$ & $\$ 75,131,767$ & $\$ 413,102,330$ \\
\hline Virginia & 200,887 & 31,586 & $\$ 4,585,425,088$ & $\$ 894,035,490$ & $\$ 5,479,460,578$ \\
\hline Washington & 61,419 & 9,657 & $\$ 3,415,376,276$ & $\$ 904,635,347$ & $\$ 4,320,011,623$ \\
\hline West Virginia & 38,523 & 6,057 & $\$ 721,659,623$ & $\$ 236,635,803$ & $\$ 958,295,427$ \\
\hline Wisconsin & 142,350 & 22,382 & $\$ 3,288,298,860$ & $\$ 632,672,393$ & $\$ 3,920,971,253$ \\
\hline Wyoming & 20,645 & 3,246 & $\$ 436,601,720$ & $\$ 117,323,693$ & $\$ 553,925,413$ \\
\hline Total USA & $7,481,166$ & $1,176,284$ & $\$ 177,191,124,801$ & $\$ 44,251,596,322$ & $\$ 221,442,721,123$ \\
\hline
\end{tabular}


Table 2: Data for calculating the total ROI and cost per seized-drug case, Part 2 of 3

\begin{tabular}{|c|c|c|c|c|c|}
\hline State & \begin{tabular}{|c|} 
Estimated Total \\
Expenditures for Seized \\
Drug Cases (whole dollar \\
amount)
\end{tabular} & $\begin{array}{l}\text { Full-Time } \\
\text { Equivalent } \\
\text { LE/CR/CL }\end{array}$ & $\begin{array}{c}\text { Personnel Expenditures } \\
\text { for } L E / C R / C L \text { (whole US } \\
\text { dollars) }\end{array}$ & \begin{tabular}{|c|} 
Full-Time \\
Equivalent \\
Employees CJ
\end{tabular} & $\begin{array}{l}\text { Personnel Expenditures } \\
\text { for CJ (whole US dollars) }\end{array}$ \\
\hline Alabama & $\$ 148,491,934$ & 22,431 & $\$ 976,101,100$ & 3,131 & $\$ 178,628,621$ \\
\hline Alaska & $\$ 37,221,762$ & 3,879 & $\$ 281,509,725$ & 1,453 & $\$ 110,461,185$ \\
\hline Arizona & $\$ 499,565,285$ & 34,763 & $\$ 1,977,045,660$ & 2,068 & $\$ 120,309,673$ \\
\hline Arkansas & $\$ 144,054,450$ & 15,842 & $\$ 645,047,730$ & 1,336 & $\$ 65,341,39$ \\
\hline California & $\$ 6,932,143,742$ & 181,065 & $\$ 15,933,478,159$ & 5,909 & $\$ 491,368,003$ \\
\hline Colorado & $\$ 238,900,789$ & 25,243 & $\$ 1,606,067,818$ & 4,416 & $\$ 278,107,340$ \\
\hline Connecticut & $\$ 235,147,371$ & 15,316 & $\$ 1,236,510,851$ & 5,796 & $\$ 412,241,068$ \\
\hline Delaware & $\$ 138,865,227$ & 5,238 & $\$ 317,372,812$ & 1,726 & $\$ 99,866,135$ \\
\hline Florida & $\$ 2,041,608,232$ & 103,161 & $\$ 5,776,162,346$ & 18,828 & $\$ 948,994,439$ \\
\hline Georgia & $\$ 866,857,215$ & 54,543 & $\$ 2,223,295,768$ & 3,602 & $\$ 198,666,017$ \\
\hline Hawaii & $\$ 56,674,158$ & 5,881 & $\$ 416,122,500$ & 2,416 & $\$ 132,939,422$ \\
\hline Idaho & $\$ 118,107,330$ & 7,543 & $\$ 376,734,596$ & 463 & $\$ 46,853,330$ \\
\hline Illinois & $\$ 2,281,843,985$ & 61,848 & $\$ 4,516,192,269$ & 2,556 & $\$ 280,460,090$ \\
\hline Indiana & $\$ 308,243,484$ & 27,486 & $\$ 1,230,616,200$ & 1,398 & $\$ 117,839,16=$ \\
\hline lowa & $\$ 138,460,934$ & 11,412 & $\$ 660,638,137$ & 2,150 & $\$ 145,154,10$ \\
\hline Kansas & $\$ 197,525,774$ & 14,839 & $\$ 700,291,871$ & 2,036 & $\$ 109,065,282$ \\
\hline Kentucky & $\$ 227,196,776$ & 17,849 & $\$ 768,357,507$ & 5,565 & $\$ 247,549,415$ \\
\hline Louisiana & $\$ 550,257,666$ & 30,185 & $\$ 1,373,195,923$ & 1,653 & $\$ 91,326,170$ \\
\hline Maine & $\$ 73,434,290$ & 4,811 & $\$ 254,889,726$ & 674 & $\$ 47,746,402$ \\
\hline Maryland & $\$ 859,765,021$ & 34,082 & $\$ 2,159,267,200$ & 4,978 & $\$ 335,315,178$ \\
\hline Massachusetts & $\$ 393,383,209$ & 30,958 & $\$ 2,369,203,370$ & 8,682 & $\$ 599,593,097$ \\
\hline Michigan & $\$ 885,891,839$ & 39,094 & $\$ 2,491,622,264$ & 1,390 & $\$ 121,178,11 c$ \\
\hline Minnesota & $\$ 394,128,952$ & 20,707 & $\$ 1,331,013,022$ & 3,450 & $\$ 222,414,499$ \\
\hline Mississippi & $\$ 184,330,529$ & 14,892 & $\$ 528,507,577$ & 719 & $\$ 52,537,619$ \\
\hline Missouri & $\$ 492,672,772$ & 32,972 & $\$ 1,327,268,053$ & 4,052 & $\$ 189,785,218$ \\
\hline Montana & $\$ 53,527,731$ & 4,327 & $\$ 224,449,846$ & 695 & $\$ 38,332,570$ \\
\hline Nebraska & $\$ 185,166,387$ & 9,123 & $\$ 464,806,971$ & 722 & $\$ 43,948,066$ \\
\hline Nevada & $\$ 230,690,756$ & 13,172 & $\$ 963,343,590$ & 709 & $\$ 57,096,173$ \\
\hline New Hampshire & $\$ 118,779,472$ & 5,594 & $\$ 332,660,427$ & 868 & $\$ 44,439,735$ \\
\hline New Jersey & $\$ 1,222,988,187$ & 47,607 & $\$ 4,189,119,943$ & 12,861 & $\$ 1,007,817,098$ \\
\hline New Mexico & $\$ 137,836,439$ & 11,803 & $\$ 594,048,992$ & 3,126 & $\$ 169,318,556$ \\
\hline New York & $\$ 4,492,876,400$ & 134,959 & $\$ 11,259,788,258$ & 18,660 & $\$ 1,637,828,949$ \\
\hline North Carolina & $\$ 432,771,603$ & 52,556 & $\$ 2,336,442,139$ & 6,592 & $\$ 391,962,998$ \\
\hline North Dakota & $\$ 56,196,214$ & 2,880 & $\$ 140,505,214$ & 554 & $\$ 35,034,693$ \\
\hline Ohio & $\$ 1,008,589,176$ & 51,446 & $\$ 2,924,915,824$ & 2,969 & $\$ 220,205,036$ \\
\hline Oklahoma & $\$ 348,012,020$ & 17,271 & $\$ 807,893,580$ & 2,579 & $\$ 141,158,552$ \\
\hline Oregon & $\$ 432,723,962$ & 17,029 & $\$ 1,110,309,605$ & 2,889 & $\$ 173,597,126$ \\
\hline Pennsylvania & $\$ 1,220,074,710$ & 63,072 & $\$ 3,866,725,180$ & 2,899 & $\$ 269,995,795$ \\
\hline Rhode Island & $\$ 47,747,900$ & 4,543 & $\$ 337,587,254$ & 1,123 & $\$ 82,956,522$ \\
\hline South Carolina & $\$ 371,555,544$ & 25,153 & $\$ 987,356,419$ & 767 & $\$ 46,573,03$ \\
\hline South Dakota & $\$ 64,718,095$ & 3,419 & $\$ 150,635,898$ & 612 & $\$ 32,995,292$ \\
\hline Tennessee & $\$ 422,927,629$ & 31,565 & $\$ 1,350,250,802$ & 2,407 & $\$ 159,429,274$ \\
\hline Texas & $\$ 2,548,800,519$ & 139,622 & $\$ 6,850,521,565$ & 5,490 & $\$ 350,045,990$ \\
\hline Utah & $\$ 206,069,772$ & 11,360 & $\$ 549,258,711$ & 1,580 & $\$ 88,491,591$ \\
\hline Vermont & $\$ 22,533,526$ & 2,590 & $\$ 143,846,840$ & 668 & $\$ 36,077,998$ \\
\hline Virginia & $\$ 685,691,148$ & 45,392 & $\$ 2,239,269,381$ & 3,595 & $\$ 218,142,87 €$ \\
\hline Washington & $\$ 254,901,631$ & 26,832 & $\$ 1,924,972,341$ & 1,880 & $\$ 133,524,12$ \\
\hline West Virginia & $\$ 146,149,029$ & 7,350 & $\$ 285,691,576$ & 1,522 & $\$ 87,237,762$ \\
\hline Wisconsin & $\$ 373,486,284$ & 28,822 & $\$ 1,680,135,110$ & 2,170 & $\$ 168,433,594$ \\
\hline Wyoming & $\$ 75,643,226$ & 3,993 & $\$ 204,783,887$ & 540 & $\$ 37,007,735$ \\
\hline Total USA & $\$ 30,727,242,462$ & $1,577,520$ & $\$ 97,395,831,538$ & 168,922 & $\$ 11,315,392,142$ \\
\hline
\end{tabular}


Table 3: Data for calculating the total ROI and cost per seized-drug case, Part 3 of 3

\begin{tabular}{|c|c|c|c|c|c|c|c|}
\hline State & Total FTE & $\begin{array}{c}\text { Total Personnel } \\
\text { Expenditures (whole US } \\
\text { dollars) }\end{array}$ & \begin{tabular}{|c|} 
Percentage of \\
Seized Drug \\
Arrests
\end{tabular} & \begin{tabular}{|c|} 
Estimated \\
Total FTE for \\
Seized Drug \\
Cases \\
\end{tabular} & \begin{tabular}{|c|} 
Estimated Total \\
Personnel Expenditures \\
for Seized Drug Cases \\
(whole US dollars) \\
\end{tabular} & \begin{tabular}{|c|}
2015 Return on \\
Investment for \\
Seized Drug \\
Cases \\
\end{tabular} & \begin{tabular}{|c|} 
Cost Per Seized \\
Drug Case in \\
2015 (whole US \\
dollars) \\
\end{tabular} \\
\hline Alabama & 25,562 & $\$ 1,154,729,721$ & $6.4 \%$ & 1632 & $\$ 73,723,470$ & 0.000059 & $\$ 16,998$ \\
\hline Alaska & 5,331 & $\$ 391,970,910$ & $3.9 \%$ & 206 & $\$ 15,128,614$ & 0.000027 & $\$ 37,259$ \\
\hline Arizona & 36,830 & $\$ 2,097,355,333$ & $11.0 \%$ & 4050 & $\$ 230,631,536$ & 0.000044 & $\$ 22,649$ \\
\hline Arkansas & 17,178 & $\$ 710,389,129$ & $10.0 \%$ & 1717 & $\$ 70,992,516$ & 0.000083 & $\$ 12,053$ \\
\hline California & 186,974 & $\$ 16,424,846,161$ & $17.8 \%$ & 33279 & $\$ 2,923,406,233$ & 0.000029 & $\$ 34,742$ \\
\hline Colorado & 29,659 & $\$ 1,884,175,158$ & $6.4 \%$ & 1887 & $\$ 119,875,698$ & 0.000048 & $\$ 20,827$ \\
\hline Connecticut & 21,111 & $\$ 1,648,751,919$ & $8.9 \%$ & 1889 & $\$ 147,529,163$ & 0.000030 & $\$ 32,925$ \\
\hline Delaware & 6,964 & $\$ 417,238,951$ & $16.5 \%$ & 1151 & $\$ 68,972,472$ & 0.000039 & $\$ 25,937$ \\
\hline Florida & 121,989 & $\$ 6,725,156,786$ & $14.9 \%$ & 18148 & $\$ 1,000,460,995$ & 0.000053 & $\$ 18,790$ \\
\hline Georgia & 58,145 & $\$ 2,421,961,785$ & $15.1 \%$ & 8765 & $\$ 365,084,215$ & 0.000038 & $\$ 26,502$ \\
\hline Hawaii & 8,297 & $\$ 549,061,922$ & $5.7 \%$ & 477 & $\$ 31,539,339$ & 0.000033 & $\$ 30,684$ \\
\hline Idaho & 8,007 & $\$ 423,587,926$ & $12.5 \%$ & 1004 & $\$ 53,116,994$ & 0.000048 & $\$ 20,623$ \\
\hline Illinois & 64,404 & $\$ 4,796,652,359$ & $26.4 \%$ & 17016 & $\$ 1,267,338,886$ & 0.000009 & $\$ 105,945$ \\
\hline Indiana & 28,884 & $\$ 1,348,455,363$ & $11.0 \%$ & 3169 & $\$ 147,944,428$ & 0.000050 & $\$ 20,003$ \\
\hline lowa & 13,562 & $\$ 805,792,246$ & $9.0 \%$ & 1224 & $\$ 72,734,737$ & 0.000053 & $\$ 18,965$ \\
\hline Kansas & 16,875 & $\$ 809,357,153$ & $12.5 \%$ & 2105 & $\$ 100,941,887$ & 0.000036 & $\$ 28,026$ \\
\hline Kentucky & 23,413 & $\$ 1,015,906,922$ & $11.3 \%$ & 2649 & $\$ 114,922,797$ & 0.000095 & $\$ 10,572$ \\
\hline Louisiana & 31,838 & $\$ 1,464,522,092$ & $15.9 \%$ & 5052 & $\$ 232,396,663$ & 0.000030 & $\$ 33,021$ \\
\hline Maine & 5,485 & $\$ 302,636,128$ & $13.1 \%$ & 721 & $\$ 39,791,666$ & 0.000075 & $\$ 13,344$ \\
\hline Maryland & 39,060 & $\$ 2,494,582,378$ & $16.4 \%$ & 6418 & $\$ 409,876,412$ & 0.000029 & $\$ 35,025$ \\
\hline Massachusetts & 39,641 & $\$ 2,968,796,467$ & $8.4 \%$ & 3326 & $\$ 249,068,926$ & 0.000024 & $\$ 41,157$ \\
\hline Michigan & 40,484 & $\$ 2,612,800,384$ & $14.4 \%$ & 5833 & $\$ 376,463,954$ & 0.000037 & $\$ 27,117$ \\
\hline Minnesota & 24,157 & $\$ 1,553,427,522$ & $11.7 \%$ & 2825 & $\$ 181,647,124$ & 0.000039 & $\$ 25,449$ \\
\hline Mississippi & 15,611 & $\$ 581,045,196$ & $12.5 \%$ & 1956 & $\$ 72,796,279$ & 0.000047 & $\$ 21,086$ \\
\hline Missouri & 37,024 & $\$ 1,517,053,271$ & $15.3 \%$ & 5664 & $\$ 232,060,240$ & 0.000065 & $\$ 15,487$ \\
\hline Montana & 5,023 & $\$ 262,782,416$ & $7.6 \%$ & 383 & $\$ 20,061,366$ & 0.000032 & $\$ 31,339$ \\
\hline Nebraska & 9,845 & $\$ 508,755,036$ & $18.7 \%$ & 1844 & $\$ 95,285,484$ & 0.000041 & $\$ 24,473$ \\
\hline Nevada & 13,882 & $\$ 1,020,439,764$ & $10.0 \%$ & 1391 & $\$ 102,277,749$ & 0.000047 & $\$ 21,480$ \\
\hline New Hampshire & 6,462 & $\$ 377,100,162$ & $16.6 \%$ & 1074 & $\$ 62,648,875$ & 0.000057 & $\$ 17,488$ \\
\hline New Jersey & 60,468 & $\$ 5,196,937,041$ & $17.6 \%$ & 10612 & $\$ 912,064,909$ & 0.000035 & $\$ 28,278$ \\
\hline New Mexico & 14,929 & $\$ 763,367,548$ & $8.2 \%$ & 1229 & $\$ 62,846,019$ & 0.000047 & $\$ 21,163$ \\
\hline New York & 153,618 & $\$ 12,897,617,207$ & $22.8 \%$ & 35095 & $\$ 2,946,540,780$ & 0.000013 & $\$ 76,488$ \\
\hline North Carolina & 59,149 & $\$ 2,728,405,137$ & $7.7 \%$ & 4561 & $\$ 210,409,120$ & 0.000047 & $\$ 21,425$ \\
\hline North Dakota & 3,434 & $\$ 175,539,907$ & $13.7 \%$ & 472 & $\$ 24,122,250$ & 0.000073 & $\$ 13,740$ \\
\hline Ohio & 54,415 & $\$ 3,145,120,859$ & $14.5 \%$ & 7892 & $\$ 456,179,752$ & 0.000031 & $\$ 32,311$ \\
\hline Oklahoma & 19,850 & $\$ 949,052,132$ & $16.0 \%$ & 3179 & $\$ 151,977,990$ & 0.000047 & $\$ 21,124$ \\
\hline Oregon & 19,917 & $\$ 1,283,906,731$ & $14.5 \%$ & 2886 & $\$ 186,024,606$ & 0.000022 & $\$ 44,684$ \\
\hline Pennsylvania & 65,972 & $\$ 4,136,720,975$ & $13.9 \%$ & 9147 & $\$ 573,546,877$ & 0.000040 & $\$ 24,873$ \\
\hline Rhode Island & 5,665 & $\$ 420,543,776$ & $6.5 \%$ & 366 & $\$ 27,194,266$ & 0.000035 & $\$ 28,489$ \\
\hline South Carolina & 25,920 & $\$ 1,033,929,455$ & $17.0 \%$ & 4402 & $\$ 175,582,478$ & 0.000064 & $\$ 15,540$ \\
\hline South Dakota & 4,032 & $\$ 183,631,190$ & $14.7 \%$ & 592 & $\$ 26,974,462$ & 0.000094 & $\$ 10,592$ \\
\hline Tennessee & 33,971 & $\$ 1,509,680,077$ & $11.5 \%$ & 3899 & $\$ 173,292,097$ & 0.000086 & $\$ 11,686$ \\
\hline Texas & 145,112 & $\$ 7,200,567,555$ & $16.3 \%$ & 23676 & $\$ 1,174,829,490$ & 0.000048 & $\$ 20,948$ \\
\hline Utah & 12,940 & $\$ 637,750,302$ & $12.9 \%$ & 1671 & $\$ 82,377,853$ & 0.000064 & $\$ 15,562$ \\
\hline Vermont & 3,258 & $\$ 179,924,839$ & $5.5 \%$ & 178 & $\$ 9,814,375$ & 0.000026 & $\$ 38,784$ \\
\hline Virginia & 48,987 & $\$ 2,457,412,257$ & $12.5 \%$ & 6130 & $\$ 307,516,736$ & 0.000046 & $\$ 21,709$ \\
\hline Washington & 28,711 & $\$ 2,058,496,468$ & $5.9 \%$ & 1694 & $\$ 121,461,272$ & 0.000038 & $\$ 26,396$ \\
\hline West Virginia & 8,872 & $\$ 372,929,338$ & $15.3 \%$ & 1353 & $\$ 56,875,217$ & 0.000041 & $\$ 24,129$ \\
\hline Wisconsin & 30,992 & $\$ 1,848,568,703$ & $9.5 \%$ & 2952 & $\$ 176,082,662$ & 0.000060 & $\$ 16,687$ \\
\hline Wyoming & 4,533 & $\$ 241,791,622$ & $13.7 \%$ & 619 & $\$ 33,018,702$ & 0.000043 & $\$ 23,304$ \\
\hline Total USA & $1,746,443$ & $\$ 108,711,223,680$ & $13.9 \%$ & 242335 & $\$ 15,084,695,994$ & 0.000038 & $\$ 26,122$ \\
\hline
\end{tabular}


Table 4: Data for calculating the law enforcement ROI and cost per seized-drug case, Part 1 of 2

\begin{tabular}{|c|c|c|c|c|c|c|}
\hline State & \begin{tabular}{|c|} 
Number of Test \\
Performed \\
(FORESIGHT \\
mean 2014-2015) \\
\end{tabular} & \begin{tabular}{|c|} 
Seized Drug \\
Cases Processed
\end{tabular} & $\begin{array}{c}\text { Total Expenditures (whole } \\
\text { US dollars) }\end{array}$ & \begin{tabular}{|c|} 
Estimated Total \\
Expenditures for Seized \\
Drug Cases (whole dollar \\
amount)
\end{tabular} & Total FTE & \begin{tabular}{|c|} 
Total Personnel \\
Expenditures (whole US \\
dollars)
\end{tabular} \\
\hline Alabama & 55,561 & 8,736 & $\$ 1,212,530,842$ & $\$ 77,413,770$ & 14,347 & $\$ 649,678,935$ \\
\hline Alaska & 6,354 & 999 & $\$ 375,629,622$ & $\$ 14,497,901$ & 1,950 & $\$ 153,493,569$ \\
\hline Arizona & 140,283 & 22,057 & $\$ 1,965,550,854$ & $\$ 216,137,917$ & 19,556 & $\$ 1,268,510,653$ \\
\hline Arkansas & 76,015 & 11,952 & $\$ 661,086,418$ & $\$ 66,065,465$ & 8,407 & $\$ 347,621,652$ \\
\hline California & $1,269,017$ & 199,531 & $\$ 15,921,016,411$ & $\$ 2,833,731,175$ & 99,357 & $\$ 9,191,617,543$ \\
\hline Colorado & 72,956 & 11,471 & $\$ 1,813,095,427$ & $\$ 115,353,437$ & 14,841 & $\$ 1,020,730,948$ \\
\hline Connecticut & 45,423 & 7,142 & $\$ 1,169,905,775$ & $\$ 104,682,347$ & 9,871 & $\$ 810,941,278$ \\
\hline Delaware & 34,051 & 5,354 & $\$ 338,818,713$ & $\$ 56,009,067$ & 2,469 & $\$ 176,919,802$ \\
\hline Florida & 691,039 & 108,654 & $\$ 7,409,634,923$ & $\$ 1,102,286,677$ & 62,838 & $\$ 3,853,930,894$ \\
\hline Georgia & 208,029 & 32,709 & $\$ 2,424,269,943$ & $\$ 365,432,144$ & 28,371 & $\$ 1,262,050,384$ \\
\hline Hawaii & 11,747 & 1,847 & $\$ 455,976,201$ & $\$ 26,192,288$ & 3,740 & $\$ 295,162,753$ \\
\hline Idaho & 36,424 & 5,727 & $\$ 414,874,178$ & $\$ 52,024,309$ & 4,027 & $\$ 212,494,894$ \\
\hline Illinois & 136,982 & 21,538 & $\$ 5,023,555,895$ & $\$ 1,327,289,796$ & 41,732 & $\$ 3,135,910,060$ \\
\hline Indiana & 98,008 & 15,410 & $\$ 1,215,061,189$ & $\$ 133,309,220$ & 15,622 & $\$ 766,223,142$ \\
\hline lowa & 46,434 & 7,301 & $\$ 730,884,511$ & $\$ 65,973,200$ & 7,066 & $\$ 410,396,848$ \\
\hline Kansas & 44,825 & 7,048 & $\$ 759,129,309$ & $\$ 94,677,541$ & 9,017 & $\$ 452,424,718$ \\
\hline Kentucky & 136,683 & 21,491 & $\$ 717,969,870$ & $\$ 81,219,159$ & 10,049 & $\$ 493,174,506$ \\
\hline Louisiana & 105,983 & 16,664 & $\$ 1,501,608,895$ & $\$ 238,281,757$ & 17,495 & $\$ 806,847,123$ \\
\hline Maine & 34,999 & 5,503 & $\$ 259,859,192$ & $\$ 34,167,204$ & 2,968 & $\$ 162,405,311$ \\
\hline Maryland & 156,119 & 24,547 & $\$ 2,570,243,370$ & $\$ 422,308,014$ & 18,833 & $\$ 1,300,488,772$ \\
\hline Massachusetts & 60,789 & 9,558 & $\$ 2,370,577,630$ & $\$ 198,881,005$ & 19,862 & $\$ 1,656,192,238$ \\
\hline Michigan & 207,775 & 32,669 & $\$ 2,418,096,178$ & $\$ 348,410,103$ & 20,831 & $\$ 1,369,130,953$ \\
\hline Minnesota & 98,497 & 15,487 & $\$ 1,763,404,124$ & $\$ 206,200,343$ & 12,045 & $\$ 813,977,455$ \\
\hline Mississippi & 55,599 & 8,742 & $\$ 709,749,264$ & $\$ 88,920,975$ & 9,759 & $\$ 360,573,330$ \\
\hline Missouri & 202,318 & 31,811 & $\$ 1,716,201,869$ & $\$ 262,523,555$ & 18,405 & $\$ 831,855,033$ \\
\hline Montana & 10,863 & 1,708 & $\$ 297,026,687$ & $\$ 22,675,647$ & 2,574 & $\$ 138,086,439$ \\
\hline Nebraska & 48,120 & 7,566 & $\$ 417,142,626$ & $\$ 78,127,260$ & 4,922 & $\$ 279,712,048$ \\
\hline Nevada & 68,306 & 10,740 & $\$ 1,142,781,099$ & $\$ 114,539,910$ & 7,842 & $\$ 614,847,669$ \\
\hline New Hampshire & 43,197 & 6,792 & $\$ 406,310,081$ & $\$ 67,501,614$ & 3,847 & $\$ 236,873,214$ \\
\hline New Jersey & 275,064 & 43,249 & $\$ 3,381,809,892$ & $\$ 593,509,236$ & 33,230 & $\$ 3,005,807,738$ \\
\hline New Mexico & 41,423 & 6,513 & $\$ 682,061,505$ & $\$ 56,152,309$ & 5,977 & $\$ 344,614,909$ \\
\hline New York & 373,586 & 58,740 & $\$ 9,470,666,087$ & $\$ 2,163,632,506$ & 85,244 & $\$ 7,465,671,000$ \\
\hline North Carolina & 128,466 & 20,199 & $\$ 3,115,330,700$ & $\$ 240,248,042$ & 27,696 & $\$ 1,339,713,672$ \\
\hline North Dakota & 26,012 & 4,090 & $\$ 185,031,631$ & $\$ 25,426,579$ & 1,606 & $\$ 82,269,547$ \\
\hline Ohio & 198,527 & 31,215 & $\$ 3,294,269,150$ & $\$ 477,812,762$ & 31,057 & $\$ 1,848,499,007$ \\
\hline Oklahoma & 104,781 & 16,475 & $\$ 1,040,039,136$ & $\$ 166,548,340$ & 11,000 & $\$ 546,006,214$ \\
\hline Oregon & 61,590 & 9,684 & $\$ 1,220,817,930$ & $\$ 176,883,701$ & 8,979 & $\$ 631,973,744$ \\
\hline Pennsylvania & 311,977 & 49,053 & $\$ 3,558,172,667$ & $\$ 493,332,481$ & 32,659 & $\$ 2,213,208,906$ \\
\hline Rhode Island & 10,659 & 1,676 & $\$ 393,697,630$ & $\$ 25,458,273$ & 3,068 & $\$ 212,380,819$ \\
\hline South Carolina & 152,061 & 23,909 & $\$ 1,120,640,562$ & $\$ 190,307,807$ & 13,866 & $\$ 583,731,915$ \\
\hline South Dakota & 38,860 & 6,110 & $\$ 182,393,502$ & $\$ 26,792,652$ & 1,955 & $\$ 89,693,314$ \\
\hline Tennessee & 230,181 & 36,192 & $\$ 1,822,792,741$ & $\$ 209,233,453$ & 20,208 & $\$ 919,765,590$ \\
\hline Texas & 773,847 & 121,674 & $\$ 7,134,565,444$ & $\$ 1,164,060,724$ & 73,098 & $\$ 4,184,274,297$ \\
\hline Utah & 84,219 & 13,242 & $\$ 679,643,976$ & $\$ 87,789,236$ & 6,446 & $\$ 316,314,696$ \\
\hline Vermont & 3,695 & 581 & $\$ 196,937,962$ & $\$ 10,742,391$ & 1,539 & $\$ 89,078,903$ \\
\hline Virginia & 200,887 & 31,586 & $\$ 2,272,908,448$ & $\$ 284,428,217$ & 21,785 & $\$ 1,210,819,613$ \\
\hline Washington & 61,419 & 9,657 & $\$ 1,799,517,979$ & $\$ 106,180,286$ & 14,119 & $\$ 1,190,177,214$ \\
\hline West Virginia & 38,523 & 6,057 & $\$ 365,451,825$ & $\$ 55,734,827$ & 3,970 & $\$ 172,215,365$ \\
\hline Wisconsin & 142,350 & 22,382 & $\$ 1,769,760,211$ & $\$ 168,575,876$ & 15,771 & $\$ 970,532,629$ \\
\hline Wyoming & 20,645 & 3,246 & $\$ 225,806,281$ & $\$ 30,835,768$ & 2,006 & $\$ 109,326,723$ \\
\hline Total USA & $7,481,166$ & $1,176,284$ & $\$ 102,094,306,352$ & $\$ 14,166,537,014$ & 907,922 & $\$ 60,598,347,978$ \\
\hline
\end{tabular}


Table 5: Data for calculating the law enforcement ROI and cost per seized-drug case, Part 2 of 2

\begin{tabular}{|c|c|c|c|c|c|}
\hline State & $\begin{array}{c}\text { Percentage of } \\
\text { Seized Drug } \\
\text { Cases }\end{array}$ & \begin{tabular}{|c|} 
Estimated \\
Total FTE for \\
Seized Drug \\
Cases \\
\end{tabular} & \begin{tabular}{|c|} 
Estimated Total \\
Personnel Expenditures \\
for Seized Drug Cases \\
(whole US dollars)
\end{tabular} & \begin{tabular}{|c|}
$\begin{array}{c}\text { Current Return } \\
\text { on Investment } \\
\text { for } 2015\end{array}$ \\
\end{tabular} & $\begin{array}{c}\text { Cost Per Seized } \\
\text { Drug Case in } \\
2015 \text { (whole US } \\
\text { dollar) }\end{array}$ \\
\hline Alabama & $6.4 \%$ & 916 & $\$ 41,478,612$ & 0.000113 & $\$ 8,861$ \\
\hline Alaska & $3.9 \%$ & 75 & $\$ 5,924,279$ & 0.000069 & $\$ 14,512$ \\
\hline Arizona & $11.0 \%$ & 2,150 & $\$ 139,489,268$ & 0.000102 & $\$ 9,799$ \\
\hline Arkansas & $10.0 \%$ & 840 & $\$ 34,739,461$ & 0.000181 & $\$ 5,528$ \\
\hline California & $17.8 \%$ & 17,684 & $\$ 1,635,986,831$ & 0.000070 & $\$ 14,202$ \\
\hline Colorado & $6.4 \%$ & 944 & $\$ 64,941,327$ & 0.000099 & $\$ 10,056$ \\
\hline Connecticut & $8.9 \%$ & 883 & $\$ 72,562,456$ & 0.000068 & $\$ 14,657$ \\
\hline Delaware & $16.5 \%$ & 408 & $\$ 29,246,062$ & 0.000096 & $\$ 10,461$ \\
\hline Florida & $14.9 \%$ & 9,348 & $\$ 573,326,044$ & 0.000099 & $\$ 10,145$ \\
\hline Georgia & $15.1 \%$ & 4,277 & $\$ 190,240,274$ & 0.000090 & $\$ 11,172$ \\
\hline Hawaii & $5.7 \%$ & 215 & $\$ 16,954,805$ & 0.000071 & $\$ 14,181$ \\
\hline Idaho & $12.5 \%$ & 505 & $\$ 26,646,392$ & 0.000110 & $\$ 9,084$ \\
\hline Illinois & $26.4 \%$ & 11,026 & $\$ 828,548,843$ & 0.000016 & $\$ 61,625$ \\
\hline Indiana & $11.0 \%$ & 1,714 & $\$ 84,065,404$ & 0.000116 & $\$ 8,651$ \\
\hline lowa & $9.0 \%$ & 638 & $\$ 37,044,421$ & 0.000111 & $\$ 9,036$ \\
\hline Kansas & $12.5 \%$ & 1,125 & $\$ 56,425,775$ & 0.000074 & $\$ 13,433$ \\
\hline Kentucky & $11.3 \%$ & 1,137 & $\$ 55,789,554$ & 0.000265 & $\$ 3,779$ \\
\hline Louisiana & $15.9 \%$ & 2,776 & $\$ 128,033,971$ & 0.000070 & $\$ 14,299$ \\
\hline Maine & $13.1 \%$ & 390 & $\$ 21,353,623$ & 0.000161 & $\$ 6,209$ \\
\hline Maryland & $16.4 \%$ & 3,094 & $\$ 213,678,921$ & 0.000058 & $\$ 17,204$ \\
\hline Massachusetts & $8.4 \%$ & 1,666 & $\$ 138,947,222$ & 0.000048 & $\$ 20,808$ \\
\hline Michigan & $14.4 \%$ & 3,001 & $\$ 197,270,506$ & 0.000094 & $\$ 10,665$ \\
\hline Minnesota & $11.7 \%$ & 1,408 & $\$ 95,180,922$ & 0.000075 & $\$ 13,314$ \\
\hline Mississippi & $12.5 \%$ & 1,223 & $\$ 45,174,449$ & 0.000098 & $\$ 10,172$ \\
\hline Missouri & $15.3 \%$ & 2,815 & $\$ 127,247,001$ & 0.000121 & $\$ 8,253$ \\
\hline Montana & $7.6 \%$ & 197 & $\$ 10,541,811$ & 0.000075 & $\$ 13,276$ \\
\hline Nebraska & $18.7 \%$ & 922 & $\$ 52,387,683$ & 0.000097 & $\$ 10,326$ \\
\hline Nevada & $10.0 \%$ & 786 & $\$ 61,625,622$ & 0.000094 & $\$ 10,665$ \\
\hline New Hampshire & $16.6 \%$ & 639 & $\$ 39,352,517$ & 0.000101 & $\$ 9,938$ \\
\hline New Jersey & $17.6 \%$ & 5,832 & $\$ 527,520,680$ & 0.000073 & $\$ 13,723$ \\
\hline New Mexico & $8.2 \%$ & 492 & $\$ 28,371,229$ & 0.000116 & $\$ 8,622$ \\
\hline New York & $22.8 \%$ & 19,475 & $\$ 1,705,578,922$ & 0.000027 & $\$ 36,834$ \\
\hline North Carolina & $7.7 \%$ & 2,136 & $\$ 103,316,026$ & 0.000084 & $\$ 11,894$ \\
\hline North Dakota & $13.7 \%$ & 221 & $\$ 11,305,273$ & 0.000161 & $\$ 6,217$ \\
\hline Ohio & $14.5 \%$ & 4,505 & $\$ 268,113,010$ & 0.000065 & $\$ 15,307$ \\
\hline Oklahoma & $16.0 \%$ & 1,762 & $\$ 87,435,583$ & 0.000099 & $\$ 10,109$ \\
\hline Oregon & $14.5 \%$ & 1,301 & $\$ 91,566,360$ & 0.000055 & $\$ 18,266$ \\
\hline Pennsylvania & $13.9 \%$ & 4,528 & $\$ 306,856,340$ & 0.000099 & $\$ 10,057$ \\
\hline Rhode Island & $6.5 \%$ & 198 & $\$ 13,733,506$ & 0.000066 & $\$ 15,190$ \\
\hline South Carolina & $17.0 \%$ & 2,355 & $\$ 99,129,680$ & 0.000126 & $\$ 7,960$ \\
\hline South Dakota & $14.7 \%$ & 287 & $\$ 13,175,479$ & 0.000228 & $\$ 4,385$ \\
\hline Tennessee & $11.5 \%$ & 2,320 & $\$ 105,577,407$ & 0.000173 & $\$ 5,781$ \\
\hline Texas & $16.3 \%$ & 11,927 & $\$ 682,697,412$ & 0.000105 & $\$ 9,567$ \\
\hline Utah & $12.9 \%$ & 833 & $\$ 40,858,194$ & 0.000151 & $\$ 6,630$ \\
\hline Vermont & $5.5 \%$ & 84 & $\$ 4,858,994$ & 0.000054 & $\$ 18,489$ \\
\hline Virginia & $12.5 \%$ & 2,726 & $\$ 151,520,077$ & 0.000111 & $\$ 9,005$ \\
\hline Washington & $5.9 \%$ & 833 & $\$ 70,226,226$ & 0.000091 & $\$ 10,995$ \\
\hline West Virginia & $15.3 \%$ & 605 & $\$ 26,264,456$ & 0.000109 & $\$ 9,202$ \\
\hline Wisconsin & $9.5 \%$ & 1,502 & $\$ 92,446,642$ & 0.000133 & $\$ 7,532$ \\
\hline Wyoming & $13.7 \%$ & 274 & $\$ 14,929,494$ & 0.000105 & $\$ 9,500$ \\
\hline Total USA & $13.9 \%$ & 125,983 & $\$ 8,408,585,849$ & 0.000083 & $\$ 12,043$ \\
\hline
\end{tabular}


Table 6: Data for calculating the correction ROI and cost per seized-drug case, Part 1 of 2

\begin{tabular}{|c|c|c|c|c|c|c|}
\hline State & \begin{tabular}{|} 
Number of Test \\
Performed \\
(FORESIGHT \\
mean 2014-2015)
\end{tabular} & $\begin{array}{c}\text { Seized Drug } \\
\text { Cases Processed }\end{array}$ & $\begin{array}{l}\text { Total Expenditures } \\
\text { (whole US dollars) }\end{array}$ & \begin{tabular}{|c|} 
Estimated Total \\
Expenditures for Seized \\
Drug Cases (whole dollar \\
amount)
\end{tabular} & Total FTE & $\begin{array}{c}\text { Total Personnel } \\
\text { Expenditures (whole US } \\
\text { dollars) }\end{array}$ \\
\hline Alabama & 55,561 & 8,736 & $\$ 706,402,000$ & $\$ 45,100,084$ & 8,378 & $\$ 326,422,165$ \\
\hline Alaska & 6,354 & 999 & $\$ 342,392,000$ & $\$ 13,215,053$ & 1,969 & $\$ 128,016,155$ \\
\hline Arizona & 140,283 & 22,057 & $\$ 1,638,557,000$ & $\$ 180,180,684$ & 15,607 & $\$ 708,535,007$ \\
\hline Arkansas & 76,015 & 11,952 & $\$ 565,208,000$ & $\$ 56,483,885$ & 7,607 & $\$ 297,426,078$ \\
\hline California & $1,269,017$ & 199,531 & $\$ 14,306,723,000$ & $\$ 2,546,408,215$ & 83,744 & $\$ 6,741,860,615$ \\
\hline Colorado & 72,956 & 11,471 & $\$ 1,213,451,000$ & $\$ 77,202,635$ & 10,706 & $\$ 585,336,870$ \\
\hline Connecticut & 45,423 & 7,142 & $\$ 694,262,000$ & $\$ 62,122,076$ & 5,647 & $\$ 425,569,573$ \\
\hline Delaware & 34,051 & 5,354 & $\$ 294,075,000$ & $\$ 48,612,623$ & 2,820 & $\$ 140,453,010$ \\
\hline Florida & 691,039 & 108,654 & $\$ 3,974,611,000$ & $\$ 591,278,895$ & 41,610 & $\$ 1,922,231,453$ \\
\hline Georgia & 208,029 & 32,709 & $\$ 2,213,860,000$ & $\$ 333,715,150$ & 26,753 & $\$ 961,245,384$ \\
\hline Hawaii & 11,747 & 1,847 & $\$ 216,708,000$ & $\$ 12,448,190$ & 2,218 & $\$ 120,959,747$ \\
\hline Idaho & 36,424 & 5,727 & $\$ 319,932,000$ & $\$ 40,118,769$ & 3,599 & $\$ 164,239,702$ \\
\hline Illinois & 136,982 & 21,538 & $\$ 2,097,708,000$ & $\$ 554,242,151$ & 20,971 & $\$ 1,380,282,210$ \\
\hline Indiana & 98,008 & 15,410 & $\$ 1,033,443,000$ & $\$ 113,383,163$ & 12,184 & $\$ 464,393,058$ \\
\hline lowa & 46,434 & 7,301 & $\$ 444,047,000$ & $\$ 40,081,848$ & 4,491 & $\$ 250,241,289$ \\
\hline Kansas & 44,825 & 7,048 & $\$ 499,610,000$ & $\$ 62,310,657$ & 6,006 & $\$ 247,867,153$ \\
\hline Kentucky & 136,683 & 21,491 & $\$ 744,721,000$ & $\$ 84,245,336$ & 8,006 & $\$ 275,183,001$ \\
\hline Louisiana & 105,983 & 16,664 & $\$ 1,214,669,000$ & $\$ 192,748,900$ & 13,048 & $\$ 566,348,800$ \\
\hline Maine & 34,999 & 5,503 & $\$ 198,630,000$ & $\$ 26,116,573$ & 1,904 & $\$ 92,484,416$ \\
\hline Maryland & 156,119 & 24,547 & $\$ 1,791,080,000$ & $\$ 294,286,310$ & 15,635 & $\$ 858,778,428$ \\
\hline Massachusetts & 60,789 & 9,558 & $\$ 1,206,193,000$ & $\$ 101,194,271$ & 11,503 & $\$ 713,011,133$ \\
\hline Michigan & 207,775 & 32,669 & $\$ 2,525,421,000$ & $\$ 363,873,942$ & 18,690 & $\$ 1,122,491,311$ \\
\hline Minnesota & 98,497 & 15,487 & $\$ 907,601,000$ & $\$ 106,128,615$ & 8,909 & $\$ 517,035,567$ \\
\hline Mississippi & 55,599 & 8,742 & $\$ 505,213,000$ & $\$ 63,295,638$ & 5,333 & $\$ 167,934,248$ \\
\hline Missouri & 202,318 & 31,811 & $\$ 966,871,000$ & $\$ 147,900,091$ & 14,944 & $\$ 495,413,020$ \\
\hline Montana & 10,863 & 1,708 & $\$ 243,737,000$ & $\$ 18,607,399$ & 1,806 & $\$ 86,363,406$ \\
\hline Nebraska & 48,120 & 7,566 & $\$ 402,274,000$ & $\$ 75,342,493$ & 4,302 & $\$ 185,094,923$ \\
\hline Nevada & 68,306 & 10,740 & $\$ 693,289,000$ & $\$ 69,487,726$ & 5,491 & $\$ 348,495,921$ \\
\hline New Hampshire & 43,197 & 6,792 & $\$ 172,365,000$ & $\$ 28,635,557$ & 1,826 & $\$ 95,787,214$ \\
\hline New Jersey & 275,064 & 43,249 & $\$ 2,084,140,000$ & $\$ 365,767,556$ & 15,058 & $\$ 1,183,312,205$ \\
\hline New Mexico & 41,423 & 6,513 & $\$ 661,346,000$ & $\$ 54,446,857$ & 5,949 & $\$ 249,434,083$ \\
\hline New York & 373,586 & 58,740 & $\$ 6,173,988,000$ & $\$ 1,410,485,916$ & 51,461 & $\$ 3,794,117,258$ \\
\hline North Carolina & 128,466 & 20,199 & $\$ 1,737,614,000$ & $\$ 134,001,299$ & 25,428 & $\$ 996,728,467$ \\
\hline North Dakota & 26,012 & 4,090 & $\$ 127,870,000$ & $\$ 17,571,572$ & 1,307 & $\$ 58,235,667$ \\
\hline Ohio & 198,527 & 31,215 & $\$ 1,859,635,000$ & $\$ 269,728,214$ & 21,025 & $\$ 1,076,416,816$ \\
\hline Oklahoma & 104,781 & 16,475 & $\$ 751,323,000$ & $\$ 120,314,317$ & 6,496 & $\$ 261,887,366$ \\
\hline Oregon & 61,590 & 9,684 & $\$ 1,128,234,000$ & $\$ 163,469,261$ & 8,234 & $\$ 478,335,862$ \\
\hline Pennsylvania & 311,977 & 49,053 & $\$ 3,298,663,000$ & $\$ 457,352,061$ & 31,083 & $\$ 1,653,516,274$ \\
\hline Rhode Island & 10,659 & 1,676 & $\$ 206,792,000$ & $\$ 13,372,108$ & 1,538 & $\$ 125,206,436$ \\
\hline South Carolina & 152,061 & 23,909 & $\$ 736,794,000$ & $\$ 125,122,769$ & 11,571 & $\$ 403,624,504$ \\
\hline South Dakota & 38,860 & 6,110 & $\$ 173,120,000$ & $\$ 25,430,423$ & 1,505 & $\$ 60,942,585$ \\
\hline Tennessee & 230,181 & 36,192 & $\$ 1,160,093,000$ & $\$ 133,163,941$ & 11,771 & $\$ 430,485,212$ \\
\hline Texas & 773,847 & 121,674 & $\$ 5,669,731,000$ & $\$ 925,061,411$ & 68,022 & $\$ 2,666,247,268$ \\
\hline Utah & 84,219 & 13,242 & $\$ 539,588,000$ & $\$ 69,698,283$ & 5,046 & $\$ 232,944,015$ \\
\hline Vermont & 3,695 & 581 & $\$ 140,010,000$ & $\$ 7,637,137$ & 1,082 & $\$ 54,767,937$ \\
\hline Virginia & 200,887 & 31,586 & $\$ 2,295,749,000$ & $\$ 287,286,448$ & 24,054 & $\$ 1,028,449,768$ \\
\hline Washington & 61,419 & 9,657 & $\$ 1,604,142,000$ & $\$ 94,652,156$ & 13,002 & $\$ 734,795,126$ \\
\hline West Virginia & 38,523 & 6,057 & $\$ 353,625,000$ & $\$ 53,931,125$ & 3,462 & $\$ 113,476,211$ \\
\hline Wisconsin & 142,350 & 22,382 & $\$ 1,507,528,000$ & $\$ 143,597,337$ & 13,374 & $\$ 709,602,480$ \\
\hline Wyoming & 20,645 & 3,246 & $\$ 209,267,000$ & $\$ 28,577,188$ & 2,029 & $\$ 95,457,164$ \\
\hline Total USA & $7,481,166$ & $1,176,284$ & $\$ 74,552,305,000$ & $\$ 10,344,827,503$ & 688,203 & $\$ 36,797,483,559$ \\
\hline
\end{tabular}


Table 7: Data for calculating the correction ROI and cost per seized-drug case, Part 2 of 2

\begin{tabular}{|c|c|c|c|c|c|}
\hline State & \begin{tabular}{|c} 
Percentage of \\
Seized Drug \\
Cases
\end{tabular} & \begin{tabular}{|c|} 
Estimated \\
Total FTE for \\
Seized Drug \\
Cases \\
\end{tabular} & \begin{tabular}{|c|} 
Estimated Total \\
Personnel Expenditures \\
for Seized Drug Cases \\
(whole US dollars) \\
\end{tabular} & $\begin{array}{c}\text { Current Return } \\
\text { on Investment } \\
\text { for } 2015\end{array}$ & $\begin{array}{c}\text { Cost Per Seized } \\
\text { Drug Case in } 2015 \\
\text { (whole US dollar) }\end{array}$ \\
\hline Alabama & $6.4 \%$ & 535 & $\$ 20,840,353$ & 0.000194 & $\$ 5,163$ \\
\hline Alaska & $3.9 \%$ & 76 & $\$ 4,940,946$ & 0.000076 & $\$ 13,228$ \\
\hline Arizona & $11.0 \%$ & 1,716 & $\$ 77,912,652$ & 0.000122 & $\$ 8,169$ \\
\hline Arkansas & $10.0 \%$ & 760 & $\$ 29,723,182$ & 0.000212 & $\$ 4,726$ \\
\hline California & $17.8 \%$ & 14,905 & $\$ 1,199,962,371$ & 0.000078 & $\$ 12,762$ \\
\hline Colorado & $6.4 \%$ & 681 & $\$ 37,240,522$ & 0.000149 & $\$ 6,730$ \\
\hline Connecticut & $8.9 \%$ & 505 & $\$ 38,079,666$ & 0.000115 & $\$ 8,698$ \\
\hline Delaware & $16.5 \%$ & 466 & $\$ 23,217,850$ & 0.000110 & $\$ 9,080$ \\
\hline Florida & $14.9 \%$ & 6,190 & $\$ 285,958,774$ & 0.000184 & $\$ 5,442$ \\
\hline Georgia & $15.1 \%$ & 4,033 & $\$ 144,897,214$ & 0.000098 & $\$ 10,203$ \\
\hline Hawaii & $5.7 \%$ & 127 & $\$ 6,948,197$ & 0.000148 & $\$ 6,740$ \\
\hline Idaho & $12.5 \%$ & 451 & $\$ 20,595,297$ & 0.000143 & $\$ 7,005$ \\
\hline Illinois & $26.4 \%$ & 5,541 & $\$ 364,688,784$ & 0.000039 & $\$ 25,733$ \\
\hline Indiana & $11.0 \%$ & 1,337 & $\$ 50,950,419$ & 0.000136 & $\$ 7,358$ \\
\hline lowa & $9.0 \%$ & 405 & $\$ 22,587,999$ & 0.000182 & $\$ 5,490$ \\
\hline Kansas & $12.5 \%$ & 749 & $\$ 30,913,643$ & 0.000113 & $\$ 8,841$ \\
\hline Kentucky & $11.3 \%$ & 906 & $\$ 31,129,624$ & 0.000255 & $\$ 3,920$ \\
\hline Louisiana & $15.9 \%$ & 2,071 & $\$ 89,870,663$ & 0.000086 & $\$ 11,567$ \\
\hline Maine & $13.1 \%$ & 250 & $\$ 12,160,177$ & 0.000211 & $\$ 4,746$ \\
\hline Maryland & $16.4 \%$ & 2,569 & $\$ 141,102,985$ & 0.000083 & $\$ 11,989$ \\
\hline Massachusetts & $8.4 \%$ & 965 & $\$ 59,818,488$ & 0.000094 & $\$ 10,587$ \\
\hline Michigan & $14.4 \%$ & 2,693 & $\$ 161,733,564$ & 0.000090 & $\$ 11,138$ \\
\hline Minnesota & $11.7 \%$ & 1,042 & $\$ 60,458,581$ & 0.000146 & $\$ 6,853$ \\
\hline Mississippi & $12.5 \%$ & 668 & $\$ 21,039,651$ & 0.000138 & $\$ 7,240$ \\
\hline Missouri & $15.3 \%$ & 2,286 & $\$ 75,782,220$ & 0.000215 & $\$ 4,649$ \\
\hline Montana & $7.6 \%$ & 138 & $\$ 6,593,165$ & 0.000092 & $\$ 10,894$ \\
\hline Nebraska & $18.7 \%$ & 806 & $\$ 34,666,702$ & 0.000100 & $\$ 9,958$ \\
\hline Nevada & $10.0 \%$ & 550 & $\$ 34,929,429$ & 0.000155 & $\$ 6,470$ \\
\hline New Hampshire & $16.6 \%$ & 303 & $\$ 15,913,441$ & 0.000237 & $\$ 4,216$ \\
\hline New Jersey & $17.6 \%$ & 2,643 & $\$ 207,671,852$ & 0.000118 & $\$ 8,457$ \\
\hline New Mexico & $8.2 \%$ & 490 & $\$ 20,535,244$ & 0.000120 & $\$ 8,360$ \\
\hline New York & $22.8 \%$ & 11,757 & $\$ 866,789,659$ & 0.000042 & $\$ 24,012$ \\
\hline North Carolina & $7.7 \%$ & 1,961 & $\$ 76,865,696$ & 0.000151 & $\$ 6,634$ \\
\hline North Dakota & $13.7 \%$ & 180 & $\$ 8,002,598$ & 0.000233 & $\$ 4,296$ \\
\hline Ohio & $14.5 \%$ & 3,050 & $\$ 156,127,405$ & 0.000116 & $\$ 8,641$ \\
\hline Oklahoma & $16.0 \%$ & 1,040 & $\$ 41,937,755$ & 0.000137 & $\$ 7,303$ \\
\hline Oregon & $14.5 \%$ & 1,193 & $\$ 69,305,844$ & 0.000059 & $\$ 16,880$ \\
\hline Pennsylvania & $13.9 \%$ & 4,310 & $\$ 229,256,240$ & 0.000107 & $\$ 9,324$ \\
\hline Rhode Island & $6.5 \%$ & 99 & $\$ 8,096,416$ & 0.000125 & $\$ 7,979$ \\
\hline South Carolina & $17.0 \%$ & 1,965 & $\$ 68,543,739$ & 0.000191 & $\$ 5,233$ \\
\hline South Dakota & $14.7 \%$ & 221 & $\$ 8,952,147$ & 0.000240 & $\$ 4,162$ \\
\hline Tennessee & $11.5 \%$ & 1,351 & $\$ 49,414,234$ & 0.000272 & $\$ 3,679$ \\
\hline Texas & $16.3 \%$ & 11,098 & $\$ 435,019,308$ & 0.000132 & $\$ 7,603$ \\
\hline Utah & $12.9 \%$ & 652 & $\$ 30,089,249$ & 0.000190 & $\$ 5,263$ \\
\hline Vermont & $5.5 \%$ & 59 & $\$ 2,987,431$ & 0.000076 & $\$ 13,145$ \\
\hline Virginia & $12.5 \%$ & 3,010 & $\$ 128,698,599$ & 0.000110 & $\$ 9,095$ \\
\hline Washington & $5.9 \%$ & 767 & $\$ 43,356,475$ & 0.000102 & $\$ 9,801$ \\
\hline West Virginia & $15.3 \%$ & 528 & $\$ 17,306,185$ & 0.000112 & $\$ 8,904$ \\
\hline Wisconsin & $9.5 \%$ & 1,274 & $\$ 67,592,129$ & 0.000156 & $\$ 6,416$ \\
\hline Wyoming & $13.7 \%$ & 277 & $\$ 13,035,487$ & 0.000114 & $\$ 8,804$ \\
\hline Total USA & $13.9 \%$ & 95,495 & $\$ 5,105,993,972$ & 0.000114 & $\$ 8,794$ \\
\hline
\end{tabular}


Table 8: Data for calculating the court system ROI and cost per seized-drug case, Part 1 of 2

\begin{tabular}{|c|c|c|c|c|c|c|}
\hline State & \begin{tabular}{|c|} 
Number of Test \\
Performed \\
(FORESIGHT \\
mean 2014-2015) \\
\end{tabular} & $\begin{array}{c}\text { Seized Drug } \\
\text { Cases Processed }\end{array}$ & $\begin{array}{l}\text { Total Expenditures } \\
\text { (whole US dollars) }\end{array}$ & \begin{tabular}{|c|} 
Estimated Total \\
Expenditures for Seized \\
Drug Cases (whole dollar \\
amount)
\end{tabular} & Total FTE & $\begin{array}{c}\text { Total Personnel } \\
\text { Expenditures (whole US } \\
\text { dollars) }\end{array}$ \\
\hline Alabama & 55,561 & 8,736 & $\$ 401,734,907$ & $\$ 25,648,679$ & 3,131 & $\$ 178,628,621$ \\
\hline Alaska & 6,354 & 999 & $\$ 243,865,223$ & $\$ 9,412,287$ & 1,453 & $\$ 110,461,185$ \\
\hline Arizona & 140,283 & 22,057 & $\$ 926,954,177$ & $\$ 101,930,685$ & 2,068 & $\$ 120,309,673$ \\
\hline Arkansas & 76,015 & 11,952 & $\$ 211,063,382$ & $\$ 21,092,553$ & 1,336 & $\$ 65,341,399$ \\
\hline California & $1,269,017$ & 199,531 & $\$ 8,615,277,821$ & $\$ 1,533,405,953$ & 5,909 & $\$ 491,368,003$ \\
\hline Colorado & 72,956 & 11,471 & $\$ 719,571,483$ & $\$ 45,780,847$ & 4,416 & $\$ 278,107,340$ \\
\hline Connecticut & 45,423 & 7,142 & $\$ 758,714,300$ & $\$ 67,889,222$ & 5,796 & $\$ 412,241,068$ \\
\hline Delaware & 34,051 & 5,354 & $\$ 205,003,443$ & $\$ 33,888,481$ & 1,726 & $\$ 99,866,139$ \\
\hline Florida & 691,039 & 108,654 & $\$ 2,310,533,259$ & $\$ 343,724,091$ & 18,828 & $\$ 948,994,439$ \\
\hline Georgia & 208,029 & 32,709 & $\$ 1,096,414,906$ & $\$ 165,272,540$ & 3,602 & $\$ 198,666,017$ \\
\hline Hawaii & 11,747 & 1,847 & $\$ 312,361,879$ & $\$ 17,942,761$ & 2,416 & $\$ 132,939,422$ \\
\hline Idaho & 36,424 & 5,727 & $\$ 204,718,376$ & $\$ 25,671,234$ & 463 & $\$ 46,853,330$ \\
\hline Illinois & 136,982 & 21,538 & $\$ 1,499,788,697$ & $\$ 396,263,976$ & 2,556 & $\$ 280,460,090$ \\
\hline Indiana & 98,008 & 15,410 & $\$ 553,466,082$ & $\$ 60,722,976$ & 1,398 & $\$ 117,839,163$ \\
\hline lowa & 46,434 & 7,301 & $\$ 355,765,592$ & $\$ 32,113,137$ & 2,150 & $\$ 145,154,109$ \\
\hline Kansas & 44,825 & 7,048 & $\$ 321,383,292$ & $\$ 40,082,473$ & 2,036 & $\$ 109,065,282$ \\
\hline Kentucky & 136,683 & 21,491 & $\$ 540,268,388$ & $\$ 61,116,972$ & 5,565 & $\$ 247,549,415$ \\
\hline Louisiana & 105,983 & 16,664 & $\$ 742,475,556$ & $\$ 117,819,214$ & 1,653 & $\$ 91,326,170$ \\
\hline Maine & 34,999 & 5,503 & $\$ 98,565,682$ & $\$ 12,959,764$ & 674 & $\$ 47,746,402$ \\
\hline Maryland & 156,119 & 24,547 & $\$ 858,281,242$ & $\$ 141,021,294$ & 4,978 & $\$ 335,315,178$ \\
\hline Massachusetts & 60,789 & 9,558 & $\$ 1,103,381,419$ & $\$ 92,568,833$ & 8,682 & $\$ 599,593,097$ \\
\hline Michigan & 207,775 & 32,669 & $\$ 1,186,457,791$ & $\$ 170,950,140$ & 1,390 & $\$ 121,178,119$ \\
\hline Minnesota & 98,497 & 15,487 & $\$ 692,916,210$ & $\$ 81,024,853$ & 3,450 & $\$ 222,414,499$ \\
\hline Mississippi & 55,599 & 8,742 & $\$ 252,636,824$ & $\$ 31,651,618$ & 719 & $\$ 52,537,619$ \\
\hline Missouri & 202,318 & 31,811 & $\$ 530,627,484$ & $\$ 81,168,897$ & 4,052 & $\$ 189,785,218$ \\
\hline Montana & 10,863 & 1,708 & $\$ 158,612,067$ & $\$ 12,108,781$ & 695 & $\$ 38,332,570$ \\
\hline Nebraska & 48,120 & 7,566 & $\$ 166,298,803$ & $\$ 31,146,349$ & 722 & $\$ 43,948,066$ \\
\hline Nevada & 68,306 & 10,740 & $\$ 460,501,010$ & $\$ 46,155,597$ & 709 & $\$ 57,096,173$ \\
\hline New Hampshire & 43,197 & 6,792 & $\$ 135,031,086$ & $\$ 22,433,153$ & 868 & $\$ 44,439,735$ \\
\hline New Jersey & 275,064 & 43,249 & $\$ 1,487,402,889$ & $\$ 261,039,911$ & 12,861 & $\$ 1,007,817,098$ \\
\hline New Mexico & 41,423 & 6,513 & $\$ 326,010,846$ & $\$ 26,839,606$ & 3,126 & $\$ 169,318,556$ \\
\hline New York & 373,586 & 58,740 & $\$ 3,976,499,881$ & $\$ 908,456,103$ & 18,660 & $\$ 1,637,828,949$ \\
\hline North Carolina & 128,466 & 20,199 & $\$ 746,175,383$ & $\$ 57,543,546$ & 6,592 & $\$ 391,962,998$ \\
\hline North Dakota & 26,012 & 4,090 & $\$ 95,109,623$ & $\$ 13,069,724$ & 554 & $\$ 35,034,693$ \\
\hline Ohio & 198,527 & 31,215 & $\$ 1,786,208,475$ & $\$ 259,078,165$ & 2,969 & $\$ 220,205,036$ \\
\hline Oklahoma & 104,781 & 16,475 & $\$ 376,369,991$ & $\$ 60,270,614$ & 2,579 & $\$ 141,158,552$ \\
\hline Oregon & 61,590 & 9,684 & $\$ 629,286,845$ & $\$ 91,177,057$ & 2,889 & $\$ 173,597,126$ \\
\hline Pennsylvania & 311,977 & 49,053 & $\$ 1,918,890,528$ & $\$ 266,049,771$ & 2,899 & $\$ 269,995,795$ \\
\hline Rhode Island & 10,659 & 1,676 & $\$ 136,393,968$ & $\$ 8,819,852$ & 1,123 & $\$ 82,956,522$ \\
\hline South Carolina & 152,061 & 23,909 & $\$ 325,114,345$ & $\$ 55,211,100$ & 767 & $\$ 46,573,037$ \\
\hline South Dakota & 38,860 & 6,110 & $\$ 83,796,594$ & $\$ 12,309,282$ & 612 & $\$ 32,995,292$ \\
\hline Tennessee & 230,181 & 36,192 & $\$ 693,087,452$ & $\$ 79,557,636$ & 2,407 & $\$ 159,429,274$ \\
\hline Texas & 773,847 & 121,674 & $\$ 2,775,973,079$ & $\$ 452,921,941$ & 5,490 & $\$ 350,045,990$ \\
\hline Utah & 84,219 & 13,242 & $\$ 372,171,549$ & $\$ 48,073,193$ & 1,580 & $\$ 88,491,591$ \\
\hline Vermont & 3,695 & 581 & $\$ 75,131,767$ & $\$ 4,098,219$ & 668 & $\$ 36,077,998$ \\
\hline Virginia & 200,887 & 31,586 & $\$ 894,035,490$ & $\$ 111,878,206$ & 3,595 & $\$ 218,142,876$ \\
\hline Washington & 61,419 & 9,657 & $\$ 904,635,347$ & $\$ 53,377,872$ & 1,880 & $\$ 133,524,127$ \\
\hline West Virginia & 38,523 & 6,057 & $\$ 236,635,803$ & $\$ 36,089,177$ & 1,522 & $\$ 87,237,762$ \\
\hline Wisconsin & 142,350 & 22,382 & $\$ 632,672,393$ & $\$ 60,264,268$ & 2,170 & $\$ 168,433,594$ \\
\hline Wyoming & 20,645 & 3,246 & $\$ 117,323,693$ & $\$ 16,021,548$ & 540 & $\$ 37,007,735$ \\
\hline Total USA & $7,481,166$ & $1,176,284$ & $\$ 44,251,596,322$ & $\$ 6,140,321,626$ & 168,922 & $\$ 11,315,392,142$ \\
\hline
\end{tabular}


Table 9: Data for calculating the court system ROI and cost per seized-drug case, Part 2 of 2

\begin{tabular}{|c|c|c|c|c|c|}
\hline State & $\begin{array}{c}\text { Percentage of } \\
\text { Seized Drug } \\
\text { Cases }\end{array}$ & \begin{tabular}{|c|}
$\begin{array}{c}\text { Estimated } \\
\text { Total FTE for } \\
\text { Seized Drug } \\
\text { Cases }\end{array}$ \\
\end{tabular} & \begin{tabular}{|c|} 
Estimated Total \\
Personnel Expenditures \\
for Seized Drug Cases \\
(whole US dollars) \\
\end{tabular} & $\begin{array}{c}\text { Current Return } \\
\text { on Investment } \\
\text { for } 2015\end{array}$ & \begin{tabular}{|c|} 
Cost Per Seized \\
Drug Case in \\
2015 (whole US \\
dollar) \\
\end{tabular} \\
\hline Alabama & $6.4 \%$ & 200 & $\$ 11,404,506$ & 0.000341 & $\$ 2,936$ \\
\hline Alaska & $3.9 \%$ & 56 & $\$ 4,263,389$ & 0.000106 & $\$ 9,422$ \\
\hline Arizona & $11.0 \%$ & 227 & $\$ 13,229,615$ & 0.000216 & $\$ 4,621$ \\
\hline Arkansas & $10.0 \%$ & 134 & $\$ 6,529,872$ & 0.000567 & $\$ 1,765$ \\
\hline California & $17.8 \%$ & 1,052 & $\$ 87,457,031$ & 0.000130 & $\$ 7,685$ \\
\hline Colorado & $6.4 \%$ & 281 & $\$ 17,693,849$ & 0.000251 & $\$ 3,991$ \\
\hline Connecticut & $8.9 \%$ & 519 & $\$ 36,887,041$ & 0.000105 & $\$ 9,506$ \\
\hline Delaware & $16.5 \%$ & 285 & $\$ 16,508,561$ & 0.000158 & $\$ 6,330$ \\
\hline Florida & $14.9 \%$ & 2,801 & $\$ 141,176,176$ & 0.000316 & $\$ 3,163$ \\
\hline Georgia & $15.1 \%$ & 543 & $\$ 29,946,726$ & 0.000198 & $\$ 5,053$ \\
\hline Hawaii & $5.7 \%$ & 139 & $\$ 7,636,336$ & 0.000103 & $\$ 9,715$ \\
\hline Idaho & $12.5 \%$ & 58 & $\$ 5,875,304$ & 0.000223 & $\$ 4,482$ \\
\hline Illinois & $26.4 \%$ & 675 & $\$ 74,101,259$ & 0.000054 & $\$ 18,398$ \\
\hline Indiana & $11.0 \%$ & 153 & $\$ 12,928,606$ & 0.000254 & $\$ 3,940$ \\
\hline lowa & $9.0 \%$ & 194 & $\$ 13,102,318$ & 0.000227 & $\$ 4,398$ \\
\hline Kansas & $12.5 \%$ & 254 & $\$ 13,602,469$ & 0.000176 & $\$ 5,687$ \\
\hline Kentucky & $11.3 \%$ & 629 & $\$ 28,003,620$ & 0.000352 & $\$ 2,844$ \\
\hline Louisiana & $15.9 \%$ & 262 & $\$ 14,492,029$ & 0.000141 & $\$ 7,070$ \\
\hline Maine & $13.1 \%$ & 89 & $\$ 6,277,865$ & 0.000425 & $\$ 2,355$ \\
\hline Maryland & $16.4 \%$ & 818 & $\$ 55,094,505$ & 0.000174 & $\$ 5,745$ \\
\hline Massachusetts & $8.4 \%$ & 728 & $\$ 50,303,216$ & 0.000103 & $\$ 9,685$ \\
\hline Michigan & $14.4 \%$ & 200 & $\$ 17,459,885$ & 0.000191 & $\$ 5,233$ \\
\hline Minnesota & $11.7 \%$ & 403 & $\$ 26,007,621$ & 0.000191 & $\$ 5,232$ \\
\hline Mississippi & $12.5 \%$ & 90 & $\$ 6,582,178$ & 0.000276 & $\$ 3,621$ \\
\hline Missouri & $15.3 \%$ & 620 & $\$ 29,031,020$ & 0.000392 & $\$ 2,552$ \\
\hline Montana & $7.6 \%$ & 53 & $\$ 2,926,390$ & 0.000141 & $\$ 7,089$ \\
\hline Nebraska & $18.7 \%$ & 135 & $\$ 8,231,098$ & 0.000243 & $\$ 4,117$ \\
\hline Nevada & $10.0 \%$ & 71 & $\$ 5,722,698$ & 0.000233 & $\$ 4,298$ \\
\hline New Hampshire & $16.6 \%$ & 144 & $\$ 7,382,918$ & 0.000303 & $\$ 3,303$ \\
\hline New Jersey & $17.6 \%$ & 2,257 & $\$ 176,872,377$ & 0.000166 & $\$ 6,036$ \\
\hline New Mexico & $8.2 \%$ & 257 & $\$ 13,939,546$ & 0.000243 & $\$ 4,121$ \\
\hline New York & $22.8 \%$ & 4,263 & $\$ 374,172,199$ & 0.000065 & $\$ 15,466$ \\
\hline North Carolina & $7.7 \%$ & 508 & $\$ 30,227,399$ & 0.000351 & $\$ 2,849$ \\
\hline North Dakota & $13.7 \%$ & 76 & $\$ 4,814,379$ & 0.000313 & $\$ 3,196$ \\
\hline Ohio & $14.5 \%$ & 431 & $\$ 31,939,338$ & 0.000120 & $\$ 8,300$ \\
\hline Oklahoma & $16.0 \%$ & 413 & $\$ 22,604,652$ & 0.000273 & $\$ 3,658$ \\
\hline Oregon & $14.5 \%$ & 419 & $\$ 25,152,401$ & 0.000106 & $\$ 9,415$ \\
\hline Pennsylvania & $13.9 \%$ & 402 & $\$ 37,434,298$ & 0.000184 & $\$ 5,424$ \\
\hline Rhode Island & $6.5 \%$ & 73 & $\$ 5,364,345$ & 0.000190 & $\$ 5,262$ \\
\hline South Carolina & $17.0 \%$ & 130 & $\$ 7,909,059$ & 0.000433 & $\$ 2,309$ \\
\hline South Dakota & $14.7 \%$ & 90 & $\$ 4,846,836$ & 0.000496 & $\$ 2,015$ \\
\hline Tennessee & $11.5 \%$ & 276 & $\$ 18,300,456$ & 0.000455 & $\$ 2,198$ \\
\hline Texas & $16.3 \%$ & 896 & $\$ 57,112,769$ & 0.000269 & $\$ 3,722$ \\
\hline Utah & $12.9 \%$ & 204 & $\$ 11,430,410$ & 0.000275 & $\$ 3,630$ \\
\hline Vermont & $5.5 \%$ & 36 & $\$ 1,967,949$ & 0.000142 & $\$ 7,054$ \\
\hline Virginia & $12.5 \%$ & 450 & $\$ 27,298,059$ & 0.000282 & $\$ 3,542$ \\
\hline Washington & $5.9 \%$ & 111 & $\$ 7,878,571$ & 0.000181 & $\$ 5,527$ \\
\hline West Virginia & $15.3 \%$ & 232 & $\$ 13,304,576$ & 0.000168 & $\$ 5,958$ \\
\hline Wisconsin & $9.5 \%$ & 207 & $\$ 16,043,891$ & 0.000371 & $\$ 2,693$ \\
\hline Wyoming & $13.7 \%$ & 74 & $\$ 5,053,721$ & 0.000203 & $\$ 4,936$ \\
\hline Total USA & $13.9 \%$ & 23,440 & $\$ 1,570,116,173$ & 0.000192 & $\$ 5,220$ \\
\hline
\end{tabular}

